NBER WORKING PAPER SERIES

\title{
EMPLOYMENT AND TRAINING PROGRAMS
}

\author{
Burt S. Barnow \\ Jeffrey Smith \\ Working Paper 21659 \\ http://www.nber.org/papers/w21659 \\ NATIONAL BUREAU OF ECONOMIC RESEARCH \\ 1050 Massachusetts Avenue \\ Cambridge, MA 02138 \\ October 2015
}

The views expressed herein are those of the authors and do not necessarily reflect the views of the National Bureau of Economic Research. Disclaimer on potential conflicts of interest: Both authors have undertaken contract research sponsored by the U.S. Department of Labor as well as serving on numerous technical advisory panels and providing comments on draft reports for various evaluations. In particular, in regard to evaluations considered in detail in this chapter, both authors were part of the NORC subcontract for the non-experimental component of the National JTPA Study, both authors reviewed drafts and provided technical advice on the recent TAA evaluation, and both are members of the technical advisory panel for the WIA experiment. It should, but does not, go without saying that the views expressed represent those of the authors alone.

NBER working papers are circulated for discussion and comment purposes. They have not been peerreviewed or been subject to the review by the NBER Board of Directors that accompanies official NBER publications.

(C) 2015 by Burt S. Barnow and Jeffrey Smith. All rights reserved. Short sections of text, not to exceed two paragraphs, may be quoted without explicit permission provided that full credit, including (C notice, is given to the source. 
Employment and Training Programs

Burt S. Barnow and Jeffrey Smith

NBER Working Paper No. 21659

October 2015

JEL No. H11,I28,J24

\begin{abstract}
$\underline{\text { ABSTRACT }}$
This chapter considers means-tested employment and training programs in the United States. We focus in particular on large, means-tested federal programs, including the Job Training Partnership Act (JTPA), its successor the Workforce Investment Act (WIA), that program's recent replacement, the Workforce Innovation and Opportunity Act (WIOA), the long-running Job Corps program, and the Trade Adjustment Assistance (TAA) program. The first part of the chapter provides details on program history, organization, expenditures, eligibility rules, services, and participant characteristics. In the second part of the chapter, we discuss the applied econometric methods typically used to evaluate these programs, which in the United States means primarily social experiments and methods such as matching that rely on an assumption of "selection on observed variables." The third part of the chapter reviews the literature evaluating these programs, highlighting both methodological and substantive lessons learned as well as open questions. The fourth part of the chapter considers what lessons the evaluation literature provides on program operation, especially how to best allocate particular services to particular participants. The final section concludes with the big picture lessons from this literature and discussion of promising directions for future research.
\end{abstract}

\author{
Burt S. Barnow \\ George Washington University \\ 805 21st St NW, Room 601T \\ Washington, DC 20052 \\ barnow@gwu.edu \\ Jeffrey Smith \\ Department of Economics \\ University of Michigan \\ 238 Lorch Hall \\ 611 Tappan Street \\ Ann Arbor, MI 48109-1220 \\ and NBER \\ econjeff@umich.edu
}




\section{Introduction}

The United States has used employment and training programs as a policy tool during two periods, first during the Great Depression, when work relief and other employment-related programs were used, and since 1961, when a broad array of employment and training programs has been implemented. This chapter focuses on employment and training programs implemented in the latter period, with emphasis on current means-tested programs and developments since 2000. ${ }^{1}$

Although people often think of employment and training programs as synonymous with vocational classroom training, workforce programs actually use a variety of approaches. Indeed, in an analysis of data from the Workforce Investment Act (WIA) from Program Years 2002 to 2005 (July 1, 2002 through June 30, 2005), Trutko and Barnow (2007) found that less than half (46.6 percent) of adults who exited the program received classroom training, with individual states ranging from 14 percent to 96 percent of participants receiving classroom training.

Both Butler and Hobbie (1976) and Perry et al. (1975) classify employment and training programs into four broad categories: (1) skill development programs, which increase vocational skills through classroom or on-the-job training; (2) job development programs, which consist of public employment programs where jobs are specifically created for the participants; (3) employability development programs, which, according to Butler and Hobbie (1976) emphasize personal attitudes and attributes needed for employment (i.e. what we would now call "soft skills”); and (4) work experience programs, which provide employment experiences intended to help workers gain the same attitudes and attributes as employability development programs through paid or unpaid work.

\footnotetext{
${ }^{1}$ For a discussion of programs during the Great Depression, see Kesselman (1978). Developments from 1961 through 2000 are discussed in more detail in LaLonde (2003).
} 
This classification system covers programs intended to increase human capital and create new jobs, although individual programs may have other goals as well. What is missing are categories that include programs intended to provide a better match between workers and jobs (sometimes called labor exchange programs) and programs that provide job seekers with more information about themselves (through counseling and assessment) and the jobs that are available (labor market information or LMI). ${ }^{2,3}$

This chapter focuses on means-tested employment and training programs in the United States. As such we generally exclude programs that do not do means testing. This set includes vocational education programs (though we do briefly discuss Pell grants, which many students use to attend vocational education, later in the chapter). ${ }^{4}$ We also exclude (1) the Unemployment Insurance (UI) program; (2) the Employment Service (ES) funded by the Wagner-Peyser Act; (3) the Worker Profiling and Reemployment Services (WPRS) and Reemployment and Eligibility Assessment (REA) programs for UI claimants; (4) registered apprenticeship programs; and (5) vocational rehabilitation and the Ticket to Work program, both of which provide services aimed at returning people with disabilities to productive employment.

To avoid duplication, we do not cover programs surveyed in other chapters, such as the earned income tax credit (Chapter 2) and the welfare-to-work programs associated with Temporary Assistance for Needy Families or TANF (Chapter 7). In addition, we exclude (1)

\footnotetext{
${ }^{2}$ LaLonde (2003) includes labor exchange programs as well as counseling and assessment and LMI in the job development category.

${ }^{3}$ Barnow and Nightingale (2007) take a broad view of policies that affect the labor force, and they include several other program categories: insurance and cash payments (e.g., unemployment insurance, disability insurance, and workers' compensation), regulations and mandates (e.g., minimum wage, living wage, occupational safety and health, and discrimination statutes and executive orders), tax incentives and credits (e.g., lifelong earning credit, earned income tax credit, and economic development programs such as empowerment zones and enterprise zones that offer place-based tax credits), and social and support services and payments (e.g., need-based stipends, transportation assistance, and subsidized or paid child care). Alternatively, labor market programs are sometimes divided into active programs, which impose requirements on those who benefit such as job search requirements, and passive programs, which provide cash or in-kind assistance with no requirements for the recipients.

${ }^{4}$ Vocational education can be classified as education rather than training, but many courses offered by community colleges as vocational education also enroll individuals in employment and training programs in the same course.
} 
programs that operate through mandates to employers, such as the minimum wage and civil rights legislation; (2) place-based programs, such as economic development programs, empowerment zones, and enterprise zones because they do not directly serve individual workers; and (3) programs for in-school youth. Finally, among the programs that remain (there are a lot of programs!) we devote the bulk of our attention to large (in persons served or budget or both) programs operated by the federal government for which credible impact evaluations exist. In that sense, we look where the light is, but there are a lot of keys there too.

The remainder of the chapter is organized as follows. We begin in the next section by briefly laying out the case for government involvement in the area of employment and training programs. Existing theory provides a case for the standard interventions, though the case would benefit from a stronger empirical foundation. Following that, we provide a history of U.S. workforce development programs and then describe the current array of means tested programs. In our view, some but by no means all of the wide diversity of existing programs can be justified based on the need to target specific interventions to specific populations.

We then describe the key issues involved in evaluating employment and training programs and how the U.S. literature has addressed them, as a prelude to our discussion of results from recent evaluations of major U.S. employment and training programs. The U.S. literature largely relies on occasional social experiments and more frequent analyses that attempt to solve the problem of non-random selection into programs or into particular services via conditioning on observed participant characteristics, particularly past labor market outcomes. The existing evidence makes it clear that some programs (in particular, the adult funding stream of the Workforce Investment Act program) have positive impacts on labor market outcomes sufficient to justify their costs, while many others do not. Explaining the differences in impacts 
among programs (and between funding streams within programs) remains an important topic for future research. In addition, we argue that the literature should shift its focus somewhat from research that estimates the impacts of program participation to research on how to better operate existing programs.

The final section summarizes and offers some suggestions for future work and institutional change. We emphasize the potential for generating additional policy-relevant knowledge via (1) improvements in the quality of administrative data as well as more intensive use of the administrative data already available and (2) "designing in" credible evaluation designs such as regression discontinuity following the (very) successful example provided by the education policy field.

\section{Justifications for government involvement}

This section considers what, if any, substantive economic justification underlies the types of means-tested employment and training programs currently operated by the U.S. government and considered in this chapter. Employment and training programs, sometimes referred to (by us and by others) as workforce development programs, clearly do not meet the usual definition of public goods as they are both excludable and rivalrous, so other explanations must be invoked.

One straightforward view sees employment and training programs as what Richard Musgrave (1959) termed "merit goods," a good that although not meeting the criteria of a public good, is so highly valued by society that it is provided publicly. Education is the most common example of a merit good, and as noted above, the line between occupational training and education is fuzzy. Musgrave and Musgrave (1973, p. 81) expand on the concept of merit goods, noting that merit goods might be provided either as the imposition of the preferences of the 
ruling elite on the poor or as a means of correcting market imperfections such as imperfect information, externalities, and interpersonal utility preferences. ${ }^{5}$

Another potential rationale for government intervention in the provision of employment and training services is market failure due to imperfect access to capital, especially among the poor. In some situations, training programs might be offered to achieve equity when some segment of the population is harmed by unforeseen market events or by specific government interventions. Programs targeted on workers who lose their jobs due to technical change, changes in consumer preferences, or changes in trade patterns exemplify the general case, while programs targeted on workers who lose their jobs due to trade agreements exemplify the second category.

Finally, imperfect information on the current and future labor market, particularly on the wages associated with occupations requiring training, could lead workers to systematically underinvest in training or to invest in the wrong types of training. Government may have a comparative advantage in collecting both labor market information and information about training providers, as it can amortize the fixed costs of doing so over many individuals. These arguments rationalize both the collection of the information and its distribution via caseworkers and websites.

Some of the rationales for government intervention in the employment and training field call for means testing, but others do not. If, for example, it is the poor who mostly experience challenges with access to capital and information, then it makes sense to have means testing for such programs. However, to the extent the public (or ruling elite in Musgrave's terminology) views employment and training programs as a merit good that should be provided to all, then means testing would not be required.

\footnotetext{
${ }^{5}$ In the latter cases, the provision of such goods does correspond to the traditional definition of a market failure. For a discussion of the rationale for in-kind redistribution to increase social welfare, see Garfinkel (1973).
} 
The existence of a rationale for government involvement in workforce development does not imply that most (or even very much) training should be financed by the government or that the government should directly provide some (or even any) training or other services. In regard to the first point, Mikelson and Nightingale (2004) conclude that private sector spending on training may be 10 times as great as public sector contributions, and other researchers have developed larger estimates. In regard to the second point, we detail below how the major U.S. federal programs contract out to other providers (some of them other units of government, such as community colleges) much of their service provision.

\section{History of U.S. employment and training programs}

Workforce programs in the United States began in the 1930s with several efforts to deal with the high unemployment associated with the Great Depression. During the Great Depression eight major work relief and public works programs were initiated. ${ }^{6}$ Under President Hoover, the Reconstruction Finance Administration provided loans to state and local governments for welfare and public employment. Although this function was in effect for less than one year, $\$ 300$ million in nominal dollars was spent on work relief, and at its peak nearly two million people were employed through the program. When Franklin Roosevelt assumed the presidency, a number of public employment programs were enacted. All these programs ended by 1943, when the unemployment rate dropped to 1.9 percent and there was no need for large-scale employment creation programs. Public employment programs largely vanished until the 1970s.

6 The discussion of programs during the Great depression is based on Kesselman (1978). 
After discussing the Wagner-Peyser Act, which began during the Great Depression, this section focuses on the flagship U.S. Department of Labor programs beginning in the 1960s. We then describe other U.S. Department of Labor programs as well as significant programs operated by other federal agencies. ${ }^{7}$

\section{The Wagner-Peyser Act}

The Wagner-Peyser Act of 1933 established the Employment Service (ES, but sometimes called the Job Service in some states), the longest continuously operating workforce program in the United States. ${ }^{8}$ The ES is open to all job seekers and employers, so it is not a means-tested program. The ES focuses on providing a variety of employment-related labor exchange services including but not limited to job search assistance, job referral, placement assistance for job seekers, reemployment services to unemployment insurance claimants, and recruitment services to employers with job openings. Services are delivered in one of three modes: self-service, facilitated self-help, and staff-assisted. Depending on the budget available and needs of the labor market, other services such as assessment of skill levels, abilities, and aptitudes; career guidance; job search workshops; and referral to training may be available. ${ }^{9}$ The services offered to employers, in addition to referral of job seekers to available job openings, include assistance in development of job order requirements; matching job seeker experience, skills and other attributes with job requirements; assisting employers with special recruitment needs; arranging for job fairs; helping employers analyze hard-to-fill job orders; assisting with job restructuring;

\footnotetext{
${ }^{7}$ For reviews of the employment and training programs between 1961 and 1973, see Clague and Kramer (1976), Perry et al. (1975), Barnow (1993), King (1999), and O’Leary, Straits, and Wandner (2004).

${ }^{8}$ See Eberts and Holzer (2004) for a review of the ES history.

${ }^{9}$ In many states the ES administers other programs and services at the direction of the governor. For example, in many states the ES administers the Trade Adjustment Assistance (TAA) program and the Supplemental Nutrition Assistance Program (SNAP), formerly known as food stamps.
} 
and helping employers deal with layoffs. ${ }^{10}$ With enactment of the Workforce Investment Act in 1998, the ES was named as a mandated partner in the One-Stop delivery system.

\section{The Area Redevelopment Act}

No major federal employment and training programs emerged following the Great Depression until the 1960s. ${ }^{11}$ In 1961, the Area Redevelopment Act (ARA) was passed to stimulate growth in areas with high unemployment by providing loans, financial assistance, and technical assistance to firms developing new products, and training for workers who would be employed by firms that expanded or relocated. The ARA was never a large program, and training enrollments ranged from 8,600 in 1962 to a high of about 12,000 before the program ended in 1965.

\section{The Manpower Development and Training Act}

The Manpower Development and Training Act of 1962 (MDTA) was the first federal program to provide training on a larger scale. The original intent of MDTA was to retrain workers who lost their jobs due to "automation," the term used at that time for technical change. From the beginning, the program also served disadvantaged workers, and services to the economically disadvantaged soon predominated, as job losses due to automation failed to materialize. A total of approximately 1.9 million workers enrolled in MDTA between 1963 and 1972, with about two-thirds of the participants enrolled in classroom training and one-third enrolled in on-the-job training (OJT, which is informal training by employers who receive subsidies of up to 50 percent of wages for up to six months). ${ }^{12}$

\footnotetext{
${ }^{10}$ The description of the Employment Service is from http://www.doleta.gov/programs/wagner_peyser.cfm, accessed on November 1, 2014.

${ }^{11}$ This discussion is based largely on Barnow (1993).

${ }^{12}$ See Mangum (1968).
} 
Administration of MDTA was complex. The original legislation called for states to eventually pay for half the program, but these requirements were postponed and diluted, and eventually states were only required to make a 10 percent match that could be an "in-kind" contribution. Administration of the OJT component of the program was eventually shifted from the U.S. Department of Labor to the Job Opportunities in the Business Sector (JOBS) program, which was operated by the National Alliance of Business, a nonprofit business trade association. The institutional classroom training was largely administered by the U.S. Department of Labor, with relatively minor roles played by state and local governments.

Although MDTA was by far the largest employment and training program in the 1960s and early 1970s, there were many other workforce development programs in operation. Table 8.1 describes the major programs that operated during this period. Barnow (1993) describes 10 programs that operated during this period, and Perry et al. (1975) provide detailed information about most of the programs as well as evidence on their effectiveness. Franklin and Ripley (1984, p. 7) note the consequences of having so many programs available with similar intent: "The need for coordination among manpower programs and agencies serving the poor became increasingly apparent during the 1960s. A fearsome degree of fragmentation and rococo complexity resulted from the large number of separate programs, each with its own target groups, application procedures, funding cycles, and delivery mechanisms."13

The only U.S. Department of Labor program providing training still in operation from the 1960s is the Job Corps, a primarily residential program for disadvantaged youth that we describe in more detail below.

\footnotetext{
${ }^{13}$ It is not clear what the optimal number of employment and training programs is, and there is still debate about whether there are "too many" programs. We discuss this issue later in the chapter, but note here that to a large extent there are many programs because they serve different populations or provide a different mix of services. Interesting research opportunities exist on the issue of how many programs there should be and how they should be differentiated in mission and targeting.
} 


\section{The Comprehensive Employment and Training Act of 1973}

In 1973, MDTA was replaced by the Comprehensive Employment and Training Act (CETA). The new program included a change in the mix of activities offered and in the responsibilities of different levels of government. President Nixon was a strong advocate for the "New Federalism," which sought to give state and local governments more control over who was served and how they were served. The CETA program represented a major departure from MDTA in several ways. First, decisions about who would be served and how they would be served were primarily made at the local level rather than at the federal or state level; in fact, CETA was the high point for local authority compared to the MDTA program that preceded it and the Job Training Partnership Act (JTPA), Workforce Investment Act (WIA), and Workforce Innovation and Opportunity Act (WIOA) programs that succeeded it.

Under CETA Title I prior to the 1978 amendments, funds were distributed by formula to cities, counties, or consortia of local governments. Any jurisdiction with a population of 100,000 or more was entitled to be recognized as a "prime sponsor." Areas that were ineligible for designation on their own and failed to join a consortium were included in a "balance of state" prime sponsor that was administered by the state. Prime sponsors were required to submit an annual plan to the U.S. Department of Labor for approval, and they were also required to establish a planning council with representatives of various constituencies, including the private sector. Prime sponsors had significant latitude in determining their mix of activities and participants under Title I; activities available included classroom and on-the-job training, public service employment, and work experience.

A concern under MDTA that persists to the present day is that states and local programs would engage in "creaming" or "cream skimming" by selecting as participants those among the 
eligible applicants most likely to do well after participation whether or not the program helps them (Perry et al., 1975, p. 151; Mangum, 1968, p. 169; Mirengoff and Rindler, 1978, p. 176). Several features of CETA were designed to mitigate this issue. First, categorical programs were established for groups with severe barriers-Indians and Native Americans, and migrant and seasonal farmwokers - and these categorical programs remain part of the program mix today. Additionally, prime sponsors were required to make assurances in their annual plans that they would serve those "most in need," including "low-income persons of limited English-speaking ability." The original CETA statute included a public service employment program in Title II, and 1974 legislation added a countercyclical public service employment program as Title VI. Over time, the public service employment components grew to be the largest part of CETA. In 1977, the Youth Employment and Demonstration Projects Act (YEDPA) created two new categorical youth programs for the prime sponsors to administer, the Youth Employment and Training Program (YETP) and the Youth Community Conservation and Improvement Projects (YCCIP); YETP provided training and work experience, primarily for in-school disadvantaged youth, and YCCIP provided training and work experience primarily for out-ofschool disadvantaged youth. The legislation also established a large demonstration program, the Youth Incentive Entitlement Program (YIEPP), to test the feasibility and impact of guaranteeing part-time school-year and full-time summer jobs to disadvantaged youth to encourage them to remain in school. A year later, the Young Adult Conservation Corps (YACC) was added to provide participating youth a conservation experience. Although over $\$ 1$ billion was spent on the YEDPA programs, only a few of the programs were rigorously evaluated. A National Academy of Sciences review of the evidence on the YEDPA programs concluded that “...despite the magnitude of resources devoted to the objectives of research and demonstration, there is little 
reliable information on the effectiveness of the programs in solving youth employment problems" (Betsey, Hollister, and Papageorgiou, 1985, p. 22). ${ }^{14}$

Several other national programs were added to CETA during this period, including the Skill Training Improvement Program (STIP), which was one of the first U.S. initiatives to offer long-term training to dislocated workers through competitively funded projects; Help through Industry Retraining and Employment (HIRE), which provided training to veterans though the National Alliance of Business initially and later through prime sponsors; and the Private Sector Initiative Program (PSIP), which provided training in conjunction with the newly established private industry councils affiliated with the CETA prime sponsors. HIRE and PSIP were early efforts to try to more effectively involve the private sector in federally sponsored training programs, an effort whose goals have yet to be fully achieved.

By 1976, concern had increased that the public service employment (PSE) slots were allowing local governments to substitute federal funds for state and local funds to support positions, a phenomenon known as fiscal substitution. ${ }^{15}$ As a result, several modifications were made to PSE Title VI requirements. PSE positions that became vacant could only be used in special projects that lasted for 12 or fewer months. In addition, individuals hired for new Title VI positions and half the Title VI positions that became vacant were required to be individuals unemployed for at least 15 weeks and a member of a low-income family.

\footnotetext{
${ }^{14}$ The director of the YEDPA program was more optimistic about what was learned from the experience. See Taggart (1981).

${ }^{15}$ Butler and Hobbie (1976), a report prepared by the Congressional Budget Office, summarized the research by Johnson and Tomola (1976), which concluded that fiscal substitution reached 100 percent within 18 months of a PSE slot being funded. A reanalysis of the data by Borus and Hamermesh (1978) found that the amount of substitution was very sensitive to the assumptions of the statistical model used. A qualitative field analysis conducted at roughly the same time concluded that much of what appeared to be substitution was instead maintenance, where PSE workers filled slots that would have been abolished in the absence of the PSE funding. See Nathan et al. (1981).
} 
Amendments to CETA in 1978 were enacted to address concerns that the program was not creating jobs but instead substituting federal funds for state and local funds. Among the changes that were instituted, PSE wages in most places were capped at $\$ 10,000$ annually, but in high-wage areas salaries could be up to $\$ 12,000$; average national wages were capped at $\$ 7,200$, lowering the national average by $\$ 600 ;{ }^{16}$ new PSE participants could not have their wages supplemented by the prime sponsor; and prime sponsors were required to establish independent monitoring units to investigate violations of laws and regulations. Cook, Adams, and Rawlins (1985, p. 13) refer to the 1978 amendments as "the beginning of the end for PSE." All the restrictions on qualifications, salaries, and project characteristics made PSE unattractive to prime sponsors, so that when the Reagan Administration proposed barring PSE in the new Job Training Partnership Act, there was little objection.

\section{The Job Training Partnership Act of 1982}

CETA was due to expire in 1982, and the replacement program, the Job Training Partnership Act (JTPA) was a bipartisan effort sponsored by Senators Edward Kennedy and Dan Quayle. The new law reflected President Reagan's view of federalism, which included a larger role for state government and smaller roles for the federal government and local government. Public service employment, which had become increasingly unpopular with the public and less desirable for local governments as restrictions on participants and activities were added, was prohibited under JTPA. Some key features of JTPA included: programs for economically disadvantaged youth and adults continued to be locally administered; states assumed a much greater role in monitoring the performance of local programs; the private sector was given the opportunity to play a major role in guiding and/or operating the local programs; and the system was to be "performance driven," with local programs rewarded or sanctioned based on their

\footnotetext{
${ }^{16}$ All these figures are in nominal dollars.
} 
performance. As we describe below, both the role of the private sector and the performance measurement system remain important but unsettled issues.

JTPA included three categorical funding streams that were distributed by formula to the states and then to local areas. ${ }^{17}$ The Title II-A program provided funding for economically disadvantaged adults and youth, the Title II-B program was for summer youth employment and training, and the Title III program served dislocated workers. ${ }^{18}$ National programs for Indians and Native Americans, and migrant and seasonal farmworkers were authorized by Title IV of the legislation. The Title II programs were conducted through local service delivery areas (SDAs), which were similar in nature to the prime sponsors under CETA. The minimum population size for automatic designation as an SDA was increased from 100,000 under CETA to 200,000 in an effort to reduce the number of local programs from the over 450 prime sponsors under CETA; the failure to have a provision for balance of state units actually led to an increase in the number of local programs to over 600. Major activities provided under Title II-A were occupational and basic skills training, OJT, job search assistance, and work experience. ${ }^{19}$

JTPA focused on the poor. All out-of-school youth and at least 90 percent of those served in the adult program had to meet income-based eligibility requirements. There were no incomerelated eligibility requirements for those served in the dislocated worker program. ${ }^{20}$

As noted above, JTPA attempted to increase the role of the private sector in guiding employment and training programs. In 1978, CETA was amended to authorize the creation of

\footnotetext{
${ }^{17}$ Allocations for the adult and youth program to states and substate areas were based equally on the number unemployed in areas of substantial unemployment (local areas with at least a 6.5 percent unemployment rate), the number unemployed in excess of 4.5 percent of the labor force, and the number of economically disadvantaged adults; allocations for the dislocated worker program distributed by formula were based equally on the number unemployed, the number unemployed in excess of 4.5 percent, and the number unemployed for 15 weeks or longer. See Johnston (1987).

${ }^{18}$ The 1992 JTPA amendments established a separate program, Title II-C, for services to youth.

${ }^{19}$ Reviews of the JTPA literature are found in Johnston (1987) and Levitan and Gallo (1988).

${ }^{20}$ Devine and Heckman (1996) analyze the eligibility requirements for JTPA from equity and efficiency perspectives.
} 
private industry councils (PICs), but the PICs gained much more authority under JTPA, where the PICs served as boards of directors for the local programs and could operate the programs if they voted to do so. PIC members were appointed by the chief local official(s) in the SDA, and a majority of the members were required to be from the private sector.

The Title III program for dislocated workers was originally a state-level program, and states were required to match federal funding on a dollar-for-dollar basis. Congressional concern about services to dislocated workers was high, and JTPA was modified in major ways in 1988 with the Economic Dislocation and Worker Adjustment Assistance Act (EDWAAA). ${ }^{21}$ This legislation required governors to distribute at least 60 percent of the Title II funds to sub-state areas.

Major amendments to JTPA were enacted in August $1992 .{ }^{22}$ The amendments made the program more prescriptive in terms of who could be served and what activities could be undertaken. For example, the amendments required that at least 65 percent of the Title II-A participants possess at least one characteristic that classified them as "hard to serve.",23

\section{The Workforce Investment Act of 1998}

The Workforce Investment Act (WIA) was enacted August 7, 1998 to replace JTPA. ${ }^{24}$ States had the option of being "early implementers," but most states began implementing the

\footnotetext{
${ }^{21}$ In addition to modifying JTPA, Congress also passed the Worker Adjustment and Retraining Notification (WARN) Act in 1988, which required employers under certain circumstances to provide workers with notice 60 days in advance of plant closings and major layoffs.

${ }^{22}$ For a summary of the amendments, see Barnow (1993), and for a thorough discussion of the amendments and their impacts, see Trutko and Barnow (1997).

${ }^{23}$ These characteristics were basic skills deficient, high school dropout, welfare recipient, disabled, homeless, or an offender. Youth could also meet the requirement if they were pregnant or a parent, or below the appropriate grade level for their age.

${ }^{24}$ The Workforce Investment Act reauthorized several programs in addition to the workforce program commonly referred to as WIA. Title I of WIA establishes the workforce program usually referred to as WIA; Title II authorizes the federal adult education and literacy program; Title III amends the Wagner-Peyser Act to better integrate
} 
new law July 1, 2000. The WIA program maintained the formulas used to distribute funds to states and sub-state areas. WIA is based on seven guiding principles: ${ }^{25}$

(1) Streamlined services: Integrating multiple employment and training programs at the "street level" through the One-Stop delivery system to simplify and expand access to services for job seekers and employers.

(2) Individual empowerment: Empowering individuals to obtain the services and skills they need to enhance their employment opportunities through Individual Training Accounts (ITAs), voucher-like instruments that enable eligible participants to choose the qualified training program they prefer. Vendors were to meet performance criteria established by the states, and vendors that met the criteria were to be included in an eligible training provider list.

(3) Universal access: Granting access to all job seekers and others interested in learning about the labor market through the One-Stop delivery system. The concept was that anyone interested in what were termed core employment-related services could obtain job search assistance as well as labor market information about job vacancies, the skills needed for occupations in demand, wages paid, and other relevant employment trends in the local, regional, and national economy. ${ }^{26}$

(4) Increased accountability: Holding states, localities, and training providers accountable for their performance. WIA was intended to improve the performance measurement system established under JTPA by holding states accountable for their performance and building continuous improvement into the system.

\footnotetext{
Wagner-Peyser labor exchange activities by requiring that Employment Service activities be integrated with the One-Stop Career Center system; Title IV amends the Rehabilitation Act of 1973, which authorizes the state vocational rehabilitation program for individuals with disabilities; and Title V includes general provisions dealing with matters such as state unified plans and state incentive grants. See Bradley (2013).

${ }^{25}$ This is based on Barnow and King (2005), and the principles are described in the WIA White Paper available at www.doleta.gov/usworkforce/documents/misc/wpaper3.cfm, accessed November 9, 2014.

${ }^{26}$ Access to staff-assisted services varied among local service delivery areas, depending on state and local policies and funding availability.
} 
(5) A strengthened role for local Workforce Investment Boards (WIBs) and the private sector: The framers of WIA envisioned that the local WIBs would have a stronger role in administering the system than the PICs under JTPA and that employers would participate more in administering the system than they had under JTPA. ${ }^{27}$

(6) Enhanced state and local flexibility: Giving states and localities the flexibility to build on existing reforms to implement innovative and comprehensive workforce investment systems was a priority under WIA. Through such mechanisms as unified planning and waivers, states and their local partners were provided flexibility to tailor delivery systems to meet the particular needs of individual communities.

(7) Improved youth programs: Linking youth programs more closely to local labor market needs and the community as a whole, and providing a strong connection between academic and occupational learning were envisioned under WIA.

Many of the guiding principles do in fact reflect meaningful changes in the delivery system for workforce investment services in the nation's primary employment and training program. The utilization of a one-stop system began several years prior to enactment of WIA on a voluntary basis in local areas, but the 1998 statute required many workforce development programs to co-locate and coordinate services in One-Stop Career Centers, which the U.S. Department of Labor has recently rebranded as American Job Centers (AJCs). ${ }^{28}$ The One-Stop centers were intended to provide the "core" and "intensive" services mandated by WIA (described below); to provide access to workforce development programs and services offered by

\footnotetext{
${ }^{27}$ Although the Department of Labor envisioned a stronger role for the private sector under WIA, there is scant evidence of this occurring. There were no major changes in the WIA statute that would have mandated a stronger role for employers, and neither of the two studies of WIA implementation, D'Amico et al. (2004) and Barnow and King (2005) found growth in the role of the private sector under WIA.

${ }^{28}$ Ironically, when local programs first formed one-stop centers on their own, state and federal officials sometimes expressed concern that employees of one organization might provide services to customers who were supposed to be served by a different program, and the practice was often discouraged.
} 
One-Stop partners; and to provide access to the labor market information, job search, placement, recruitment, and labor exchange services offered by the Employment Service (Bradley, 2013).

The One-Stops were required to include over a dozen programs that provide services to job seekers: WIA adult, youth, and dislocated worker programs; federal Department of Labor programs authorized under WIA including Job Corps, the Native American program, and the Migrant and Seasonal Farmworker program; Employment Service programs authorized by the Wagner-Peyser Act; adult education and literacy programs; vocational rehabilitation; welfare-towork programs; the Senior Community Service Employment Program; postsecondary vocational education; Trade Adjustment Assistance (TAA); programs administered by the Veterans' Employment and Training Service; community services block grants; employment and training activities operated by the U.S. Department of Housing and Urban Development; unemployment insurance; and registered apprenticeship programs. ${ }^{29}$

Depending on state and local policies, other relevant programs may be present at the One-Stops. Optional partners noted by the Department of Labor include Temporary Assistance for Needy Families (TANF), employment and training programs operated in conjunction with the Food Stamps program (now the Supplemental Nutrition Assistance Program or SNAP), Department of Transportation employment and training programs, and programs operated under the National and Community Service Act of $1990 .{ }^{30}$

Although the Department of Labor's White Paper called for "streamlined services," this goal was hindered by another feature of WIA, namely the requirement that the program offer services in sequence from core to intensive to training. D'Amico and Salzman $(2004$, p. 102)

\footnotetext{
${ }^{29}$ Retrieved from http://www.doleta.gov/usworkforce/onestop/partners.cfm on November 15, 2014; also available from http://www.doleta.gov/programs/factsht/pdf/onestoppartners.pdf retrieved November 15, 2014. The programs are described slightly differently at the two sites. Note that the welfare-to-work programs, which referred to special programs for TANF recipients that were operated through local WIA programs, are no longer in operation. ${ }^{30}$ Ibid.
} 
note that "JTPA was faulted for authorizing expensive training services as a first, rather than as a last, resort." As a result, WIA established three levels of service that customers were required to access sequentially: ${ }^{31}$ (1) Core services, including outreach, job search and placement assistance, and labor market information available to all job seekers; (2) intensive services, including more comprehensive assessments, development of individual employment plans and counseling, and career planning; and (3) training services, including both occupational training and training in basic skills. Participants who reach the third step use an "individual training account" (ITA) to select an appropriate training program from a qualified training provider. ${ }^{32}$

Individual empowerment was an important feature of WIA, implemented largely through the ITAs. ${ }^{33}$ Although vouchers were used by some local areas under JTPA, ITAs were the default approach to training under WIA. ${ }^{34}$ Local areas had a great deal of flexibility in administering the ITAs, and some local areas tended to give customers wide latitude in using their ITA, while others restricted customers in terms of cost, past performance of the vendor, and qualifications and aptitude of the customer for the course. ${ }^{35}$

Universal access was envisioned as an important feature of WIA to avoid stigmatizing the program due to its having poor and low-skilled customers. With the co-location of the Employment Service in most One-Stop centers, it was anticipated that all adult job seekers, not

\footnotetext{
${ }^{31}$ Several reviewers questioned whether WIA specifically required sequencing of services or if the sequencing was imposed by the Department of Labor. Section 134 of the statute reserves intensive services for those unable to obtain or retain employment after receipt of core services, and training is reserved for individuals who are unable to obtain or retain employment after receipt of intensive services. As the Department of Labor noted when it later emphasized that WIA was not a "work first" program, there are no minimum time periods that a person must receive core or intensive services before receiving training.

${ }_{32}^{32} \mathrm{http://www.doleta.gov/programs/general \_ info.cfm} \mathrm{retrieved} \mathrm{November} \mathrm{15,} 2014$.

33 Although WIA required that ITAs be available to training customers in most circumstances, exceptions included when on-the-job training and customized training are provided, when the local board determines that there are too few providers available to meet the intent of vouchers, and when the local board determines that there is a local program of demonstrated effectiveness for meeting the needs of special low-income participant populations that face multiple barriers to employment (Patel and Savner, 2001, p. 1).

${ }_{35}^{34}$ For a review of the use of vouchers under JTPA, see Trutko and Barnow (1999).

${ }^{35}$ See D'Amico et al. (2004), Barnow (2009), and King and Barnow (2011). We discuss the ITA experiment later in the chapter.
} 
just the poor or unemployment insurance claimants who were required to search for work, would use the One-Stops to obtain labor market information and search for work. Access to intensive services and training was restricted, however, to public assistance recipients and other lowincome individuals when the local workforce area had insufficient funds to serve all potential customers who might benefit from training. ${ }^{36}$

The goal of increased accountability was addressed in two ways - changes were made to the performance measurement system used under JTPA, and states and local areas were asked to establish an eligible training provider (ETP) list of vendors with strong performance. Only vendors on the list could accept ITAs from WIA participants.

The performance measures varied over the existence of JTPA, with a trend toward longer post-program follow-up for earnings measures. ${ }^{37}$ Changes in the performance system between JTPA and WIA include the following: ${ }^{38}$ Under JTPA, only local areas were subject to performance measures, but under WIA, the federal government sets standards for states, and the states establish standards for local areas; under JTPA, after the initial few years, local standards were adjusted by a regression model intended to hold areas harmless for differences in customer characteristics and economic conditions, but under WIA standards were established through negotiations. ${ }^{39}$ Performance was initially measured under JTPA at the time of program exit and 13 weeks after exit, and under WIA the employment and earnings measures used the second and third quarters after program exit. JTPA did not specify a source for the data used to measure performance, but WIA specified the use of unemployment insurance wage records.

\footnotetext{
${ }^{36}$ Later in the chapter we discuss the characteristics of WIA exiters. In Table 8.3 we note that among adult exiters who left the program between April 2012 and March 2013, 60.9 percent received training.

${ }^{37}$ See Barnow (2011) for a discussion of the WIA performance measurement system and a comparison with the JTPA system. In the same volume, Borden (2011) discusses the problems associated with measuring performance. ${ }^{38}$ This information is from Blank, Heald, and Fagnoni (2011), King and Barnow (2011), and Barnow (2011).

${ }^{39}$ In the last few years of WIA, the Department of Labor resurrected the idea of using statistical models to adjust performance standards. Results of these efforts are described in Eberts, Bartik, and Huang (2011).
} 
During the WIA period, the Office of Management and Budget (OMB) sought to have all workforce-oriented federally sponsored programs use "common measures" so that programs could be compared, but only the Department of Labor complied. Originally, the WIA Adult program had four measures — entered employment rate, employment retention rate, earnings change, and the employment and credential rate; these measures are defined below when program outcomes are provided. For dislocated workers, an earnings replacement rate was used instead of an earnings change measure. Youth ages 19 to 21 had the same measures as adults, and youth ages 14 to 18 had three core measures - the skill attainment rate, the diploma or equivalent attainment rate, and the retention rate (D'Amico et al., 2004). In addition, there were employer and participant customer satisfaction measures.

The performance measures were modified somewhat in 2006, as described in Training and Guidance Letter 17-05 (TEGL 17-05). The TEGL indicated three common measures to be used for adults in the Adult and Dislocated Worker programs — entered employment rate, employment retention (the proportion of adults employed in the first quarter after exit who were employed in the second and third quarters after exit), and average earnings (total earnings in the second and third quarters after exit for adults employed in each of the first three quarters after exit). The three common youth measures beginning in 2006 are placement in employment or education, attainment of a degree or certificate, and literacy and numeracy. The states using common measures stopped using customer satisfaction measures beginning in 2006, as they were not included in the common measures.

The second effort to increase accountability in WIA was the use of an eligible training provider (ETP) list. With customers having a greater role in selecting their field of training and vendors through the use of ITAs, there was a risk that customers might select vendors based on 
vendor claims rather than the performance of the programs and the customer's suitability for the program selected. Governors were thus given the opportunity to establish an ETP list that only included vendors who had a good track record for that program. Evidence indicates that although some states were able to develop satisfactory ETP lists, there were severe challenges in meeting this requirement of WIA, and 35 states received waivers that permitted them to implement only a portion of the ETP requirements or to delay implementation (Van Horn and Fichtner, 2011). ${ }^{40}$

WIA included several changes to the eligibility requirements for youth participants as well as changes in the programs themselves. There was separate funding for a summer youth program and a year-round program under JTPA, while WIA included only a year-round program; as D’Amico et al. (2004, p. VIII-1) note, the summer program was a major DOL program for 36 years so this was a substantial change. The specific eligibility requirements varied somewhat, but in both JTPA and WIA there was a heavy emphasis on serving poor youth; a study by the U.S. General Accounting Office (GAO, 2002, p. 7) suggested that the eligibility changes may have resulted in the youth served by WIA coming from poorer families than under JTPA, and D'Amico et al. (2004, p. VIII-1) drew a similar conclusion. The new program also required that at least 30 percent of the funds be spent on out-of-school youth. GAO $(2002$, p. 6) notes that WIA's intent was for longer-term and more comprehensive services than had been provided under JTPA, and the statute required that 10 program elements be made available to youth enrolled in the program. ${ }^{41}$

\footnotetext{
${ }^{40}$ Van Horn and Fichtner (2011. p. 155) note that "Education and training establishments and their trade organizations marshaled opposition to performance reporting and undermined or quashed implementation throughout the country." D'Amico et al. (2004, p. I-12) also note the failure of the ETP list to achieve its expected role in the system.

${ }^{41}$ The 10 required youth services are: (1) tutoring, study skills training, and instruction leading to completion of secondary school; (2) alternative secondary school services; (3) summer employment linked to academic and occupational learning; (4) paid and unpaid work experience; (5) occupational skills training; (6) leadership development; (7) supportive services; (8) adult mentoring during the program and at least 12 months afterward; (9)
} 
There were two large-scale studies of the implementation of WIA in its early years: D'Amico et al. (2004) and Barnow and King (2005). D'Amico et al. (2004) conducted their study in 21 states and 38 local areas between 1999 and 2004. Barnow and King (2005) based their analysis on eight states and 16 local areas visited in 2002. Below we briefly summarize the major findings of the two studies, starting with D'Amico et al. (2004). D'Amico et al. (2004) organize their summary of accomplishments and challenges by a slightly modified list of the seven guiding principles listed above.

Regarding the principle of streamlining services through integration, D'Amico et al. (2004, p. I-4) conclude "Despite numerous challenges that have been encountered along the way (and sometimes outright resistance), partnership formation represents a highly successful and, in the long term, potentially critically important accomplishment engendered by WIA." The authors note that the system encountered a number of challenges, and the greatest challenge appeared to be finding each partner's share of financing the One-Stop infrastructure. Other challenges they note include differing visions among partners on what service integration means, differences in program goals and customer needs across partners, varying cultures among One-Stop partners, logistical issues in arranging co-location, different management information systems for various programs, and separate performance and reporting requirements among programs.

D'Amico et al. (2004) found that states and local areas had made great progress in promoting universal access through the One-Stop system. As evidence, they note that states and local areas established nearly 2,000 One-Stop Centers by 2003, and that 40 percent of the local areas had six or more access points to services. The authors observe that promoting universal access creates some important tensions in the system; for example, by broadening services to the

at least 12-month follow-up after program completion; and (10) guidance and counseling. See U.S. General Accounting Office (2002, p. 7). 
entire population, fewer resources are available for the poor, and local areas must decide how to balance provision of lower tier services with the desire to provide training to those who need more skills. $^{42}$

The study found that the principle of empowering customers through choice has been “enthusiastically embraced by One-Stop administrators and staff” (p. I-11). Specifically, they point to the widespread use of ITAs to be evidence of the popularity of giving customers choice. The authors note that many local areas cap the ITAs at levels as low as \$1,500 so that resources are spread across many participants.

The goal of enhancing state and local flexibility is considered a major success by D’Amico et al. (2004, p. I-12). The authors state:

...our field researchers were struck by the enormous diversity in WIA service designs and delivery structures across the country. Thus, within the broad constraints of the legislation, local areas vary markedly in their governance and administrative structures, the way local boards operate, the procedures for designating One-Stop operators and the responsibilities with which the operator is charged, the ways partners work together to staff various services, how adult and dislocated workers move through the service levels, how priority for target groups is established, whether or not training is emphasized, caps placed on ITA amounts, and so forth.

Although states and local areas appreciated the freedom, the researchers felt that the states and local areas would have benefited from technical assistance on promising practices.

Although employment and training programs have had performance measurement systems since the 1970s, D'Amico et al. (2004) found the principle of promoting performance accountability was the most challenging of the WIA principles to implement. One aspect of the accountability system is the requirement that states and local areas establish an ETP list of training vendors. Problems cited regarding the ETP list include that high standards limit the choice of vendors available to customers, many vendors (including a number of low-cost, high-

\footnotetext{
${ }^{42}$ As is shown in Tables 8.5 and 8.6 , only about one-half of those served by the WIA adult program meet the definition of low-income, and fewer than 10 percent of the customers received training.
} 
quality community colleges) dislike the ETP application procedures and may not seek to be listed, and the data used to compile the list is often of questionable reliability.

States and local areas also expressed concern about the performance measurement system used for the WIA program. The concerns included that the measures were too numerous and complex, the definitions used for some of the measures (such as credentialing) were vague and potentially unreliable, the system promoted "cream skimming" of the potential customers most likely to look good on the performance measures, the states and local governments spent a significant effort managing their numbers rather than focusing on providing appropriate services, the system was not useful for program management because of the long lag between when customers were served and when the results were measured, and the differing measures across programs hindered partnership development.

D’Amico et al. (2004) found that although WIA continued the requirement that business representatives make up a majority of state and local boards and the Department of Labor encouraged states to make increased use of business in shaping their programs, "in practice [local workforce areas] are lagging in their ability to engage businesses seriously in strategic planning or serve them as customers with high-quality services" (p. I-17).

The final guiding principle for WIA was improving youth programs. D’Amico et al. (2004) found that at the time of their site visits, states and local areas were "lagging badly behind in their implementation of youth programming, partly because of the time delays inherent in needing to appoint a Youth Council [one of the new requirements of WIA] and competitively select service providers." Other challenges for the WIA youth program included the abolition of the summer youth program, the requirement that individual eligibility be documented rather than being able to use presumptive measures such as participation in free and reduced price school 
lunch programs, dealing with the statutory requirement that 10 program elements be included in youth programs, and connecting WIA programs with the One-Stop system for older youth.

Barnow and King (2005) organized their findings around five major topics: (1)

leadership, (2) system administration and funding, (3), organization and operation of One-Stop Career Centers, (4) service orientation and mix, and (5) use of market mechanisms.

The study states exhibited a range of leadership patterns in setting up, implementing, and operating their workforce development systems. In five of the eight states, the governor's office played a strong leadership role, but in others the governor gave discretion to local workforce areas. The state legislature had a leadership role in three states, resulting in bipartisan state workforce legislation. Business's role was strong at the state level in only a few of the states. At the local level, however, business engagement was found to be strong in half of the states.

WIA's administrative structure is complex, distinguishing between policy development, program administration, and service delivery more explicitly than earlier workforce legislation. It also requires states to balance state and local responsibilities and make decisions about how to administer WIA in conjunction with other state employment security, economic development, and related programs. The most common approach in the states in the study is that policy was developed by the state and local WIBs, program administration was undertaken by agencies at the state and local level, and service delivery was carried out by vendors. Some study states adopted this separation of responsibilities several years prior to WIA. Some states and local areas found that they did not have sufficient funding to provide training to all they believed would benefit from the service, and they limited training by rationing it and/or by limiting the amount that would be paid for training programs. 
Barnow and King (2005) found wide variation in how states and local areas interpreted the requirement to operate programs through the One-Stop system. They found that challenges arose related to how the mandatory and optional partners relate to each other at the centers and regarding how the centers are operated and funded. In some states, key programs such as WIA, the Employment Service, and TANF are highly integrated, but in others TANF, which is an optional partner, has no presence at One-Stop Centers, and/or the Employment Service has a separate office. Although Unemployment Insurance (UI) is a mandatory partner, the study found its role in the One-Stop Career Centers to be minimal; this is because in the years prior to WIA, UI staff in most states were located in call centers and primarily dealt with clients through telephone and internet contact. The study found that TANF, Vocational Rehabilitation, and the Veterans Employment and Training Service did not fit well in One-Stop Career Centers because of conflicting goals, cultures, or other differences. There was variation in how the infrastructure of One-Stop Centers was financed, and the issue of funding the centers was a source of contention in most of the study sites.

Barnow and King (2005) found that service orientation evolved significantly in the early years of WIA implementation in many states. Initially, states and local areas interpreted the statutory language to require a "work-first" or labor market attachment orientation based on early guidance provided by the Department of Labor and the statutory requirement for sequencing of core, intensive, and training services. Later, the Department of Labor made it clear that a workfirst orientation was not required and that states could place greater emphasis on training. After that, states diverged in their orientation, with some still emphasizing finding work, and others focusing more on human capital development through training, and still others leaving orientation up to local areas. 
Market mechanisms were to play a major role under WIA, and Barnow and King (2005) analyzed the ETP list requirement and the use of performance measures to reward and sanction states and local areas based on how well they did in terms of customers' employment and earnings. They found that three states already had systems in place to monitor training provider performance, and these states had little problems with the ETP list concept. Of the remaining states in the study, three had problems initially with the ETP concept but were able to adapt, and two states found the system to be burdensome for training providers and reported that some vendors refused to participate in WIA because of the ETP requirements. ${ }^{43}$

A second market mechanism implemented in WIA is the use of ITAs. Barnow and King (2005) reached conclusions similar to D'Amico et al. (2004), finding that the ITAs were popular with customers and accepted by local programs as a useful feature. ${ }^{44}$

Barnow and King (2005) also reached conclusions similar to D'Amico et al. (2005) on the WIA performance standards system. State and local areas were critical of the elimination of a regression-based adjustment system to level the playing field and replacement of this approach with negotiations between states and the Department of Labor, particularly because many states believed that the Department of Labor representatives often did not negotiate fairly. Barnow and King (2005) also found that a majority of states in their sample engaged in strategic behavior designed to make their measured performance look good.

\footnotetext{
${ }^{43}$ This is one of the few areas where Barnow and King (2005) reach different conclusions from D'Amico et al. (2004). We believe that the somewhat more positive conclusions regarding the ETP list for Barnow and King relate to the nature of their sample of states, which included a relatively high proportion of states with something resembling an ETP list in place prior to WIA. As noted earlier, Van Horn and Fichtner (2011) reported that a majority of states now have waivers to some or all the ETP list requirements, indicating that this feature has not been widely implemented.

${ }^{44}$ Perez-Johnson, Moore, and Santilano (2011) provide results from an experimental evaluation comparing three models for administering ITAs. We discuss this experiment in detail below.
} 


\section{The Workforce Innovation and Opportunity Act of 2014}

Although WIA was originally authorized for five years, 15 years passed before the two houses of Congress and the Administration were able to agree on new legislation. In 2014, working largely behind the scenes, the House and Senate reached agreement on the Workforce Innovation and Opportunity Act (WIOA) as a replacement for WIA, again with broad bipartisan, bicameral support. The bill was introduced in May 2014 with sponsorship by both parties in both houses of Congress, and the bill was signed July 22, 2014. WIOA makes some significant changes to the nation's workforce development system and is authorized through 2020 . Highlights of the new law are described below. Proposed regulations were issued April 16, 2015 but are not discussed in this chapter, as they are subject to revision. ${ }^{45}$ Most of the new legislation became effective July 1, 2015. The new legislation maintains much of the structure of WIA, with states having a prominent administrative role and services delivered through local workforce areas designated by the states. WIOA also maintains WIA's funding streams for Adults, Dislocated Workers, and Youth, and requires activities at the state and local levels to be overseen by a board with a majority of the members from the private sector. Funds are distributed to the state and sub-state levels using formulae similar to those used under WIA.

States are required to establish unified strategic planning across core programs defined as the WIOA Adult, Dislocated Worker, and Youth programs; Adult Education and Literacy programs; the Wagner-Peyser Employment Service, and state Vocational Rehabilitation programs. If taken seriously by the states this could be important, but a unified plan could simply consist of separate plans attached to each other.

\footnotetext{
${ }^{45}$ Interpretation of the WIOA statute is based on the U.S. Department of Labor's WIOA Fact Sheet, accessed at http://www.doleta.gov/wioa/pdf/WIOA-Factsheet.pdf retrieved on November 16, 2014, and National Skills Coalition (2014).
} 
The boards at the state and local levels have streamlined membership requirements, which are expected to reduce their size; boards under JTPA sometimes included 50 members or more. The desire to be inclusive of many interest groups is admirable, but such large bodies may not (and often did not) function well. The boards also have new responsibilities to develop strategies to meet worker and employer needs.

The Act adds flexibility at the local level to provide incumbent worker training and transitional jobs as allowable activities and promotes work-based training by increasing the maximum reimbursement rate for on-the-job training from 50 percent to 75 percent; the law also emphasizes training that leads to industry-recognized post-secondary credentials. These changes are all efforts to make the program more attractive to employers and, it is hoped, increase their participation.

WIOA attempts to strengthen program accountability in several ways. The performance measures for core workforce development programs are aligned, and new performance indicators are added related to services to employers and post-secondary credential attainment. ${ }^{46}$ Data on training providers' outcomes must be made available, and programs are to be evaluated by third parties.

States are required to identify economic regions within the state, and local areas are required to coordinate planning and service delivery on a regional basis. Prior legislation has also mentioned regional coordination. Although perhaps laudable in concept, these efforts are difficult to enforce. Also, these provisions cannot address issues of labor market areas that cross state borders.

\footnotetext{
${ }^{46}$ The statute is more prescriptive than previous laws. For example, the law requires that median post-program earnings be used as a performance measure and that statistical adjustment models be developed to adjust standards for variations in customer characteristics and economic conditions.
} 
The statute seeks to provide better services to job seekers in a number of ways. First, WIOA promotes the use of career pathways programs and sectoral partnerships for training programs, two approaches that appear promising. ${ }^{47}$ Second, the statute allows states to transfer unlimited amounts of their grant between the adult and dislocated worker programs. ${ }^{48}$ Third, WIOA adds basic skills deficient as a priority category for participants, along with low income, for Adult services. Fourth, WIOA requires that 75 percent of Youth funds be used for out-ofschool youth, a large increase over the 30 percent required under WIA. Fifth, WIOA combines the core and intensive service categories under WIA into a new category called career services, and it abolishes the requirement that customers pass through core and intensive services before receiving training. WIOA also permits direct contracts with higher education institutions (rather than placing participants on an individual basis or with ITAs), a practice that was commonly used prior to WIA and was permitted with funds provided under the American Reconstruction and Recovery Act (ARRA).

Finally, WIOA changes the partners required to be in the American Job Centers. Under WIOA, the Wagner-Peyser Employment Service is required to be co-located in the AJCs, and the TANF program is made a mandatory partner instead of an optional partner. WIOA also authorizes the use of performance-based contracting for training providers. ${ }^{49}$

\footnotetext{
${ }^{47}$ Career pathways are defined in Section 3 of the statute. Training and Employment Notice 39-11 (TEIN 39-11) issued by the Employment and Training Administration states that "Career pathways programs offer a clear sequence of education coursework and/or training credentials aligned with employer-validated work readiness standards and competencies. TEIN 39-11 has links to information about career pathways programs. The approach has been adopted by the U.S. Department of Labor, the U.S. Department of Education, and the U.S. Department of Health and Human Services. Sectoral programs are programs that provide training for an industry sector, presumably with significant input from sector employers.

${ }^{48}$ Under WIA, states had to receive permission from DOL to transfer funds among the Adult and Dislocated Worker programs. Although such transfers used to be routinely approved, in recent years DOL was more rigid. See Barnow and Hobbie (2013).

${ }^{49}$ The Department of Labor has changed policies on the use of performance-based contracting several times. Although there is appeal to pay for performance, some abuses of performance-based contracting appear to have led to large profits for some vendors, so the policy was tightened. See Spaulding (2001).
} 
Although there is currently hope in the workforce development community that WIOA will improve the workforce development system, sometimes promising ideas, like the eligible training provider list, prove more beneficial in theory than in practice.

\section{Employment and Training Program Expenditures and Enrollments over Time}

Table 8.2 shows estimated expenditures on Department of Labor employment and training programs except the Wagner-Peyser Act from 1965 to 2012; Figure 8.1 shows the trend in total funding in real 2012 dollars graphically, and Figure 8.2 shows the trend in funding for Department of Labor programs as a percentage of gross domestic product (GDP). The data from 1984 on were compiled by the Employment and Training Administration Budget Office and are believed to accurately reflect final budget authority for each year, including supplemental appropriations, recissions, and transfers. ${ }^{50}$ Data from 1965 through 1983 were obtained primarily from unpublished data from the ETA Budget Office, and the data are believed to be accurate but may not reflect all recissions, supplemental appropriations, and transfers. ${ }^{51}$ Data on dislocated workers is unavailable prior to 1984 , as there was not a separate program for dislocated workers before that, and from 1984 through 1992, JTPA youth and adult funding are not available separately.

In addition to the MDTA, JTPA, and WIA programs, the table includes other ETA programs, such as the Senior Community Service Employment Program, the Indian and Native

\footnotetext{
${ }^{50}$ Budget authority is the amount of money available for spending, but actual expenditures in a year can reflect carryovers of funds from prior years and amounts available but unspent. Transfers reflected in the table refer to transfers among programs at the national level, but they do not reflect transfers of funds within states between the WIA Adult and Dislocated Worker programs. Finally, the Job Corps was removed from the ETA in FY 2008 and although it was later added back to the ETA budget, it was maintained in a separate account. We obtained Job Corps data for FY 2008 and after from OMB budget documents for the Department of Labor. The detailed Employment and Training Administration budget data was obtained from http://www.doleta.gov/budget/bahist.cfm accessed on February 15, 2015.

${ }^{51} \mathrm{We}$ are grateful to Anita Harvey of the ETA Budget Office for providing the data, but she is not responsible for the analysis performed. Data on Job Corps was obtained from other budget documents, but we were not able to find data for all individual years. For years where Jobs Corps data are missing, Job Corps budget authority is included in the total column but was not available separately.
} 
Americans program, the Migrant and Seasonal Farmworker program, and a number of other national activities. ${ }^{52}$ The table must be read with caution because of the ways that programs were funded at various times. For example, during the Great Recession, the American Recovery and Reconstruction Act (ARRA) added $\$ 4.279$ billion for the covered programs. The ARRA funds were intended to be spent in a timely manner, and there were restrictions on how long the funds were available for spending. Eberts and Wandner (2013) find that the WIA Adult program spent 72 percent of the ARRA funds available in the first five quarters, and the Dislocated Worker program spent 60 percent. Thus, most of the ARRA funds were actually spent in PY 2009 and PY 2010. Other examples of appropriations expected to fund programs over several years include funding for public service employment (beyond what was provided for in the regular CETA program) in 1977 and the Youth Employment and Demonstration Projects Act of $1977 .{ }^{53}$ The table and graphs show that overall funding in nominal terms has increased over the period covered, but the share of GDP devoted to workforce development programs has followed an irregular course. In the 1960s, the programs constituted between 0.04 and 0.10 percent of GDP. Employment and training programs peaked as a share of GDP in the 1970s, due in large part to one-time efforts such as a large-scale public service employment appropriation of $\$ 6.8$ billion in 1977 and the Youth Employment and Demonstration Projects Act, also in 1977. During the 1970 s, employment and training programs were consistently over 0.10 percent, and reached a peak of 0.64 percent in 1977. During the WIA era in the 1980s and 1990s, funding as a share of GDP gradually declined, from about 0.07 percent of GDP in the earlier years to the $0.04-0.05$

\footnotetext{
${ }^{52}$ Programs are described on the Employment and Training Administration's web site, http://www.doleta.gov/\# accessed March 2, 2015.

${ }^{53}$ We were unable to locate original budget documents for the 1977 fiscal year, but we did find several documents that gave total YEDPA spending each year, so we have included YEDPA based on these spending figures.
} 
range toward the end of the WIA era; as noted earlier, there was a temporary increase in expenditures due to the ARRA during the Great Recession.

Although the focus of this chapter is on U.S. programs, it is instructive to compare U.S. expenditures on publicly-funded training with those of other nations. The Organization for Economic Cooperation and Development (OECD) estimated the share of GDP devoted to training in a number of countries. OECD estimates that the United States spent 0.04 percent of GDP on training in 2012, which is substantially less than in most of the countries tracked, including Austria (0.45 percent), Belgium (0.15 percent), Canada (0.08 percent), Denmark (0.74 percent), Estonia (0.17 percent), Finland (0.52 percent), France ( 0.34 percent), Germany (0.22 percent), Italy ( 0.15 percent), Japan (0.05 percent), Korea ( 0.07 percent), the Netherlands $(0.11$ percent), New Zealand (0.13 percent), Norway (0.15 percent), Portugal ( 0.27 percent), and Sweden (0.09 percent). There were several countries that spent the same percentage of GDP or less on training, including Chile, Czech Republic, Mexico, and the Slovak Republic. ${ }^{54}$

The programs that have fared the best since the 1980s (in terms of funding, but not in terms of program effectiveness) are the Dislocated Worker programs under JTPA and WIA. Unlike the other programs, funding for Dislocated Workers has grown substantially since 1985.

\section{Characteristics of Employment and Training Program Participants}

This section describes the characteristics of employment and training program participants, or “customers," as they are sometimes called.

\footnotetext{
${ }^{54} \mathrm{OECD}$ data on training as a share of GDP was obtained from http://stats.oecd.org/Index.aspx?.DatasetCode=LMPEXP accessed March 1, 2015.
} 


\section{Characteristics of Recent WIA Exiters}

The most recent data available on the Adult, Dislocated Worker, and Youth WIA participants are shown in Tables 8.3. Unfortunately, data on WIA enrollments are not easy to interpret. As noted above, the WIA Adult and Dislocated Worker programs require participants to receive core and intensive services before they can receive the more expensive training services. Core services can be accessed with or without staff assistance (including, in the latter case, via the internet), and states are asked to report only customers who receive staff assistance; it is likely that states and localities vary in how they interpret the definition of "staff assisted," particularly since customers who are recorded as staff assisted count in calculating performance while those who are recorded as self-service do not. Moreover, WIA core services include the same types of services provided by the ES, whose staff members are co-located with WIA at the One-Stop centers, and states vary in their policies regarding co-enrollment in the ES and WIA. In addition to varying by state, all of these policies also vary over time in some states, leaving both cross-sectional and longitudinal comparisons open to misinterpretation. For example, in PY 2006, New York adopted a policy of co-enrolling all Wagner-Peyser customers in WIA, resulting in an increase in the number of Adult WIA exiters entering employment from 20,963 in PY 2005 to 210,049 in PY 2007-more than a 900 percent increase. ${ }^{55}$ The general trend over time was for increased co-enrollment of Wagner-Peyser participants in WIA, making comparisons of enrollments over time difficult to assess.

Table 8.3 shows the characteristics of exiters from the WIA Adult and Dislocated Worker programs from April 2012 through March 2013. ${ }^{56}$ Nine percent of the exiters from the Adult

\footnotetext{
55 See Trutko and Barnow (2010) for more examples in the variation in how customers are classified across states and over time.

${ }^{56}$ The WIA data system is designed to provide data for performance measurement. Because the performance measures track cohorts of exiters, data are provided on exit cohorts rather than all participants in a given period.
} 
program are ages $18-21$, and thus were also eligible for the Youth program. ${ }^{57}$ The program served a slightly higher percentage of men than women, 52 percent compared to 48 percent. Individuals with disabilities constitute nearly 4 percent of all Adult exiters and about 3 percent of those who received training. A majority of the Adult exiters, 59 percent, are white, with black non-Hispanics making up 25 percent of the exiters and Hispanics constituting 10.5 percent. Preprogram quarterly earnings were about $\$ 6,000$ for those with earnings for all exiters and about $\$ 5,400$ for Adult exiters who received training. ${ }^{58}$

Because core services under WIA are open to all and access to training is only restricted to low-income individuals if there is not sufficient funding available for all customers the programs would like to enroll, the WIA customers are not as economically disadvantaged as one might expect. Only one-half of the exiters from the Adult program are classified as low-income, and only 61 percent of Adult exiters who received training are classified as low income, which is somewhat surprising given the focus on low-income families and the relatively broad definition of low income. ${ }^{59}$ About one-quarter of all Adult exiters and one-third of Adult exiters receiving training are public assistance recipients. ${ }^{60}$

\footnotetext{
${ }^{57}$ Customers who are co-enrolled in two programs are reported for both programs. Thus, some adults are also included in youth program data and dislocated worker program data.

${ }^{58}$ Quarterly earnings are derived from state unemployment insurance wage records and thus do not include selfemployment income or earnings from government, military, or informal employment. Earnings are the average for the second and third quarters prior to entry if earnings were positive for both quarters. If earnings were positive for only one of the second and third quarters, then the value used is earnings in that quarter. Individuals with zero earnings in both quarters are not included in the average. See Appendix B in Social Policy Research Associates (2013) for definitions of terms used.

${ }^{59}$ The WIA definition of "low income" is complex; see Social Policy Research Associates (2013, p. 299) for the full definition. It is broader than being in poverty, and includes all recipients of cash assistance (such as TANF), SNAP (food stamps), and individuals whose family income is less than 70 percent of the lower living standard income level. In 2014, the poverty level for a family of four in the 48 contiguous states was $\$ 23,850$ and 70 percent of the lower living standard income level for a family of four ranged from $\$ 23,285$ to $\$ 31,945$, depending on the state of residence and whether the family lived in a specific metro area or a non-metro area. See Federal Register (2014). ${ }^{60}$ Public assistance recipient for WIA reporting is broadly defined and includes TANF, general assistance, SNAP, supplemental security income, and refugee cash assistance. See Social Policy Research Associates (2013).
} 
The educational attainment of the Adult exiters is fairly high. Less than 11 percent of the exiters had not completed high school or passed the GED, 30 percent had some postsecondary education, and 13 percent had at least a bachelor's degree. Adult exiters who received training had roughly equivalent levels of education.

Characteristics of Dislocated Worker exiters are not markedly different from those of the Adult exiters. Dislocated Worker exiters are less likely to be under 21 (3 percent compared to 9 percent for Adults), and they are more likely to be age 55 and above (20 percent compared to 14 percent). They are slightly more likely to be white (63 percent compared to 59 percent). Not surprisingly, their quarterly pre-program earnings are substantially higher than Adult exiters $(\$ 8,566$ compared to $\$ 6,006)$.

Characteristics of WIA Youth exiters are presented in Table 8.4. In addition to presenting the data for all youth, data are available for two categories of in-school youth (high school or below and post-secondary) and two categories of out-of-school youth (high school dropouts and high school graduates). Roughly 40 percent of the Youth exiters attended high school or a lower level of school, and nearly one-quarter of the exiters were in each of the out-of-school categories (high school dropouts and high school graduates); the balance, about 4 percent of the total, attended a post-secondary school.

The WIA Youth program is much more income targeted than the Adult or Dislocated Worker programs, and 97 percent of the exiters were low-income youth (not shown in table). The Youth participants differ in several other ways from those served by the Adult and Dislocated Worker programs. Women made up a majority of the exiters in all categories, with the smallest proportion among dropouts, most likely because young women are more likely to stay in school than young men. The racial/ethnic mix of Youth exiters also differs from what we 
see for Adults and Dislocated Workers. In contrast to the other two programs, whites comprised only about 30 percent of exiters, with similar numbers of Hispanic non-blacks and non-Hispanic blacks exiting the program.

WIA Youth exiters had a high prevalence of conditions likely to serve as barriers to employment. The proportion of participants with a disability was considerably higher among youth than in the two other programs, running at 13 percent of all Youth exiters compared to 4 percent for the Adult program and 3 percent for the Dislocated Worker program. Nearly 5 percent of the Youth were classified as homeless or runaway youth, with a rate of nearly 7 percent for dropouts. Nearly 4 percent of the Youth exiters had been in foster care, with a higher rate for those attending high school (4.7 percent) and a considerably lower rate for high school graduates (2.6 percent). Nearly two-thirds of the Youth exiters were classified as being deficient in basic literacy skills, with nearly 3 out of 4 deficient among high school dropouts.

\section{Services Received by WIA Exiters}

Table 8.5 summarizes the services received by WIA Adult and Dislocated Worker exiters for recent years (Program years 2008 through 2012). Among the Adult customers, only 10 to 13 percent received training. Training was somewhat more common for Dislocated Workers, ranging from 14 percent to 19 percent during this period. Some of the participants received specialized training. Among those receiving training, on-the-job training was received by between 7 percent and 13 percent of the adults and 6 percent and 12 percent of the Dislocated Workers. Skill upgrading and retraining was slightly more common, with 12 percent to 15 percent of the Adults and 14 percent to 16 percent of the Dislocated Workers receiving this type of training. The incidence of entrepreneurial training, adult basic education (ABE) or English as a Second Language (ESL) in combination with training, and customized training were all less 
than 5 percent for both Adult and Dislocated Worker exiters. ${ }^{61}$ About three-quarters of the Adult and Dislocated Worker exiters received other types of training, presumably mostly classroom training.

\section{Outcomes for WIA Exiters}

The WIA statute requires that data on the satisfaction levels of employers and participants be collected as part of the performance measurement system. However, when the Department of Labor adopted the common measures for performance, most states were given waivers from this requirement. Seven states still report satisfaction data, and collectively their satisfaction scores (among respondents) averaged 84 for participants and 77 for employers. ${ }^{62}$

Data on outcomes for recent exiters from WIA are shown in Table 8.6. There are three common measures for Adults, Dislocated Workers, and Older Youth: (1) Entered Employment: Of those who are not employed at the date of participation, [Number of participants who are employed in the first quarter after the exit quarter]/[Number of participants who exit during the quarter]; (2) Employment Retention: Of those who are employed in the first quarter after the exit quarter, [Number of participants who are employed in both the second and third quarters after the exit quarter]/[Number of participants who exit during the quarter]; Average Earnings ${ }^{63}$ : Of those who are employed in the first, second, and third quarters after the exit quarter, [Total earnings in

\footnotetext{
${ }^{61}$ Customized training refers to vocational training developed with input from employers regarding eligibility, curriculum and requirements for successful completion. Also sometimes referred to as "employer-based training," customized training often includes provisions for employers to hire or give preference in hiring to individuals who have successfully completed the training.

${ }^{62}$ Satisfaction is measured by a three-question survey called the American Consumer Satisfaction Instrument (ACSI). Employers and participants respond to each question on a 1 to 10 scale, and the total score is a weighted average of the three responses, scaled to range from 0 to 100. The ASCI measure and its use are described in the Department of Labor TEGL 36-10, accessed at http://wdr.doleta.gov/directives/corr_doc.cfm?DOCN=3052 retrieved November 22, 2014. Satisfaction data are only available for Arizona, Hawaii, Michigan, Minnesota, Puerto Rico, Rhode Island, and Vermont.

${ }^{63}$ Previously, instead of post-program earnings, the measure for Adults was change in earnings from pre-enrollment earnings, and the measure for Dislocated Workers was the earnings replacement rate.
} 
the second quarter plus total earnings in the third quarter]/[Number of participants who exit during the quarter].

The entered employment rate for Adult and Dislocated Worker exiters in PY 2012 was 60 percent, but there was a great deal of variation among subgroups. Subgroups with lower entered employment rates include individuals with disabilities (41 percent for Adults and 46 percent for Dislocated Workers), and older individuals ${ }^{64}$ (48 percent for both programs). Based on data from Social Policy Research Associates (2013), which covers a slightly different period, there is little variation in the entered employment rate by race/ethnicity and gender. Perhaps surprisingly, Adults who were receiving public assistance at entry had an above average entered employment rate. Another surprising finding is that the entered employment rate for Older Youth (70 percent) is a full 10 percentage points higher than the rate for exiters from the Adult and Dislocated Worker programs (60 Percent). ${ }^{65}$

The entered employment rate differs by a fairly large amount for individuals who received training (75 percent for Adults and 81 percent for Dislocated Workers) compared to those who only received core and/or intensive services (59 percent for Adults and 56 percent for Dislocated Workers). As noted earlier, under WIA, states vary greatly in the proportion of participants that receives training. An analysis of 2002-2005 data found that the percentage ranged from 14 percent to 96 percent (Trutko and Barnow 2007). ${ }^{66}$

Subgroup outcomes varied by considerably less for employment retention. Most subgroups fell within a range of 80 percent to 90 percent retention. The only exceptions were individuals with disabilities ( 75 percent) and older youth veterans (60 percent). The range of

\footnotetext{
${ }^{64}$ The published data do not include a definition for "older individual," but based on data in Social Policy Research (2013) it is likely that this refers to participants age 55 and above.

${ }^{65}$ The older youth outcomes are reported only for six states that have a waiver from using the common measures.

${ }^{66}$ Training was much more prevalent in the period covered by Trutko and Barnow (2007), perhaps in part because co-enrollment of all Employment Service customers became more common after 2005.
} 
outcomes among subgroups was also not large for six month average earnings. In part, the compression in the range in outcome results across subgroups is likely an artifact of the way the measures are defined. The entered employment rate is based on data for all exiters, but the employment retention measure only includes individuals who were employed in the first quarter after exit, and the average earnings measure is based only on exiters who were employed in all three quarters after exit; because these measures are based on customers with initial postprogram success, it is not surprising that customers included in the calculations tend to do well on the measures.

The three outcome measures used for youth are: (1) Placement in Employment or Education: Of those who are not in postsecondary education or employment at the date of participation, [Number of youth participants who are in employment or enrolled in postsecondary education and/or advanced training/occupational skills training in the first quarter after the exit quarter]/[Number of youth participants who exit during the quarter]; (2) Attainment of a Degree or Certificate: Of those enrolled in education at the date of participation or at any point during the program, [Number of youth participants who attain a diploma, GED, or certificate by the end of the third quarter after the exit quarter]/[Number of youth participants who exit during the quarter]; and (3) Literacy and Numeracy Gains: Of those out-of-school youth who are basic skills deficient, [Number of youth participants who increase one or more educational functioning levels]/[Number of youth participants who have completed a year in the program plus the number of youth participants in the program who exit before completing a year in the youth program].

Although we report the youth common measure results in Table 8.6, we do not discuss them here because we do not consider them of particular interest. We would prefer to see youth 
measures based on school status at the time of entry, as employment and earnings measures are of interest for out-of-school youth, but educational measures are of more interest for in-school youth. ${ }^{67}$

\section{Current Funding Levels}

Table 8.7 lists major means-tested employment and training programs funded by the Department of Labor and other federal agencies. Only programs with at least $\$ 30$ million in budget authority for 2014 are included. We also omit temporary programs, pilots, and demonstrations regardless of their size. So, for example, we omit the Transition Assistance Program that provides assistance to separating veterans so that they can reenter the civilian labor market because the program is only funded at $\$ 14$ million annually and the Trade Adjustment Assistance Community College and Career Training (TAACCCT) grants, which included \$464 million in funding for FY 2014 because it is a temporary program with no funding for future years. For each program, we provide a brief description of funding level, program eligibility, and activities.

\section{U. S. Department of Labor Programs}

$\underline{\text { Job Corps }} .{ }^{68}$ Job Corps is a largely residential education and vocational training program serving young people ages 16 through 24 through vocational and academic training. Through a nationwide network of campuses, Job Corps offers a comprehensive array of career development services to at-risk young women and men to prepare them for careers. Job Corps integrates the teaching of academic, vocational, and employability skills, and social competencies through a combination of classroom, practical, and work-based learning experiences. Enacted budget authority for the Job Corps for PY 2014 is \$1,684 million.

\footnotetext{
${ }^{67}$ The Department of Labor does report the outcomes used for Adults and Dislocated Workers for subgroups as well as all older youth, but these results are only available for six states.

${ }^{68}$ Material on Job Corps is from http://www.jobcorps.gov/AboutJobCorps.aspx retrieved November 23, 2014.
} 
WIA Adult and Dislocated Worker Programs. The WIA Adult and Dislocated Worker programs are "designed to provide quality employment and training services to assist eligible individuals in finding and qualifying for meaningful employment, and to help employers find the skilled workers they need to compete and succeed in business." ${ }^{, 69}$ The program funds are allocated to states by formula based on their unemployment rates and on their number of economically disadvantaged individuals and then distributed to local areas by the same formula. Participants can receive core, intensive, and training services at local American Job Centers, which were described above. Core services are available to all, but intensive and training services are reserved for low-income individuals if there are insufficient funds to serve everyone. The Dislocated Worker program is restricted to individuals who have lost their job or are about to lose their job; the definition also includes self-employed individuals (including farmers and ranchers) who have lost their potential livelihood and displaced homemakers who have lost their financial support from another family member. For PY 2014, the funds appropriated are \$764 for the Adult program and $\$ 1,219$ million for the Dislocated Worker program. ${ }^{70}$

WIA Youth Program. ${ }^{71}$ The WIA Youth program serves eligible low-income youth, ages 14-21, who face barriers to employment. Funds for youth services are allocated to state and local areas based on a formula distribution. Service strategies, developed by workforce providers, prepare youth for employment and/or post-secondary education through strong linkages between academic and occupational learning. Local communities provide youth activities and services in partnership with the WIA American Job Center system and under the direction of local

\footnotetext{
${ }^{69}$ http://www.doleta.gov/programs/general_info.cfm retrieved November 23, 2014.

70 The Dislocated Worker appropriation includes formula grants to states and funds for the national reserve fund, which is distributed by ETA based on proposals from the states.

${ }^{71}$ Material on the WIA Youth program is from http://www.doleta.gov/youth_services/wiaformula.cfm retrieved November 23, 2014.
} 
Workforce Investment Boards. To participate, youth must have low income and one or more prescribed barriers to employment. Budget authority for PY 2014 is \$818 million.

Wagner-Peyser Employment Service. ${ }^{72}$ The Wagner-Peyser Act of 1933 established a nationwide system of public employment offices known as the Employment Service (ES). The Act was amended in 1998 to make the Employment Service part of the One-Stop services delivery system. The Employment Service focuses on providing a variety of employment-related labor exchange services including but not limited to job search assistance, job referral, and placement assistance for job seekers; and reemployment services to unemployment insurance claimants. As described earlier, the ES also provides a variety of services to employers. The Employment Service is open to all, but veterans receive priority of service and are eligible for other special services; although the Employment Service is not means tested, we include it here because many WIA customers are co-enrolled in the Employment Service program. Budget authority for PY 2014 is $\$ 664$ million.

$\underline{\text { Senior Community Service Employment Program. }}{ }^{73}$ The Senior Community Service Employment Program (SCSEP) is a community service and work-based job training program for older Americans. Authorized by the Older Americans Act, the program provides training for low-income, unemployed seniors. Participants also have access to employment assistance through American Job Centers. SCSEP participants gain work experience in a variety of community service activities at nonprofit and public facilities, including schools, hospitals, daycare centers, and senior centers. The program provides over 40 million community service hours to public and nonprofit agencies, allowing them to enhance and provide needed services. Participants work an average of 20 hours a week, and are paid the maximum of the relevant

\footnotetext{
${ }^{72}$ Material on the Wagner-Peyser Act Employment Service is from http://www.doleta.gov/programs/Wagner_Peyser.cfm retrieved November 23, 2014

${ }^{73}$ Material on the SCSEP is from http://www.doleta.gov/seniors/ retrieved November 24, 2014.
} 
federal, state or local minimum wages. This training is intended to serve as a bridge to unsubsidized employment opportunities for participants. Participants must be at least 55 years old, be unemployed, and have a family income of no more than $125 \%$ of the federal poverty level. Funding for PY 2014 is \$433 million.

$\underline{\text { Trade Adjustment Assistance (TAA) }} .{ }^{74}$ The Trade Adjustment Assistance (TAA) Program is a federal entitlement program that assists U.S. workers who have lost or may lose their jobs as a result of foreign trade. This program seeks to provide adversely affected workers with opportunities to obtain the skills, credentials, resources, and support necessary to become reemployed. Participants are eligible to receive employment and case management services, training, cash payments called trade readjustment allowances (TRA) when unemployment insurance is exhausted, and job search and relocation allowances. The program also includes a wage subsidy for up to two years that is available to reemployed older workers and covers a portion of the difference between a worker's new wage and their old wage (up to a specified maximum amount). Note that this program is not means tested. Enacted budget authority for PY 2014 is $\$ 306$ million.

\section{Employment Services for Veterans. ${ }^{75}$ The Veterans' Employment and Training Service}

(VETS) offers employment and training services to eligible veterans through the Jobs for Veterans State Grants Program. Under this grant program, funds are allocated to State Workforce Agencies in direct proportion to the number of veterans seeking employment within their state.

The grants support two principal state workforce agency staff positions: Disabled Veterans' Outreach Program Specialists (DVOPs) and Local Veterans' Employment Representatives

\footnotetext{
${ }^{74}$ Material on Trade Adjustment Assistance is from http://www.doleta.gov/tradeact/docs/program brochure2014.pdf.

${ }^{75}$ Material on Employment Services for Veterans is from http://www.dol.gov/vets/programs/empserv/employment_services_fs.htm.
} 
(LVERs). DVOP and LVER staff provides services to all eligible veterans, but their efforts are concentrated on outreach and the provision and facilitation of direct client services to those who have been identified as most in need of intensive employment and training assistance. Disabled Veterans Outreach Program (DVOP) specialists provide intensive services to meet the employment needs of disabled veterans and other eligible veterans, with the maximum emphasis directed toward serving those who are economically or educationally disadvantaged. Local Veterans' Employment Representatives conduct outreach to employers and engage in advocacy efforts with hiring executives to increase employment opportunities for veterans, encourage the hiring of disabled veterans, and generally assist veterans to gain and retain employment. LVER staff conducts seminars for employers and job search workshops for veterans seeking employment, and facilitate priority of service in regard to employment, training, and placement services furnished to veterans by all staff of the employment service delivery system. Combined enacted budget authority in PY 2014 for DVOP and LVER positions is \$175 million.

H-1B Job Training Grants. ${ }^{76}$ The Job Training for Employment in High Growth Industries Grants are designed to provide training for workers according to need in different sectors of the economy. The funding for this program is provided from $\mathrm{H}-1 \mathrm{~B}$ visa fees. The Department's long-term goal for the program is to decrease the need for these visas by helping American workers develop the high level skills needed by these employers. The Department intends to use this program to support training and education models that lead to highly-skilled technical jobs. The fees collected for this program in FY 2014 totaled \$166 million.

\footnotetext{
${ }^{76}$ Material on H-1B Job Training Grants is from U.S. Department of Labor (2014)
} 


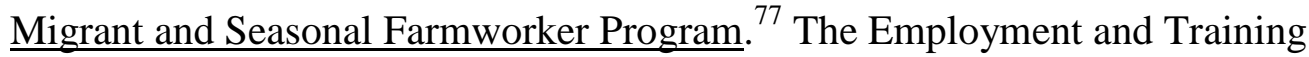

Administration's Migrant and Seasonal Farmworker Program, also sometimes called the

National Farmworker Jobs Program, provides services to the American farmworker population to help combat the chronic underemployment experienced by workers who depend primarily on agricultural labor jobs. The National Farmworker Jobs Program provides funding to communitybased organizations and public agencies to assist migrant and seasonal farmworkers and their families attain greater economic stability. Farmworkers also receive training and employment services through the nationwide network of American Job Centers. Funding for PY 2014 is $\$ 82$ million, which is expected to serve approximately 19,000 participants. $^{78}$

Reintegration of Ex-Offenders (RExO).${ }^{79}$ The RExO program provides funding to pilots and demonstration projects designed to test the effectiveness of successful models and practices found in community and faith-based environments and other government systems that have not been tested for their adaptability to the public workforce system. RExO is designed to strengthen communities through projects that incorporate mentoring, job training, education, legal aid services, and other comprehensive transitional services. Grants are awarded through a competitive process open to any nonprofit organization with 501(c)(3) status, unit of state or local government, or any Indian and Native American entity eligible for grants under Workforce Investment Act Section 166 in areas with high poverty and crime rates that meet the requirements of the solicitations. Enacted budget authority for the program in PY 2014 is $\$ 80$ million.

\footnotetext{
${ }^{77}$ Material on the Migrant and Seasonal Farmworker Program is from http://www.doleta.gov/Farmworker/ retrieved November 23, 2014.

${ }^{78}$ Number of participants expected and funding level are from U.S. Department of Labor (2014).

${ }^{79}$ Material on RExO is from http://www.doleta.gov/RExO/.
} 
YouthBuild. ${ }^{80}$ YouthBuild is a community-based alternative education program that provides job training and educational opportunities for at-risk youth ages 16-24. The program was transferred from the Department of Housing and Urban Development to the Department of Labor in 2006. Youth learn construction skills while constructing or rehabilitating affordable housing for low-income or homeless families in their own neighborhoods. Youth split their time between the construction site and the classroom, where they earn their GED or high school diploma, learn to be community leaders, and prepare for college and other postsecondary training opportunities. YouthBuild includes significant support systems, such as a mentoring, follow-up education, employment, and personal counseling services; and participation in community service and civic engagement. There are over 250 DOL funded YouthBuild programs in 45 states serving over 10,000 youth per year. ${ }^{81}$ Funding for YouthBuild in PY 2014 is $\$ 78$ million.

The Indian and Native American Program. ${ }^{82}$ The Indian and Native American Program serves American Indians and Native Americans through a network of 178 grantees. To meet the employment and training needs of the Indian, Alaskan Natives, and Native Hawaiian populations, the enacted budget authority for PY 2014 is $\$ 46$ million. At this funding level, the program serves approximately 28,000 unemployed and under-skilled Indian, Alaskan Native, and Native Hawaiian adults and youth.

\section{Homeless Veterans Reintegration Program. ${ }^{83}$ The purpose of the Homeless Veterans'}

Reintegration Program (HVRP) is to provide services to assist in reintegrating homeless veterans into meaningful employment within the labor force and to stimulate the development of effective

\footnotetext{
${ }^{80}$ Material on YouthBuild is from http://www.doleta.gov/Youth_services/Youth_Build.cfm retrieved November 23, 2014

${ }^{81}$ The data on enrollment and the number of program sites is from YouthBuild's web site, https://youthbuild.org/; the numbers are higher than what is found on the Department of Labor web site.

${ }_{83}^{82}$ Material on the Indian and Native American Program is from U.S. department of Labor (2014).

${ }^{83}$ Material on the Homeless Veterans Reintegration Program is from http://www.dol.gov/vets/programs/fact/Homeless_veterans_fs04.html.
} 
service delivery systems that will address the complex problems facing homeless veterans. Funds are awarded on a competitive basis to eligible applicants. Grantees provide an array of services utilizing a case management approach that directly assists homeless veterans as well as critical linkages for a variety of supportive services available in their local communities. The program is "employment focused," and veterans receive the employment and training services they need in order to re-enter the labor force. Job placement, training, job development, career counseling, and resume preparation, are among the services that are provided. Supportive services such as clothing; provision of or referral to temporary, transitional, and permanent housing; referral to medical and substance abuse treatment; and transportation assistance are also provided to meet the needs of this target group. Budget authority for the program in FY 2014 is $\$ 38$ million.

\section{Employment and Training Programs Operated by Other Agencies}

Pell Grants (U.S. Department of Education) ${ }^{84}$ The Pell Grant program provides needbased grants to low-income undergraduate and certain post-baccalaureate students to promote access to postsecondary education. ${ }^{85}$ Students may use their grants at any one of approximately 5,400 participating postsecondary institutions. Grant amounts are determined by the student's expected family contribution, the cost of attendance (as determined by the institution), the student's enrollment status (full-time or part-time), and whether the student attends for a full academic year or less. The maximum Pell Grant for the award year beginning July 1, 2015 is $\$ 5,775 .{ }^{86}$ Financial need is determined by the U.S. Department of Education. Pell Grants may be used at two-year and four-year institutions, and at public and private institutions. Students can receive Pell Grants for study toward a degree or eligible certificate programs. The funds can be

\footnotetext{
${ }^{84}$ Information on Pell grants is from http://www2.ed.gov/programs/fpg/index.html.

${ }^{85}$ Pell Grants to students pursuing post-baccalaureate study are rare and restricted to students pursuing a teaching certificate.

${ }^{86}$ From https://studentaid.ed.gov/types/grants-scholarships/pell accessed February 1, 2015.
} 
used to pay for tuition, fees, and other expenses, or to help pay for the living expenses of the student. Although the program is not an entitlement, sufficient funds are generally appropriated to meet the needs of all eligible applicants. For the 2013-2014 school year, the latest period for which data are available, an estimated $\$ 33.7$ billion was spent on Pell Grants, according to Baum, Elliott, and Ma (2014). Analysis of National Postsecondary Student Aid Survey (NPSAS) indicates that $\$ 5,060$ million was used for occupational degrees and another $\$ 3,121$ million was used for certificate programs in the 2011-2012 school year. ${ }^{87}$ Thus, Pell Grant spending is the largest single source of funding for means-tested employment and training programs, and it is roughly twice the spending for the WIA Adult, Dislocated Worker, and Youth programs combined. $^{88}$

\section{Temporary Assistance for Needy Families (TANF) (U.S. Department of Health and}

Human Services). ${ }^{89}$ TANF is the federal welfare program for families with children. Under TANF, the federal government provides block grants to the states, which use these funds to operate their own programs. In order to receive federal funds, states must also spend some of their own dollars on programs for needy families. States can use federal TANF and state maintenance of effort (MOE) dollars to meet any of the four goals set out in the 1996 law: “(1) provide assistance to needy families so that children may be cared for in their own homes or in the homes of relatives; (2) end the dependence of needy parents on government benefits by promoting job preparation, work, and marriage; (3) prevent and reduce the incidence of out-of-

\footnotetext{
${ }^{87} \mathrm{We}$ are extremely grateful to Sandy Baum for performing the analyses generating these estimates. The Department of Education's programs that are classified as career and technical education can be found at http://nces.ed.gov/surveys/ctes/tables/postsec tax.asp accessed March 1, 2015.

${ }^{88}$ Pell Grants can be used for WIA participants if the income and program requirements are met, and the WIA statute required that funding sources such as Pell Grants be used when possible. However, training programs offered by WIA are often too short to qualify for Pell Grants, and dislocated workers enrolled in WIA training programs may not meet the income requirements. For the period from April 1, 2012 through March 31, 2013, Social Policy Research Associates (2013) reports that out of 1.6 million exiters, 17,246 Adult programs participants, 10,836 Dislocated Worker participants, and 14,115 youth received Pell Grants.

${ }^{89}$ Material on TANF is from Center on Budget and Policy Priorities (2012).
} 
wedlock pregnancies and establish annual numerical goals for preventing and reducing the incidence of these pregnancies; and (4) encourage the formation and maintenance of two parent families." The 1996 law sets forth 12 categories of work activities that can count toward the required work rates. Nine of these 12 categories are core categories that can count toward any hours of participation; participation in the three non-core categories can only count if the individual also participates in core activities for at least 20 hours per week (30 hours for twoparent families). The nine core activities are: Unsubsidized employment, subsidized privatesector employment, subsidized public-sector employment, work experience, on-the-job training, job search and job readiness assistance, community service programs, vocational educational training (for up to 12 months), and providing child care services to an individual who is participating in a community service program. The three non-core activities are: Job skills training directly related to employment, education directly related to employment, and satisfactory attendance at secondary school or in a course of study leading to a GED. Federal expenditures for work-related TANF activities for FY 2013 were $\$ 1,517$ million.

\section{Adult Education Basic Grants to States (U.S. Department of Education). This program}

provides grants to states to fund local programs of adult education and literacy services, including workplace literacy services, family literacy services, English literacy programs, and integrated English literacy-civics education programs. Participation in these programs is limited to adults and out-of-school youths age 16 and older who are not enrolled or required to be enrolled in secondary school under state law. More than 2,500 programs deliver instruction through public schools, community colleges, libraries, and community-based organizations, and other providers. The programs provide instruction in reading, numeracy, GED preparation, and 
English literacy. More than 1.8 million adults participated in programs in program year 2011-12. The appropriation for the program for FY 2014 is $\$ 564$ million.

\section{$\underline{\text { Supplemental Nutrition Assistance Program Employment and Training (SNAP E\&T) }}$}

(U.S. Department of Agriculture). ${ }^{90}$ SNAP E\&T is a funding source that allows states to provide employment and training and related supportive services to individuals receiving Supplemental Nutrition Assistance Program (SNAP) benefits. These services are intended to assist recipients in gaining skills, training, work, or experience that will increase their employment and earnings and reduce their need for SNAP. In an average month in FY 2013, more than 47 million individuals received SNAP benefits; however, in 2012, the most recent year for which data are available, only 15.3 percent of non-elderly adult SNAP recipients participated in SNAP E\&T activities. SNAP E\&T supports a range of employment and training activities for SNAP recipients. Such activities can include job search, job search training, work experience or workfare, and education and training including basic skills instruction. Employability assessments and case management services can be part of a component but cannot be stand-alone activities. SNAP E\&T can also be used to provide job retention services for up to 90 days after an individual who received other services under SNAP E\&T gains employment. The 2013 appropriation for the program was $\$ 416$ million.

\section{Program evaluation issues}

Employment and training programs in the United States have received more attention from evaluators than many programs far larger in budgetary terms, such as SNAP or Social Security Disability Insurance (SSDI). Relatively large participant populations as well as available administrative data plus the absence of a constituency powerful enough to block serious

\footnotetext{
${ }^{90}$ Material on SNAP E\&T is from Lower-Basch (2014).
} 
evaluation conspire to make this so. ${ }^{91}$ We have (much) more to say about the substantive findings from that evaluative activity later on. In this section, we lay the foundation for our substantive discussion by describing the fundamental evaluation problem, along with the usual approaches to solving it, both in the broad sense of evaluation policy and in the narrow sense of applied econometrics. Our discussion presumes voluntary rather than mandatory participation because almost all participants in the major (and most minor) US employment and training programs volunteer for the privilege.

To fix ideas, it helps to adopt some formal notation. We use the standard potential outcomes framework, in which $Y_{1 i}$ denotes the outcome that individual " $i$ " would experience if she received program services (and so is "treated" in the jargon of the literature), while $Y_{0 i}$ denotes the outcome that same individual would receive if she did not receive program services (and so is not "treated"). ${ }^{92}$ The outcome remains generic at this point; it could be earnings, employment, an indicator for obtaining a job with employer-provided health insurance, etc. The term "potential" outcomes refers to the fact that each individual will actually experience only the outcome associated with their program participation status, while the other outcome remains an unrealized, and thus unobserved, potential. If we define $D_{i}$ as an indicator variable for program participation, then we can write the observed outcome $Y_{i}$ as a function of the potential outcomes: $Y_{i}=D_{i} Y_{i 1}+\left(1-D_{i}\right) Y_{0 i}$

\footnotetext{
${ }^{91}$ Perusing the last print version of the Digest of the Social Experiments, Greenberg and Shroder (2004), suggests a strong revealed preference for experimenting on disadvantaged people and criminals and a strong revealed preference against experimenting on the middle class. Greenberg, Shroder and Onstott (1999) provide some quantitative confirmation of these patterns based on an earlier edition of the book. ${ }_{92}$ The potential outcomes framework is variously attributed to Frost (1920), Neyman (1923), Fisher (1935), Roy (1951), Quandt (1972) and Rubin (1974). Disciplinary affiliation and academic genealogy strongly predict attributions.
} 
The impact of the program on individual " $i$ " equals the difference between their treated and untreated potential outcomes, or $\delta_{i}=Y_{1 i}-Y_{0 i}$.

Interest in impact evaluations centers on various means of these individual impacts. The most common parameter of interest in practice is the average impact of the treatment on the treated, given by $E\left(Y_{1}-Y_{0} \mid D=1\right)$. In words, this parameter captures the mean difference between the outcome with treatment and the outcome without treatment for those who receive the treatment. If the policy question at hand concerns whether to keep or eliminate a program as it currently operates, versions of this parameter for different outcomes lie on the benefit side of the relevant cost-benefit calculation. A second parameter of interest is the average treatment effect in the population, or ATE. In notation, we have $E\left(Y_{1}-Y_{0}\right)$. Typically, interest lies in the ATE for some actual or potential eligible population. Versions of this parameter for various outcomes figure in a cost-benefit calculation designed to answer the question of whether or not a mandatory version of program makes sense from an (economic) efficiency point of view.

Less frequently, evaluations of job training programs consider other parameters of interest, which in turn address other substantive questions of interest. Quantile treatment effects (QTEs) reveal how a treatment affects the entire distribution of outcomes. In practice, they consist of differences between the corresponding quantiles of the outcome distributions for the treated and (corrected for selection, if required) untreated units, i.e. differences of quantiles of $F\left(Y_{1} \mid D=1\right)$ and $F\left(Y_{0} \mid D=1\right)$. Thus, for example, with experimental data, the QTE at the median is the difference between the median outcome in the treatment group and the median outcome in the control group. They also provide information about how the program affects inequality within the treated population and, as in Bitler, Gelbach, and Hoynes (2006), they can 
even play a role in testing theoretical models of participant behavior. We find them surprisingly underutilized in practice in evaluations of job training programs. ${ }^{93}$

Another question of frequent policy interest concerns the impact of programs on participants at the margin of participation, where the margin may depend on the choices of would-be participants, of program staff, or both. The effect on marginal participants informs choices about whether to modestly expand or contract the program. Pinning down effects on marginal participants requires additional work at the design stage and/or additional measurement. That additional work enables estimation of impacts at the margin as in the discontinuity design exploited in Black, Smith, Berger, and Noel (2003), or of local average treatment effect in a randomized encouragement design, or a subgroup analysis of impacts on likely marginal participants as identified by program staff or the participants themselves. In our view, such work gets done far too infrequently in this literature, given that the relevant policy question (at least implicitly) is almost always expansion or contraction rather than eliminating the program or making it mandatory.

The final parameters of interest require the joint distribution of the treated and untreated outcomes rather than just their marginal distributions. Examples of such parameters include the variance of impacts, the fraction of impacts that are positive, and quantiles of the distribution of impacts (which are not the same thing as impacts on quantiles of the outcome distribution). Because (perhaps wrongly) the literature rarely analyzes these parameters in practice, we deem them beyond the scope of our chapter; see Heckman, Smith, and Clements (1997) and Djebbari and Smith (2008) for more.

One path to avoid all of the conceptual and econometric complications associated with

\footnotetext{
${ }^{93}$ For more on QTEs see e.g. Koenker and Bassett (1978), Heckman, Smith and Clements (1997), Abadie, Angrist and Imbens (2002), Bitler, Gelbach and Hoynes (2005), and Djebbari and Smith (2008).
} 
alternative treatment effect parameters leads to the common effect model. Much of the applied literature, especially the older applied literature, implicitly assumes a common effect world, in which "the effect" of training is the same for all participants. A more sophisticated version of this view allows that the effect of training varies, but assumes that neither potential participants nor program gatekeepers can predict the variation, with the result that it plays no role in program participation decisions. In our view, the available evidence militates strongly against the common effect view, particularly in the context of training programs as operated in the United States.

One very compelling reason for thinking that there are heterogeneous treatment effects is that there are, almost always in the U.S. program context, heterogeneous treatments. In this sense, the programs covered in this chapter differ from both the budgetary treatments (e.g. the Earned Income Tax Credit) and the cash and in-kind transfer programs (e.g. Temporary Assistance for Needy Families) considered in the other chapters of this volume. Coding up an indicator variable for receipt of training or, even more dramatically, receipt of any services from some employment and training program, implicitly disguises a substantial amount of heterogeneity in the program as experienced by participants. One trainee may take a community college course in cosmetology, while another takes a course from the Salvation Army in computer repair, and still another receives subsidized on-the-job training at Whataburger. More broadly, some participants may receive instruction designed to prepare them to obtain a GED, while others receive only job search assistance. Some evaluations distinguish among broad categories of services, such as classroom training or job search assistance ${ }^{94}$, but as the examples

\footnotetext{
${ }^{94}$ For instance, Hotz, Imbens, and Klerman (2006) apply non-experimental methods to the experimental data from the California Greater Avenues to Independence experiment in order to disentangle the effects of particular service types.
} 
just listed illustrate, most programs embody substantial heterogeneity even within broad service categories.

In addition to heterogeneous services, programs operate in heterogeneous contexts in terms of aggregate labor market conditions, industry and occupation mix, and so on. Lechner and Wunsch (2009) and Heinrich and Mueser (2014), among others, provide evidence that the effect of training varies with local labor market conditions.

The literature also offers a long history of estimated differences in impacts between different demographic groups and participants at different sites. For instance, LaLonde (2003) describes the durable finding (in the US literature) that adult women benefit the most from training, followed by adult men, followed by male and female youth. We have more to say about subgroup effects below; for our purposes here, differences by age, sex, and site suggest the presence of differences on other unmeasured dimensions as well.

As another argument for heterogeneity in treatment effects, think about the relationship between impacts on earnings and employment over some period during and after training. If some participants have zero earnings, but the program has a non-zero mean impact, then some heterogeneity in impacts must exist, as the participants with zero earnings must have had a zero or negative impact (because earnings are bounded below by zero) while some other participants had positive impacts. Finally, and a bit more technically, as noted in Heckman, Smith, and Clements (1997) it is possible to place an empirical lower bound on the impact variance. This lower bound corresponds to the variance of the quantile treatment effects described above. Heckman, Smith and Clements (1997) calculate this lower bound for the adult women in the Job Training Partnership Act experiment and find that it is statistically and (what is more important) substantively different from zero. Taken together, we find the case for heterogeneous treatment 
effects that substantively matter quite compelling, and assume them in all that follows.

To motivate the problem of non-random selection into programs, it helps to think about a simple model of program participation. We draw here on the models in Heckman and Robb (1985) and Heckman, LaLonde, and Smith (1999). We begin with a simple model in which training is available in only one period, lasts exactly one period, and is not announced in advance. This allows us to view the participation choice as a static problem, though one with dynamic implications. Call the period of program availability period $k$.

In periods prior to $k$, all individuals have the outcome function $Y_{0 i t}=X_{i t} \beta_{X}+\eta_{i}+\varepsilon_{i t}$ for $t<k$

Here $X_{i t}$ denotes various determinants of outcomes unaffected by treatment, with an associated vector of coefficients $\beta_{X}, \eta_{i}$ denotes the time-invariant unobserved component of outcomes for individual " $i$," and $\varepsilon_{i t}$ denotes the transitory component of outcomes for person " $i$ " in period " $t$." After period $k$, the same function persists, but with the addition of an additive treatment effect received only by participants. In notation

$Y_{i t}=X_{i t} \beta_{X}+D_{i} \beta_{D i}+\eta_{i}+\varepsilon_{i t}$ for $t \geq k$

with

$Y_{1 i t}=Y_{0 i t}+\beta_{D i}$

The " $i$ " subscript on $\beta_{D i}$ captures heterogeneity in the treatment effect; we assume for simplicity that the heterogeneous effect persists indefinitely. Potential trainees may know their treatment effect, or not know it, or something in between. ${ }^{95}$ Extending the model to allow the

\footnotetext{
${ }^{95}$ See Carniero, Hansen, and Heckman (2003) for an analysis that estimates the fraction of the variation in treatment effects known ex ante in an educational context.
} 
treatment effect to vary with observed characteristics - to capture systematic heterogeneity in treatment effects in the terminology of Djebbari and Smith (2008) - via interaction terms follows easily.

As unobserved variables that affect outcomes may vary over time at lower frequency than the observed data, we allow for serial correlation in the "error" term; in particular, we assume for convenience an autoregressive form, with

$\varepsilon_{i t}=\rho \varepsilon_{i, t-1}+v_{i t}$

where $v_{i t}$ is an independently and identically distributed (over time and people) shock and $-1<\rho<1$ to keep the process from diverging.

The participation decision depends on a comparison of costs and benefits. The benefit comes in the form of the discounted present value of the stream of future treatment effects. The costs come in the form of direct costs $C_{i}$, which may include tuition, transportation, or books as well as negative direct costs in the form of subsidies to participation, and the opportunity cost of having $Y_{i k}=0$ during the training period. Formally, the potential participant calculates $D_{i}^{*}=\frac{\beta_{D i}}{r}-C_{i}-Y_{0 i k}+u_{i}$ where $r$ denotes the interest rate, $u_{i}$ denotes unobserved factors affecting the net utility of training, and we make the simplifying assumption that the potential trainee lives forever. We do not make costs a function of observed characteristics, but it would be easy and reasonable to do so. If $D^{*}>0$ then the individual chooses to participate in period $k$ while if $D^{*} \leq 0$ the individual forgoes the opportunity and continues to receive $Y_{0 i t}$ in all future periods.

What do we learn from this model? First, opportunity costs play a key role. The fact that 
the untreated outcome in period $k$ enters the decision problem along with the direct costs and the discounted impacts means that individuals who choose to train will have differentially low values of $Y_{0 k}$. Those low values in period $k$ can result from a low value of the time invariant unobserved component of earnings, a low value of the transitory component, and/or values of $X$ associated with low earnings. Thus, to the extent that the time-invariant unobserved component accounts for a substantial amount of the variation in earnings for the relevant population, we would expect substantively important selection on it, with trainees having a lower average value than non-trainees. This selection will lead to persistent differences in the mean earnings of participants and non-participants both before and after period $k$. If this were the only source of selection into training, researchers would naturally gravitate toward difference-in-differences and related longitudinal estimators of program impact. In practice (more about this below) such estimators play only a minor role in this literature, because of empirically important selection on the transitory unobserved component as well. Due to the assumed serial correlation in the transitory unobserved component, selection on this component operating via selection on the opportunity cost of participation leads to the empirically ubiquitous "Ashenfelter dip," first identified in this literature in Ashenfelter's (1978) paper on MDTA, the programmatic greatgreat-grandparent of WIOA. This combination of selection on both transitory and more permanent components of the outcome process complicates credible estimation of the causal effects of training.

In addition to opportunity costs, participation depends on direct costs and on the personspecific impact of training. Though some literatures make intensive use of direct cost measures as sources of exogenous variation in participation, the training literature has not seen much work along these lines. The training literature does pay close attention to heterogeneous treatment 
effects. As noted in Heckman, LaLonde, and Smith (1999), heterogeneous treatment effects uncorrelated with other factors affecting participation and outcomes act like (partial) random assignment and so reduce the difficulty of the selection problem; the empirical relevance of that observation remains largely unexplored. The simple model also illustrates why we would expect participants to have different impacts than non-participants. Indeed, with impacts known in advance, and conditional on particular values of direct costs and opportunity costs, everyone who participates has a higher impact than everyone who does not participate. Even impacts estimated without bias but with some uncertainty prior to the training choice imply that the ATET > ATE > ATNT, where the ATNT is the average treatment effect on the non-treated. The ATE is, of course, just a weighted average of the ATET and ATNT and so must lie between them. More ex ante uncertainty about individual impacts weakens this pattern. Also clear from the model is the fact that the ATET provides an upper bound, and possibly a distant upper bound, on the treatment effects that would be experienced by marginal participants enticed into the program by a small reduction in the direct costs $C{ }^{96}$

Of course, as we intend the name "simple model" to signal, this model leaves a lot out, even as it also captures quite clearly the key factors that make compelling non-experimental estimation of the impacts of training programs challenging to evaluators. One omission from the model concerns the underlying behavioral foundations of the Ashenfelter dip. In the model, the dip results from the fact that individuals select into training based in part on having a low opportunity cost; this results, via the serial correlation in $\varepsilon$, in many individual participants having a gentle decline in their mean earnings in the periods prior to period $k$. In reality, almost no one experiences this gentle decline. Instead, most individuals have a sharp drop in earnings at

\footnotetext{
${ }^{96}$ See the Monte Carlo study that builds on this model in Section 8 of Heckman, LaLonde, and Smith (1999) for further analyses and intuition.
} 
a discrete point in time due to job loss. The smooth dip observed in the aggregate results from the averaging of these sharp falls, which become more common as period $k$ approaches.

Another omission from the model concerns selection on earnings trajectories, as opposed to just selection on earnings shocks (i.e., on $\mathcal{E}$ ) and on persistent differences in earnings levels (i.e., on $\eta$ and/or $X$ ). By way of illustration, consider two scenarios. In one scenario, some individuals select into training when they decide to get serious about life, or at least about the labor market. In another scenario, some individuals select into training because they have lost a job in which their pay well exceeded the value of their marginal product in the other jobs available to them. In many industries the number of such jobs has declined over time due to freer trade or deregulation; as a result those who lose such jobs often experience persistent earnings decreases, as in Jacobson, LaLonde, and Sullivan (1993).${ }^{97}$ We will return to this scenario below when we discuss the evidence on the WIA dislocated worker funding stream. ${ }^{98}$

Our simple model also omits the justifications for government intervention in the training market discussed at the beginning of the chapter. One could easily have the direct $\operatorname{costs} C$ reflect a government subsidy, which would capture the justification from credit constraints but the model still ignores any of the informational justifications for government intervention. First, the government may have better information on the state of the labor market (the "labor market information" aspect of active labor market programs) for particular occupations. This can help the would-be trainee choose between skill upgrading in their existing occupation (or just more effective search in that market) and investing in human capital associated with a new occupation. The government, via knowledgeable and experienced caseworkers armed with standardized tests,

\footnotetext{
${ }^{97}$ See Krolikowski (2014) for a new look at displaced workers through the lens of the dynamic treatment effect literature.

${ }^{98}$ The data from the JTPA experiment (described below) imply little selection on earnings trajectories for adults, but modest amounts for youth. See Heckman and Smith (1999).
} 
may have a better sense of how a given participant's skills and interests match up to particular occupations. This allows more effective investments in training and more effective job search. Finally, the government, again via the caseworkers, may provide quality signals to firms looking for workers to hire into subsidized on-the-job training slots. Because programs recommend only a subset of their participants for these slots, and because they are engaged in a repeated game with individual employers in which reputation matters on both sides, it can make these signals credible in a way that the workers themselves cannot. The literature on government sponsored job-training lacks formal models capturing these aspects of the process, though the directed search model in Plesca's (2010) equilibrium analysis of the Employment Service implicitly captures some of them by having different matching technologies for workers who search via the ES than for workers who search on their own.

The simple model above also completely ignores the supply side of the "market" for services provided by government employment and training programs. Instead, it focuses solely on the participation decision facing the potential trainee. We rectify this omission in the model later in our discussion of performance management, which plays a very important role in shaping the supply responses of the major U.S. employment and training programs. Finally, the model discussed here ignores general equilibrium effects (i.e. effects on those not participating in the program); we discuss those later in the context of cost-benefit analysis.

The standard theory, along with empirical evidence from both experimental and nonexperimental studies, strongly indicates selection into employment and training programs based on both transitory and relatively more permanent components of outcomes. The literature that evaluates employment and training programs in the United States has adopted a variety of data sources, identification strategies, and econometric estimators to deal with the problem of non- 
random selection into programs. Indeed, as we will have some occasion to note, this literature has played an important role in the evolution of applied econometric methods more broadly. We turn now to a limited methodological review, emphasizing those identification strategies and related estimators and data sets, most commonly used in the U.S. literature, namely random assignment and "selection on observed variables." We focus almost exclusively on impact evaluations (we are economists after all) but note that, in our experience, well-designed and executed process and implementation evaluations are important complements to econometric impact evaluations.

Unlike every other country, at least until the last decade or so, the United States sometimes evaluates its employment and training programs using random assignment designs. ${ }^{99}$ In terms of our notation, random assignment as typically implemented involves taking a sample of would-be participants, i.e. $D=1$ individuals, and randomly forcing some of them to experience the untreated outcome $Y_{0}$ (the experimental control group) while randomly allowing others to experience the treated outcome $Y_{1}$ (the experimental treatment group). Randomly assigning treatment assures (statistically) equivalent distributions of all the relevant variables (i.e. $X, \eta, \mathcal{E}, C$, and $u$ ) in the two groups. As a result, a simple comparison of means provides a consistent (in the statistical sense) and compelling estimate of the ATET.

Running experimental evaluations and meaningfully interpreting the resulting data in the real world differs from the pleasant but over-simplified description in the preceding paragraph. We briefly note a subset of the issues here, focusing on those most important to the literature

\footnotetext{
${ }^{99}$ Experimental evaluations of labor market programs outside the U.S. include the Self-Sufficiency Project in Canada described in Ford et al. (2003), the UK Employment Retention and Advancement Demonstration documented in Hendra et al. (2011), caseworker experiments in Denmark evaluated in Pederson, Rosholm and Svarer (2012), and a very impressive multi-level randomized evaluation in France recounted in Crépon et al. (2013). White and Lakey (1992), who evaluate the UK RESTART program, provide a rare exception to our general claim.
} 
whose evidence we review later in this chapter, and starting with randomization bias. ${ }^{100}$

Randomization bias means bias induced by the presence of an experimental evaluation. It is bias relative to the population value of the impact parameter of interest in a world without randomization, i.e. in the world of the program as it normally operates. Consider the following examples: First, the presence of random assignment may change the participant population because potential participants on the margin of participation may find it optimal to pay the fixed cost of attempting to participate in the absence of random assignment, but not in its presence, because the possibility of randomization into the control group reduces the expected value of the attempt. Second, as noted in Heckman and Smith (1995), the presence of randomization may lead individuals to change their behavior even if they do still choose to participate, as when participants reduce pre-random-assignment investments complementary to the treatment due to the uncertainty of receiving it. Third, the institutional trappings associated with randomized evaluations, but not generally with non-experimental evaluations, may lead to differences between the participant population of interest and that in the evaluation, due, for example to selective removal of those put off by signing consent forms. Sianesi (2014) documents the empirical importance of this behavior, and of the resulting bias, in the context of the evaluation of a program providing on-going support for unemployed workers who find a job in the United Kingdom. Fourth, randomization will affect the scale of program intake and thereby lead to differences between the population served by the program as it normally operates and during the randomized evaluation. For example, in the Job Training Partnership Act experiment (described in more detail in the results section), sites were instructed to keep the number of individuals they served the same during the evaluation, so as to avoid randomization bias due to a change in

\footnotetext{
${ }^{100}$ For more on social experiments see e.g. Ferber and Hirsch (1981), Heckman (1992), Burtless and Orr (1995), Heckman and Smith (1995), Orr (1998), and Heckman, LaLonde, and Smith (1999, Section 5).
} 
program scale. But this stricture, coupled with a 2:1 random assignment ratio, meant that sites had to recruit a substantially larger number of potential participants than they normally would. Indeed, this requirement played a role in the site selection difficulties we discuss in the next paragraph, because many sites worried about the quality of the marginal participants drawn in as part of the larger pool of potential participants. ${ }^{101}$

In multi-site programs (like JTPA, WIA, WIOA, and the Job Corps), random assignment can increase the per-site costs of the evaluation and can complicate external validity by making sites more reluctant to participate due to the disruptions in normal program operation necessitated by random assignment. For example, as detailed in e.g. Hotz (1992) and Doolittle and Traeger (1990), the JTPA experimental evaluation's attempt to recruit a random sample of sites that would allow compelling generalization to the population of sites failed miserably. In the end, and after non-trivial side payments plus some design compromises, a non-random sample of 16 sites was obtained. ${ }^{102,103}$ The result was controversy regarding the external validity of the experimental findings; see e.g. Heckman and Smith (2000) or Heckman and Krueger (2003). While the literature offers various strategies for generalizing from non-random samples of sites, these strategies remain controversial and thus inferior to including all sites or evaluating at a random sample of sites. ${ }^{104}$

Finally, and the best documented (if not necessarily the most important) empirically, we

\footnotetext{
${ }^{101}$ One member of the design team (Barnow) for the JTPA evaluation suggested having sites identify the marginal participants; this was not done in that study but is being done in the WIA experimental evaluation described below.

102 The least attractive design compromise allowed the experimental sites to provide control group members with a list of alternative service providers in the community, thereby increasing substitution and muddying the interpretation of the counterfactual. At one site, this list ran to over 10 pages!

${ }^{103}$ Section 5.II of Doolittle and Traeger (1990) makes the positive (but weak in our view) case for the representativeness of the sites in the JTPA evaluation.

${ }^{104}$ See e.g. Hotz, Imbens, and Mortimer (2005), Gechter (2014), Muller (2015), or Vivalt (2015).
} 
may have treatment group dropout ${ }^{105}$ and control group substitution. In an ideal experiment, everyone randomized into the experimental treatment group would receive treatment, and no one in the experimental control group would receive treatment. In this pure case, the experimental contrast clearly represents the causal effect of receipt of treatment rather than no treatment for the relevant population. In practice, because of institutional factors, as well as evaluation design choices and the sometimes chaotic lives of the individuals who participate, or consider participating, in active labor market programs, real experiments rarely look this clean. Heckman, Hohmann, Smith, and Khoo (2000) document the empirical relevance of dropout and substitution for a variety of experimental evaluations of active labor market programs, with a particular focus on the JTPA evaluation.

Three factors appear particularly important in explaining the extent of dropout and substitution in evaluations of employment and training programs in the United States. The first factor is the extremely decentralized nature of the provision of employment and training programs. Many federal government programs have an employment and training component, as do some state programs and many nonprofit social service organizations. This means that wouldbe trainees who get randomized out of one training opportunity can easily find others. For instance, because community colleges provide much of the training in WIA (and now WIOA) control group members can easily enroll in the same or similar courses on their own. Second, high intensity, expensive programs tend to have low rates of dropout, presumably because they

\footnotetext{
${ }^{105}$ Our usage follows that of Heckman, Smith, and Taber (1998), who denote as "dropouts" those individuals randomly assigned to the treatment group in the JTPA experiment who never enroll in the program. This usage makes more sense in their context than it might seem at first blush because, as documented in Kemple, Doolittle and Wallace (1993), many treatment group members received (typically low intensity) services without formal enrollment for reasons related to the JTPA performance management system. More generally, the literature tries to capture variation in the extent of treatment among those with some contact with a program in a variety of ways, such as categorizing individuals who receive no substantive services as "no-shows" or by estimating a "dose-response" function that links outcomes to the amount of service received, or via the related notion of different impacts for different combinations or sequences of services.
} 
appear valuable to potential participants, and low rates of substitution, because the supply of substitutes is far smaller for expensive services than for inexpensive ones. For example, both the Supported Work Demonstration and the Job Corps evaluation have very low rates of dropout and substitution: 0.05 and 0.11 for the former and 0.28 and 0.02 for the latter. ${ }^{106}$ Both are quite expensive. In contrast, the more modest services on offer in the JTPA evaluation elicited substantial rates of both substitution and dropout. For example, according to Table II of Heckman, Hohmann, Smith, and Khoo (2000), among adult women recommended to receive classroom training in occupational skills, 48.8 percent of the treatment group actually did so, compared to 27.4 percent of the control group (who received it from other sources, or from the same sources with different funding). Finally, the experimental design itself can affect the amount of treatment group dropout via its interaction with the process of program participation. For instance, random assignment in the JTPA evaluation took place at the JTPA office rather than at the service provider locations for cost reasons, but doing so introduced a temporal wedge between assignment and service receipt that allowed some treatment group members time to find a job or wind up in jail or just get dissatisfied with the services offered to them.

Researchers typically adopt one of two strategies in the presence of dropout and/or substitution. The first strategy redefines the parameter of interest to represent the average effect of the offer of treatment (sometimes called the "intention to treat" or ITT), relative to a (possibly complicated) counterfactual, rather than the ATET. For example, one can think of the experimental contrast in the JTPA study as between a treatment group with access to all of the various treatment options in the community including JTPA, and a control group with access to

\footnotetext{
${ }^{106}$ See Table I of Heckman, Hohmann, Smith, and Khoo (2000) for NSW and Table 2 of Schochet, Burghardt, and McConnell (2008) for the Job Corps study. For the Job Corps, the substitution number includes only crossovers who actually received Job Corps despite randomization into the control group; the fraction of the control group that received some sort of educational treatment was about 72 percent.
} 
just the options other than JTPA. This represents a reasonable causal parameter, but also one quite different in substantive interpretation from treatment versus no treatment. The second strategy rescales the experimental difference in outcomes by the difference in the probability of treatment between the treatment group and the control group. The resulting estimand represents the mean impact of treatment on the treated when the experiment features dropout but not substitution, and a Local Average Treatment Effect (LATE) when both are present. ${ }^{107}$ The LATE gives the mean effect of treatment on those induced to participate as a result of ending up in the treatment group rather than the control group, whom the literature calls "compliers." It says nothing about the mean impact on those who would get treated in either state, the so-called "always-takers" in the language of Angrist, Imbens, and Rubin (1996). The LATE is also a reasonable and often interesting causal estimand, but it differs from both the ATET and from the ITT. Again, comparisons with non-experimental estimates of the ATET require care. ${ }^{108}$

The decade since LaLonde (2003) has seen a combination of triumphalism and humility among advocates for greater social experimentation. The triumphalism comes from the rapid movement of policy-relevant random assignment designs into development economics and into education, and the broader "credibility revolution" described by Angrist and Pischke (2010) and

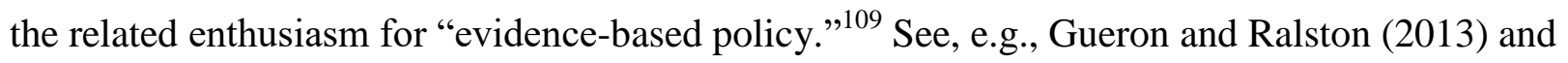
Institute for Education Sciences (2008) for more of this view. At the same time, the practice of randomized evaluations has become much more nuanced, with greater attention to the role of dropout and substitution, to the importance of careful definition and interpretation of the estimand in the context of heterogeneous treatment effects, and to the fact that random

\footnotetext{
${ }^{107}$ The LATE is called the "Complier Average Causal Effect" or CACE in some literatures.

${ }^{108}$ For more on these issues see e.g. Bloom (1984), Heckman, Smith, and Taber (1998), or Heckman, Hohmann, Smith, and Khoo (2000).

${ }^{109}$ One always wonders what it was they were doing before "evidence-based policy." It is probably best not to think too hard about that.
} 
assignment does not magically overcome the general problems of either empirical research (e.g. outliers and so on, see Heckman and Smith, 2000) or of partial equilibrium evaluation (see our discussion of general equilibrium issues below). Also relevant in this sense is the pendulum in economics swinging back toward a balanced approach that emphasizes both the depth of the economics and the quality of the identification strategy, a view that naturally sees experiments and "structure" as complements as in, e.g., Todd and Wolpin (2006), rather than as substitutes.

We aim here to walk down a middle road on random assignment, avoiding excessive cheerleading and excessive cynicism, both of which one can find in e.g. the current methodological debate in development economics. Instead, we view the deliberate creation of high-quality exogenous variation as an important complement to the other activities that economists and other evaluators of programs undertake. We think the literature needs more, and more thoughtful, use of randomization.

The continued flourishing of experimental evaluation has coincided with ongoing progress in non-experimental evaluation, spurred on in part by improvements in the available data (particularly in Europe, but also to some extent in the United States) and in part by developments (and rediscoveries) in the realm of applied econometrics. Methods for solving the selection problem via conditioning on observed covariates consume most of our attention, as they do most of this literature. We then briefly remark on developments and applications of other identification strategies, such as discontinuity designs.

Selection on observed variables identification strategies attempt to solve the problem of non-random selection into training (or a program more generally) via conditioning on a sufficiently rich set of observed covariates. Put differently, under this strategy the researcher tries to make the case that they have observed all the variables, or good proxies for all the variables, 
that affect both participation in training and outcomes in the absence of training. In formal notation, the researcher assumes either $E(\mu+\varepsilon \mid X, D)=0$ in the case of parametric linear regression, or $E(\mu+\varepsilon \mid X, D=1)=E(\mu+\varepsilon \mid X, D=0)$ for matching and weighting estimators. Depending on the researcher, this assumption might get called the "conditional independence assumption" (CIA), "exogeneity" or, to use the awkward term contributed by the statistics literature, "unconfoundedness."

Making these assumptions is easy; making a compelling case for them is not. The literature has responded to the task of learning what variables suffice for the conditional independence assumption in three ways. First, some studies implicitly adopt the view that, perhaps because of some benevolent identification deity, the data at hand necessarily include some set of conditioning variables that suffice for the CIA. Indeed, some writers implicitly hold this faith with such fervor that they see no need even to attempt an explicit case for the CIA.

More serious researchers make an explicit case for the CIA based on theory, institutions (sometimes helpfully embodied in high-quality process analyses), and existing empirical knowledge. Theory, like our simple model above, suggests the importance of transitory outcome shocks and of fixed characteristics that affect both outcomes and participation. The former signals the importance of conditioning on histories of labor market outcomes in the period prior to the decision to take training or not, and of doing so flexibly and at a relatively fine level of temporal detail. The latter signals the importance of conditioning on things like ability and motivation, or at least for compelling proxies for them. Longer lags of labor market outcomes (i.e. before the "dip") often assume this proxy role.

Existing evidence relevant to the justification of conditional independence assumptions takes a number of forms. One very common form in this literature arises from "within-study" 
comparisons that use experiments as benchmarks to learn which conditioning variables lead to non-experimental estimates based on the CIA that replicate (up to statistical variation) the experimental estimates and which do not. A long series of papers starting with LaLonde (1986) and Fraker and Maynard (1987) and continuing through Dehejia and Wahba (1999, 2002), Heckman, Ichimura, Smith and Todd (1998), and Smith and Todd (2005a, b) embodies this idea. ${ }^{110}$ These papers also highlight the importance of conditioning flexibly on labor market outcomes in the period prior to participation.

A second form of evidence on conditioning variables comes from studies that take a relatively compelling set of conditioning variables and adding in an additional set of more novel conditioning variables. If the impact estimates move upon adding the new variables, they matter and future evaluations should include them. If estimates do not change much, then the new variables do not aid in solving the selection problem at the margin. ${ }^{11}$ That is very useful knowledge as well, as it helps avoid spending resources collecting data on variables not necessary to solve the selection problem and (not unrelated) increases the credibility of future CIA-based evaluations that do not include them. Lecher and Wunsch (2013) provide a thorough analysis along these lines using the (very) rich German administrative data. Andersson et al. (2013) use the U.S. Longitudinal Employer Household Dynamics (LEHD) data to examine the value of conditioning on the characteristics of the firm at which WIA participants last worked in addition to the usual flexible form in earnings and employment. They find, to their and our surprise, that the firm characteristics do not matter.

\footnotetext{
${ }^{110}$ These papers do not always frame their analysis as we do here. Instead, some studies frame the question as "does matching work?" which in our view represents a very silly question indeed. Matching "works" when you match on variables that suffice for the CIA and it does not work when you do not. What matters is the conditioning set.

${ }^{111}$ Note that having the estimates not move (much) when adding new variables does not imply that the old variables suffice for the CIA, though it suggests they do. The key is the absence of an additional unobserved factor, uncorrelated with all of the included covariates, that affects both participation and outcomes. See e.g. the discussion in Heckman and Navarro (2004).
} 
A final way to think about justifying the CIA centers on the so-called support condition. Semi-parametric and non-parametric estimators based on the CIA require variation in training status conditional on observed characteristics. Put another way, for any given set of observed characteristics, the data must include non-trainees to compare to the trainees. Lurking in the background, some unobserved instruments generate this conditional variation in training. Thinking about the nature of these instruments (random information shocks, distance from the training provider, and so on) can aid in making the case for the CIA in a given context.

The econometric literature provides a wealth of semi-parametric and non-parametric estimators that build on the CIA and complement the traditional parametric linear regression model. The most commonly used estimators in applied work in economics undertake nonparametric matching on the conditional probability of training - the so-called propensity score given by $\operatorname{Pr}(D=1 \mid X)$. With a parametric (though ideally relatively flexible) propensity score model (typically a logit or probit) this general class of semi-parametric estimators balances parametric assumptions with uni-dimensional non-parametric flexibility. The economics literature sometimes frames this class of estimators as non-parametric regression estimators. Essentially the matching implicitly estimates a non-parametric regression of $Y_{\mathrm{o}}$ on the estimated propensity score and uses predicted values from that estimated regression as estimates of the expected counterfactual for each trainee. A lively Monte Carlo literature that includes Frölich (2004), Huber, Lechner, and Wunsch (2013), and Busso, Dinardo, and McCrary (2014) guides the applied researcher in choosing among the many available estimators. ${ }^{112}$

A variety of other identification strategies allow the evaluation of active labor market programs but have not attracted wide use in the recent empirical literature on training programs.

\footnotetext{
${ }^{112}$ An odd history of applied econometrics aside: some of the CETA evaluations summarized in Barnow (1987) and reconciled in Dickinson, Johnson, and West (1987) anticipate the "Coarsened Exact Matching" (CEM) of Iacus, King, and Porro (2012) that has gained some traction in literatures outside of economics.
} 
These include the bivariate normal selection model, instrumental variables, regression discontinuity, and the bias stability assumption that justifies the difference-in-differences estimator. The bivariate normal model has fallen out of favor with labor economists in recent years for several reasons, including a growing aversion to difficult-to-justify functional form assumptions and the realization that sensible application of the model required a hard-to-find exclusion restriction (i.e. a variable affecting outcomes only via its effect on training participation). ${ }^{113}$ Similarly, instrumental variables methods have seen little use in the training literature due to a paucity of plausible instruments. ${ }^{114}$

Discontinuity based methods have run rampant in many quarters of applied economics in the past decade - see Cook (2008) for their history - but they play almost no role in the training literature. We know of only two examples. One is the Urban Institute's evaluation of the High Growth Job Training Initiative (HGJTI) in Eyster et al. (2010) which lacks compelling results due to the deadly combination of a modest sample size and a high variance outcome variable. The other is the analysis of the WPRS in Black, Galdo, and Smith (2007). This astounding lack of discontinuity designs relative to, say, the evaluation literature in K-12 education, results from, in our view, two factors. First, even before researchers started thinking along these lines, educational institutions had a lot of policy discontinuities built in. We do not have a compelling technological explanation for this difference across substantive domains, but it meant that researchers had lots of low-hanging fruit to pick when the design became salient in economics. Second, the employment and training world has seen little in the way of attempts to "design in"

\footnotetext{
${ }^{113}$ See Puhani (2000) for a survey of the literature on the bivariate normal model and Bushway, Johnson and Slocum (2007) for examples of how things can go wrong in practice.

${ }^{114}$ Frölich and Lechner (2010), which studies Swiss active labor market programs, is the only example of which we are aware in the recent literature. Back in the dinosaur days, Mallar et al. (1982) used distance to the Job Corps center as an instrument. The marginal treatment effect approach, a semi-parametric generalization of the classic bivariate normal selection model well described and illustrated in Carniero, Heckman, and Vytlacil (2011), also awaits application in the training literature.
} 
discontinuities that can serve as the foundation for causal research, even though they seem quite natural for courses that require some level of academic preparation as measured by a test score.

Another design common in other literatures and much less common in the evaluation of employment and training programs builds "difference-in-differences" or other panel estimators atop assumptions about bias stability. Bias stability holds that, possibly conditional on observed characteristics, the difference in untreated outcomes between participants and non-participants is constant over time. As a result of the temporal stability, differencing takes care of bias due to selection on unobserved variables. At the individual level, the bias stability assumption runs afoul of Ashenfelter's dip, which clearly indicates selection on both time-varying and timeinvariant unobserved variables. Heckman and Smith (1999) show the trouble this causes; in particular, they emphasize that the choice of the "pre" period matters tremendously in the presence of the dip.

Another style of difference-in-differences study operates at the jurisdictional level rather than the individual level, and exploits policy changes that occur in some but not all jurisdictions. This type of study faces two difficulties in the training context. First, very little of the policy action in the training world occurs at jurisdictional levels that correspond to standard data sets, such as the state-level analyses often used to study things like the minimum wage or (in the old days) the minimum legal drinking age. Second, data detailing the variation in policies across jurisdictions requires a lot of digging, because no one collects it and disseminates it in easy-touse form, as Huber, Kassabian, and Cohen (2014) do for the TANF program. With new programs, a staged roll-out, ideally with the jurisdictional timing randomized, allows the application of this design. We know of one attempt along these lines, namely the Social Security Administration's evaluation of the Ticket-to-Work voucher program for disability recipients; see 
Stapleton et al. (2008) for details.

\section{Data and measurement issues}

Though it might come as a surprise to some, evaluations of training programs have many dimensions besides the quality of their causal identification. These attributes affect the quality of the impact estimates, in the sense that they affect the amount of error they contain relative to the parameter of interest that arises from sources other than sampling variation and selection bias. They also affect the interpretation of the obtained impact estimates and the value of the costbenefit analysis built around those estimates. This section discusses issues related to the measurement of training and of labor market outcomes, while the following section discusses various issues that arise in the context of cost-benefit analysis.

Data on service receipt, service type, and service timing play an important role in evaluating training programs, yet we know very little about how best to measure these variables or about the quality of existing measures. Typically, data on services come from one of two sources: surveys or administrative data. These sources have differing strengths and weaknesses that vary somewhat across contexts. Administrative data avoid issues with a failure to recall receipt of services, particularly low intensity services, by survey respondents. In some cases, the use of administrative measures of enrollment in performance management schemes (we say more about these below) may increase the quality of these data, which caseworkers might otherwise have little incentive to enter with care. But use in performance management can cut both ways. In the JTPA evaluation, as documented in Table 4.5 of Kemple, Doolittle, and Wallace (1993), many treatment group members not formally enrolled in JTPA nevertheless received JTPA services, because caseworkers avoided enrolling potential participants as long as possible 
because only those actually enrolled counted for performance management purposes. On the other hand, survey data may catch services received at programs other than the one under study, as well as services explicitly not recorded in administrative data systems, such as public core services (e.g. free computers to use to search for jobs) in some WIA programs and the Employment Service. And in contexts where control or comparison group members may receive training or other services from (often quite numerous) other programs and providers, surveys of the individuals in the evaluation may represent the only cost-effective way to characterize the counterfactual.

Smith and Whalley (2015) compare data from surveys and administrative records for treatment group members in the JTPA experiment. They find a substantial amount of underreporting of services received in the survey data relative to the administrative data. Looking at particular services, they find that respondents appear to do a better job of reporting services that happen in classrooms, such as formal training in occupational skills or adult basic education, than they do at reporting services such as job search assistance or subsidized on-the-job training at private firms. Reported start and stop dates of training also often differ substantially between the two sources, though here it is less clear which source should be viewed a priori as containing less measurement error. More broadly, their paper suggests the value of both additional research on training measurement and of paying more attention to the quality of administrative data.

The same choice between survey data and administrative data arises when considering how best to measure labor market outcomes such as earnings and employment. As with the measurement of the timing and incidence of training, neither source strictly dominates the other. This is particularly true in the context of the disadvantaged populations served by means-tested government training programs. For example, administrative data typically miss sources of labor 
income outside the formal labor market and thus not reported to the authorities. These sources may include illegal activities like drug-dealing or prostitution, as well as legal but informal activities such as childcare, hair care, automotive repairs, and so on. To the extent that training programs move their trainees from such informal work into formal sector jobs, reliance on administrative data on earnings and employment overstate program impacts due to undercounting informal earnings and employment among non-trainees. At the same time, administrative data likely measure earnings and employment in the formal sector with less error than do survey data, particularly as the recall period lengthens. Kornfeld and Bloom (1999) show that measurement differences between survey and administrative data (from state Unemployment Insurance records) matter for the impact estimates obtained for the male youth sub-group in the JTPA experiment. More recently, Barnow and Greenberg (2015) show that measurement differences between survey and administrative data (usually from Unemployment Insurance wage records) often have large effects on estimated earnings impacts in the eight randomized controlled trials examined.

Earnings and employment measures within the broad categories of survey and administrative data differ as well. For example, among administrative data sources, state Unemployment Insurance (UI) wage record data do not include the earnings of many government employees or of the self-employed, while IRS earnings data do. Neither includes the value of fringe benefits, which Hollenbeck and Huang (2014) estimate at about 20 percent of earnings for this population. Smith (1997, Table 11) shows non-trivial differences in selfreported annual earnings from a simple summary question versus earnings built up from more detailed information about wages, hours, and weeks worked on individual jobs. ${ }^{115}$ Whether or

\footnotetext{
${ }^{115}$ The exact wording of the question from the background information form is "In the past year (12 months), how much did you earn (before taxes and deductions)?”
} 
not measurement error matters for impact estimates depends on its correlation with treatment status, as with the example above where training moves trainees away from informal work. See e.g. Angrist and Krueger (1999); Bound, Brown, and Mathiowetz (2001); and Hotz and Scholz (2002) for more on measuring labor market outcomes in general and Kornfeld and Bloom (1999); Wallace and Haveman (2007); Schochet, Burghardt, and McConnell (2008); and Barnow and Greenberg (2015) for discussions specific to an evaluation context.

\section{Issues for cost-benefit analysis}

Cost-benefit analysis provides a framework for combining impacts on a variety of outcomes, expressing them in common (i.e., dollar) units, and comparing their discounted present values to the present costs of training. Such analyses add substantial value to impact estimates for that subset of programs that produce positive impacts on at least some outcomes of interest. In our view, the cost-benefit analysis produced as part of the National Job Corps Study and documented in McConnell and Glazerman (2001) represents the best among the evaluations we survey here; we also draw inspiration from the analyses in Section 10.1 of Heckman, LaLonde, and Smith (1999) and in Section 12 of Andersson et al. (2013). All of these exercises compare average costs to average impacts of treatment on the treated; the literature would also benefit from attempts to compare marginal costs to benefits on marginal participants.

In many cost-benefit analyses, the magnitude, and sometimes even the sign, of the net present value will depend on a number of important choices about which the researcher may have only limited knowledge. Like Heckman, LaLonde, and Smith (1999), we favor thoughtful sensitivity analysis in such cases, so that the consumer of the cost-benefit analysis comes away with a clear understanding of the amount and sources of sensitivity in the calculations. 
One common limitation concerns the duration of follow-up data. Because training programs typically exhibit "lock-in" effects - negative impacts during the training period due to labor market withdrawal - any hope of finding enough positive impacts to pass a cost-benefit test depends on having follow-up for a reasonably long period after training. At the same time, evaluation delayed may mean policy influence denied, which argues for not waiting around too long for more follow-up. If the evidence suggested that positive impacts always persisted once they started, this issue would become less important, as researchers could feel relatively confident when projecting impacts out beyond the data. Sadly, what evidence we have provides a mixed picture about impact persistence. For instance, Couch (1992) shows that impacts on earnings from the National Supported Work Demonstration remain rock solid for many years; similarly, the U.S. General Accounting Office (1996) finds that earnings impact from the JTPA experiment also appear relatively consistent over five years. In contrast, Schochet, Burghardt, and McConnell (2008) show that earnings impacts from the Job Corps experiment fade out over time. Greenberg, Michalopoulos, and Robins (2004) find some evidence of sex differences in impact persistence between men and women in their meta-analysis but lament, as do we, the absence of many evaluations with more than three years of follow-up data. Longer-term followup using administrative data for both past and future experiments would add to our knowledge base on this dimension at relatively low cost.

Another common limitation concerns impacts on outcomes other than employment and earnings and/or on household members other than the trainee. We might, for example, expect job training to affect criminal activity, both by consuming the time of the trainee (idle hands ...) and, in the event that training leads to employment, by increasing the opportunity cost of getting caught. We might also expect job training to affect health. For female participants, training might 
affect the timing or incidence of fertility. Finally, we might expect training to have effects on other household members' choices regarding schooling and work, and possibly regarding divorce or co-residence as well.

Though often hypothesized, we know of only two U.S. studies of general training programs (as opposed to programs specifically for ex-convicts, for example) that have actually attempted to measure such effects, namely the National Job Corps Study experimental evaluation (discussed in more detail below) and the earlier non-experimental evaluation of the same program. Both of these studies devote a fair amount of effort to estimating the impact of the Job Corps on the criminal activities of participants, monetizing the resulting impacts, and then incorporating them into their cost-benefit analyses; see Mallar et al. (1982) and McConnell and Glazerman (2001). In both cases, they find that a substantively important component of program benefits, particularly in the first year, comes from reductions in criminal behavior, reductions that presumably result from the residential nature of the program, which separates participants from both dubious friends and opportunities for profitable misbehavior. Elsewhere in the world, Lechner and Wiehler (2011) find some effect of Austrian training programs on the fertility of female participants. In our view, further work along these lines, whether via survey data or matched administrative data, would provide a richer view of the overall effects of training programs. ${ }^{116}$

A dollar of government revenue to spend on training costs society more than a dollar in lost output due to costs associated with collecting the revenue. These include the direct costs of

\footnotetext{
${ }^{116}$ In addition to their value in a thorough cost-benefit analysis, examination of outcomes beyond just earnings and employment levels also informs our understanding of the mechanisms by which programs bring about any impacts on earnings and employment. For instance, studies that examine the effects of employment and training programs on the durations of subsequent employment and unemployment spells, such as Ham and LaLonde (1996) and Eberwein, Ham, and LaLonde (1997) both illuminate causal mechanisms and provide guidance on the likely persistence of impacts on employment and earnings beyond the available data.
} 
operating the tax collection system (e.g. the Internal Revenue Service and all the tax preparers and accountants) as well as the indirect costs due to the use of distortionary taxes. For example, income taxes distort choices between labor and leisure in ways that reduce welfare relative to a world with (non-distortionary) lump sum taxes. Not surprisingly, calculating the direct cost per dollar of government revenue proves relatively uncontroversial, while estimating the indirect costs proves quite complex and controversial, enough to generate a large literature and even a book, namely Dahlby (2008). The public finance literature calls one plus the sum of the direct and indirect costs of the marginal tax dollar the marginal social cost of public funds (MSCPF). We do not take a stand here on the correct value for the MSCPF other than that it exceeds one. Rather, we note that even otherwise very nice cost-benefit analyses such as that in the National Job Corps Study err by leaving it out, and we recommend the sort of sensitivity analysis using a range of MSCPF values drawn from the literature that appears in Andersson et al. (2013).

Another puzzling lacuna in many cost-benefit analyses concerns the value of the "leisure" of the participants. Consider an individual who would receive training for six months and then work for 18 months in the first two years after random assignment to the treatment group in an evaluation of a training program but who would stay at home and care for their children for two years if assigned to the control group. The standard analysis values the employment based on the earnings received and implicitly assigns a value of zero to caring for the children at home. The latter appears in the cost-benefit analysis only indirectly if the childcare used in the treated state receives a government subsidy (and the analysis sweats such details). As discussed in Greenberg and Robins (2008), the standard analysis gets the economics wrong by omitting the value of the participants' counterfactual non-market time. This omission leads to a systemic overstatement of programs' cost-benefit worthiness, as illustrated by Greenberg and Robins (2008) for the case of 
the Canadian Self-Sufficiency Project earnings supplement.

Finally, doing a good cost-benefit analysis requires good data on costs. In the case of evaluations estimating the ATET of the program as a whole, this means data on average perparticipant costs. In the case of evaluations comparing difference services, it requires data broken down by service type. For evaluations that focus on marginal participants, it requires data on marginal costs. As discussed e.g. in Andersson et al. (2013) for WIA, most U.S. programs lack any useable data on marginal costs as well as lacking data on average costs broken down by service type, client type or geographic location. ${ }^{117}$

\section{General equilibrium effects}

None of the evaluations we consider in this chapter accounts for general equilibrium effects. In the context of training programs, equilibrium effects typically take two forms: displacement and changes in relative skill prices. ${ }^{118}$ Displacement, the focus of most papers in this literature that attend to equilibrium effects at all, occurs when program participants take jobs that others would have taken in the absence of the program. This could result from their leaping ahead in the queue due to enhanced qualifications or due to changes in optimal search effort. In either case the control or comparison group used in a partial equilibrium evaluation will likely contain only a very small fraction of those displaced, meaning that such an evaluation will overstate the social impacts of the program. Changes in skill prices result when training programs increase and decrease the supply of particular types of skills in local labor markets. For example, if a training program trains many nail technicians in a particular locality, we expect the relative wages of nail

\footnotetext{
${ }^{117}$ Heinberg et al. (2005) and Barnow and Trutko (2015) document the conceptual and empirical challenges associated with cost measurement in the context of employment and training programs.

${ }^{118}$ Deterrent effects may matter for mandatory programs; see e.g. Black et al. (2003) and the broader European literature surveyed in McCall, Smith and Wunsch (2015). We follow the Office of Management and Budget (1992) in passing on "magic" multiplier effects.
} 
technicians to fall due to increased supply (and doubters of this sort of scenario should read Boo, 2004). Again, such effects will lead a partial equilibrium evaluation, whether experimental or non-experimental, to overstate the overall economic benefits to the training program.

General equilibrium evaluations typically take one of two approaches. The first makes use of spatially distinct local labor markets that have plausibly exogenous variation in program scale. Different outcomes for the non-treated in localities with a large program presence relative to those with a small program presence indicate equilibrium effects. Examples of such studies outside the US include Forslund and Krueger (1997) in Sweden and the astounding two-level random assignment study in France by Crépon et al. (2013). We know of no such studies for U.S. programs.

The second strategy writes down a complete equilibrium model and estimates or calibrates the model to obtain estimates of the size and nature of any equilibrium effects. Though we know of no U.S. training programs evaluated using this strategy ${ }^{119}$, Davidson and Woodbury (1993) uses a calibrated search model to estimate the equilibrium effects of UI bonuses (lump sum payments to UI claimants who end their claim early) on the search effort of unemployed workers not eligible for the bonuses. Along similar lines, Lise, Seitz, and Smith (2004) calibrate a search model to examine the equilibrium effects of the Canadian Self-Sufficiency Project. In contrast, Heckman, Lochner, and Taber (1998) estimate a dynamic, stochastic, general equilibrium model in their study of the equilibrium effects of a $\$ 500$ subsidy to university tuition. In their model, the equilibrium effects work through changes in the relative skill prices of high school educated and university educated labor. All three studies find substantively important equilibrium effects; in the Lise, Seitz, and Smith (2004) paper they suffice to overturn the positive verdict of a partial-equilibrium cost-benefit calculation. More work along these lines,

\footnotetext{
${ }^{119}$ Johnson (1979) considers displacement effects in an early (i.e. pre-search) equilibrium framework.
} 
including greater emphasis on the potential for equilibrium effects and some thinking about the contexts where equilibrium effects will and will not matter very much, would improve our understanding of the effects of training programs and of their fiscal worthiness.

\section{Systematic evaluation and aggregation of evaluations}

Another important development since the publication of LaLonde's (2003) survey centers on the systematic evaluation and aggregation of evidence across evaluation studies. The meta-analyses of evaluations of active labor market programs from many developed countries summarized in Card, Kluve, and Weber $(2010,2015)$ provide a fine example of this. Greenberg, Michalopoulos, and Robins (2003) undertake a similar meta-analysis restricted to U.S. evaluations. Metaanalysis in this context means estimating so-called "meta-regressions" in which impact estimates from various evaluation studies (often for particular subgroups) form the dependent variable and various characteristics of the evaluation (e.g. was it experimental or not) of the program (e.g. classroom training or job search assistance, program duration), of the participants (e.g. men or women, youth or adults) and of the context (e.g. the unemployment rate) comprise the independent variables. This differs from the original use of meta-analytic techniques in the medical literature to combine multiple under-powered studies of the same treatment applied to the same population. Here the (quite different) goal consists in accounting for the variation across studies. One perhaps surprising result from the Card, Kluve, and Weber (2010) metaanalysis is that, conditional on controlling for other features of the evaluation, the estimates provided by experimental and non-experimental methods do not differ very much on average.

The Clearinghouse for Labor Evaluation and Research (CLEAR) website represents 
another flavor of evaluative aggregation. Inspired by the U.S. Department of Education's What Works Clearinghouse (colloquially known, with some justification, as the "Nothing Works Clearinghouse"), and thus indirectly by the Cochrane Collaboration in health and the Campbell Collaboration in social policy, CLEAR grades evaluations of labor market programs relative to fixed standards of quality, and also provides summaries of evidence. ${ }^{120}$ The latter take two main forms: one comprises quality-weighted reviews of the literature related to specific programs or classes of programs and the other represents, essentially, summary translations (from researchspeak into regular English) of evaluations for practitioner and policymaker audiences. CLEAR differs from the WWC along several dimensions, some of which result from the much smaller size of the relevant literature, some from the generally lower financial stakes facing researchers who write the evaluations evaluated on the site, and some from the fact that the quality of the literature on employment and training programs has historically far exceeded that on educational interventions, with the implication that CLEAR does not, unlike WWC, explicitly see part of its mission as raising an entire field out of the research muck. While we acknowledge the difficulties in coming up with generally applicable and reasonably objective standards for evaluations, we think that CLEAR plays a very useful role in publicly grading studies relative to a good shot at such standards. Importantly, both CLEAR and WWC include mechanisms for updating the grading standards as applied econometrics moves forward over time, though neither site has successfully dealt with the problem of studies that exceeded the methodological standards of their day but fall short of the standards of the present.

\section{Review of research on program impacts}

\footnotetext{
${ }^{120}$ See clear.dol.gov for CLEAR, ies.ed.gov/ncee/wwc for the WWC, www.cochrane.org for the Cochrane Collaboration, and www.campbellcollaboration.org for the Campbell Collaboration.
} 
Rather than repeat earlier summaries in the literature of pre-2000 evaluations such as those in LaLonde (2003) and Heckman, LaLonde, and Smith (1999), we focus our energies here primarily on recent, high quality evaluations of major federal programs, namely WIA, the Job Corps, and TAA.

\section{Workforce Investment Act}

We consider the four closely related papers that examine the Workforce Investment Act (WIA): Hollenbeck (2009), Heinrich et al. (2013), Andersson et al. (2013) and Heinrich and Mueser (2014). These evaluations share a common basic design, in part because they share a common foundation of administrative data sources. Each of these papers combines administrative data from the WIA program - formally the WIA Standard Record Database (WIASRD) data - with data on earnings by calendar quarter from state Unemployment Insurance records. The WIASRD data, in addition to program-related information on enrollment and termination dates and services received, also include basic demographic information as well as limited information on schooling. $^{121}$

All four papers focus their estimation energies on one or both of two parameters: the mean effect of receiving any WIA services relative to not receiving any WIA services on those who receive them (hereinafter the "W-ATET") and the mean effect of receiving WIA training, and possibly other WIA services, compared to receiving one or more WIA core or intensive services, but not training, on those who receive the training (hereinafter the "T-ATET"). Both parameters answer interesting policy questions, though we note the absence (necessarily given the data) of any attempts to estimate impacts on marginal participants, those most relevant to

\footnotetext{
${ }^{121}$ See Decker and Berk (2011) and Van Horn, Krepcio, and Wandner (2015) for broader surveys of recent research
} on WIA. 
thinking about the effects of small expansions or contractions in the WIA budget.

In the WIA context, the two parameters present somewhat different challenges to the researcher. Andersson et al. (2013) argue that the T-ATET estimand embodies an easier selection problem than the W-ATET. We can think of two versions of this argument. First, due to the interplay of the economics and the institutions, WIA participants may differ from WIA nonparticipants more strongly in terms of observed and unobserved characteristics than do WIA trainees and WIA non-trainees. Second, we may just know more about how the WIA trainees differ from the WIA non-trainees via institutional knowledge about the service assignment process. Andersson et al. (2013) present evidence for the first claim by showing that pre-program mean earnings patterns differ only very modestly between the WIA trainees and non-trainees in their data relative to the differences found in other papers for WIA participants versus WIA nonparticipants. Bell et al. (1995) advance a closely related view in making the case for program dropouts as a comparison group for program participants; see also Section 15 of Heckman, Ichimura, and Todd (1997).

Another difference between the T-ATET and W-ATET estimands concerns comparison group selection and the related problem of temporal alignment: i.e. what time period to use as a baseline when coding up time-varying conditioning variables. The comparison group for the TATET is clear: it is the WIA participants who do not receive training. The temporal alignment problem for the T-ATET has a similarly straightforward solution: the natural choice aligns the WIA trainees and the WIA non-trainees based on their dates of WIA enrollment. All of the papers that estimate the T-ATET follow this course.

In contrast to the T-ATET, the choice of comparison group for the W-ATET requires some thought and some tradeoffs. Due to their reliance on administrative data, the WIA papers 
lack a version of the "ideal" comparison group of eligible non-participants collected as part of the JTPA experiment. Instead, data limitations require choosing among various candidate comparison groups based on their participation in other programs, as administrative data become available only via such participation. Rhetorically, the choice gets presented either as a practical alternative to the desired but too-expensive-to-obtain (because of the large number of screening interviews required) sample of eligible non-participants, with a case then made about the nature and size of the resulting bias, or as a particular way of defining the counterfactual of interest, so that the treatment contrast becomes WIA versus another program rather than WIA versus no WIA. Neither contrast necessarily dominates in terms of policy interest, but they do differ in terms of the mix of related services received by comparison group members, a difference that affects interpretation and comparisons with other studies.

In practice, the choice for researchers seeking to estimate the W-ATET boils down to either Employment Service (ES) participants or Unemployment Insurance (UI) claimants. Consider UI claimants first. This comparison group has the disadvantage that many WIA participants lack UI eligibility because they lack sufficient work experience to qualify for UI. This problem can be (and is, in these papers) "solved" by comparing UI claimant WIA participants to UI claimant non-participants. This is not an uninteresting comparison, but it does leave aside many important components of the WIA participant population, including welfare recipients and low-skill workers with spotty employment histories. Using UI claimants has the advantage that it simplifies the problem of temporal alignment as WIA participant and WIA nonparticipant UI claimants can be aligned based on their UI claim's start date.

As described in more detail earlier in the chapter, the ES dates back to the Wagner-Peyser Act of 1933 and provides labor exchange services. The UI program requires virtually all 
claimants (other than those awaiting recall) to register with the ES. ${ }^{122}$ The ES also serves many other job-seekers, including some currently employed but looking for a better match. The extent of ES integration with WIA varies substantially across states. Relative to using UI claimants as a comparison group, using ES registrants has the advantage of capturing a broader population, one that overlaps with more of the WIA participant population. The costs are two-fold. First, the process that leads some job seekers who are not UI claimants to register for the ES and others not to do so is not well understood, but has implications for the interpretation of the ES comparison group counterfactual. Second, and not unrelated, while UI claimants typically register for the ES shortly after becoming unemployed, other job seekers may wait until initial job search efforts fail before seeking help from the ES. This process complicates temporal alignment, as aligning WIA non-participant ES registrants with WIA participants using the ES registration date may do a bad job of implicitly conditioning on the duration of job search, something the literature suggests matters because it proxies for otherwise unobserved characteristics. ${ }^{123}$

The four non-experimental WIA papers also share common identification strategies, as they all assume one or both of the conditional independence assumption and the bias stability assumption. The available data and institutional variation essentially force these choices. Unlike many educational institutions, WIA does not provide helpful discontinuities in treatment assignment that depend on observed, difficult-to-manipulate running variables like test scores. Hence, an RD analysis would require purposive institutional changes. One could imagine using variation in services received due to exogenous variation in caseworker assignment (whether explicitly random or just "first available"), but the data typically available lack information on

\footnotetext{
${ }^{122}$ For more on the ES, see e.g. Balducchi, Johnson, and Gritz (1997).

${ }^{123}$ In many European countries, centralized labor market institutions that link formal registration as unemployed to benefit receipt greatly simplify the temporal alignment problem.
} 
caseworkers and on the process that matches clients to caseworkers. ${ }^{124}$ Similarly, one can imagine an analysis that attempts to use distance to the One-Stop as an instrument in an analysis of WIA versus no WIA, but the available data lack residential addresses for comparison group members. No other credible instruments suggest themselves.

At the same time, as discussed above, the literature provides some support for the idea that the available conditioning variables, particularly the lagged labor market outcomes provided by the UI data, may suffice to make identification of causal effects based on the Conditional Independence Assumption (CIA) or the Bias Stability Assumption (BSA) plausible. That is, these papers can, and sometimes do, make a positive case for a causal interpretation of impact estimates based on the CIA or BSA.

Consider the case for the CIA first. As mentioned above, this case rests on claims about having a sufficiently rich set of exogenous conditioning variables to make it plausible that participation (i.e. in WIA or in training within WIA) is conditionally unrelated to the untreated outcome. To make this case, all four papers start out by forcing exact matches on particularly important covariates. Hollenbeck (2009) employs exact matching by sex and by region within Indiana. Heinrich et al. (2013) match exactly on sex and on state. Andersson et al. (2013) match exactly on state but find similar estimates for men and women and so pool them in their preferred specifications. Heinrich and Mueser (2014) match exactly on sex and on calendar time. Exact matching identifies particular conditioning variables thought to have such a strong effect on both treatment choice and outcomes that allowing the inexact matches implicit in the application of propensity score methods in finite samples could lead to non-trivial bias. As discussed in LaLonde (2003), the earlier literature found consistent differences in the mean

\footnotetext{
${ }^{124}$ Such a strategy would mimic the literature in criminology and the economics of crime that relies on randomly assigned judges as instruments for aspects of punishment severity. See e.g. Mueller-Smith (2015).
} 
impacts of employment and training programs on men and women; combined with the broader evidence that men and women experience the labor market differently, this motivates exact matching by sex. The clear finding that local labor markets matter in Heckman, Ichimura, Smith, and Todd (1998) motivates exact matching on geography. ${ }^{125}$ For the reasons just noted, all the studies we consider include sex, calendar time, and geography at the sub-state level as conditioning variables, even if they do not match on them exactly.

All the studies also include education (categories for years of schooling), veteran status, and disability status. Education has an extremely well-documented correlation with labor market outcomes, and also should affect participation via the opportunity cost. It should also matter for whether or not enrollees train or not as it signals the ability to successfully absorb complicated material presented in a classroom format as well as proxying for the participant's taste, or distaste, for such activities.

The two remaining major categories of conditioning variables represent recent histories of labor market outcomes (earnings and employment) in all four papers and recent histories of participation in various programs, including some or all of the ES, WIA, UI, and TANF in the Heinrich et al. (2013) and Andersson et al. (2013) papers. Heinrich et al. (2013) have the richest specification of recent program participation. Hollenbeck (2009) has a somewhat less flexible specification in terms of earnings and employment than the other two papers. ${ }^{126}$ The flexibility in all the papers builds on the notions that, first, zero earnings is different, so that indicators for zero earnings in a quarter should be included, second, that dynamics matter, so that strings of zeros and/or job loss just prior to participation matter, and, third, that variability in earnings likely

\footnotetext{
${ }^{125}$ In some cases, such as sex, a desire to present subgroup estimates also motivates the exact matching.

${ }^{126}$ The full list of conditioning variables appears in Table A-1 for both Hollenbeck (2009) and Andersson et al. (2013). The conditioning variables for Heinrich et al. (2013) appear in Table A-1 of the report that underlies their published paper, Heinrich et al. (2008).
} 
matters, which motivates inclusion of the earnings variance directly or of measures of particular types of changes in employment and earnings. Andersson et al. (2013) compare conditioning sets that include eight and 12 quarters of pre-program earnings information and find little difference in their T-ATET estimates, though given the modest differences in pre-program mean earnings they find for WIA trainees and WIA non-trainees we would hesitate to generalize this finding to the W-ATET.

The UI administrative data do not allow these researchers to distinguish between zero earnings due to unemployment and zero earnings due to absence from the labor force, which Heckman and Smith (1999) find important. They also do not allow the finer level of temporal detail - namely monthly rather than calendar quarter labor market outcomes - in the "pre" period emphasized in that paper. The empirical importance of these (relative) weaknesses in the data remains unknown. Andersson et al. (2013) do examine the value of conditioning on a set of variables related to the firm at which WIA participants most recently worked in their estimation of the T-ATET and find, to their and our surprise, that they add essentially nothing in terms of reducing selection bias (as indicated by the fact that the estimates hardly budge).

Relative to the CIA, the BSA allows for the existence of selection into WIA, or into WIA training, based on time-invariant unobserved variables. The simple model we presented above comports with the BSA, but a more general model of selection on outcome trends would not. The JTPA experimental data suggest selection on trends for some demographic groups. Coincidence between estimates based on the CSA and estimates based on BSA suggests that the available conditioning variables suffice to solve the problem of selection on time-invariant characteristics.

The four WIA evaluation papers apply somewhat different econometric estimators. Heinrich et al. (2013) apply many-to-one caliper matching followed by a linear regression bias- 
correction step. Andersson et al. (2013) use inverse propensity weighting (IPW) and single nearest-neighbor matching with replacement. Hollenbeck (2009) uses single nearest-neighbor matching with replacement and a caliper. Heinrich and Mueser (2014) also use IPW. The papers that assume both the CIA and the BSA simply replace the outcome level as the dependent variable under the CIA case with the before-after outcome difference as the dependent variable under the BSA. The methodological literature provides reasons to prefer some estimators over others. For example, Hirano, Imbens, and Ridder (2003) show conditions under which IPW attains the semi-parametric efficiency bound. IPW also avoids the troublesome bandwidth choices associated with nearest neighbor and kernel matching estimators. The Monte Carlo literature, e.g. Frölich (2004), Huber, Lechner, and Wunsch (2013), and Busso, DiNardo, and McCrary (2014), reveals that single nearest neighbor matching with replacement typically has very low bias but a high enough variance that it typically performs poorly in mean-squared-error horse races. Bias correction via ex post linear regression using the IPW or matching weights can, but need not, improve finite sample performance. At the same time, in actual applications, variation in estimates due to different econometric estimators typically pales in comparison to variation due to e.g. changes in the conditioning set; see e.g. Table 7 of Plesca and Smith (2007). The four non-experimental WIA evaluations do vary on two important dimensions: the states included in their data and the calendar time period during which the WIA participants they study participated in the program. Heinrich et al. (2013) attempted, with assistance from the US Department of Labor, to recruit all 50 states. They ended up with a non-random sample of 12. Andersson et al. (2013) attempted to recruit nine states (selected based on size and ex ante likelihood of cooperation) and ended up with just two. In both studies, the states declined to have their names attached to state-specific impact estimates, which of course makes it difficult to even 
casually link those impacts to features of state programs and economic contexts. The unwillingness of many states to provide data for high-quality evaluations provided at very low cost, or to have their state-specific impacts identified when they do, provides stark evidence of the importance of issues of monitoring and control between taxpayers as principals and state program administrators as their misbehaving agents. It also limits what studies such as these can add to our store of policy-relevant knowledge. In contrast, Hollenbeck (2009) and Heinrich and Mueser (2014) examine single, identified states, namely Indiana and Missouri, respectively.

The Andersson et al. (2013) paper has the earliest sample, which includes WIA registrants from calendar years 1999 to 2005, inclusive, with the bulk in 2000-2004. Their study thus includes the "dot com" recession of the early 2000s. Heinrich et al. (2013) study WIA registrants from July 2003 to June 2005, and Hollenbeck studies program exiters from July 2003 to June 2005; both papers thus focus exclusively on program performance in good economic times. Finally, Heinrich and Mueser (2014) focus by design on the Great Recession period by studying WIA registrants from June 2007 to June 2010. There is some European evidence from Lechner and Wunsch (2009) indicating that training programs have larger impacts in slack labor markets (due to worse comparison group outcomes), while the meta-analysis of U.S. programs in Greenberg, Michalopoulos, and Robins (2003) suggests the reverse. Either way, the time period may matter in comparing estimates among the WIA studies.

We now summarize the estimated earnings impacts from three of the four WIA nonexperimental studies. ${ }^{127}$ Given the focus of this chapter on training, the T-ATET impacts occupy most of our attention. We begin with those.

Heinrich et al. (2013) present separate estimates for men and women and, within those

\footnotetext{
${ }^{127}$ We do not present numerical estimates from Heinrich and Mueser (2014) as it has not yet been published or appeared in a formal working paper series.
} 
groups, for the adult and dislocated worker funding streams. They produce separate estimates by state and quarter; within each quarter they produce an overall impact estimate by weighting the state-specific estimates by each state's overall contribution to the trainee sample. As shown in their Figure 5, for women in the adult stream, they find a modest lock-in effect that lasts for three quarters followed by impacts that increase to around $\$ 800$ per quarter and persist until the end of their 16 quarters of post-enrollment data. For men in the adult stream, they find essentially no lock-in effect, perhaps because men who receive subsidized on-the-job training at private firms have positive impacts in early quarters that cancel out the lock-in effect (on average) of the men receiving classroom training. In later quarters, positive impacts stabilize at around $\$ 500$ per quarter; this lower absolute impact represents a much lower impact in percentage terms due to the higher average earnings of men in this population. Their Figure 8 shows that both men and women in the dislocated worker stream have large and long-lasting lock-in effects and no clear positive impacts even at the end of the sample period. All estimates of any magnitude attain conventional levels of statistical significance. Guided by a specification test, Heinrich et al. (2013) report cross-sectional matching estimates of the T-ATET; the difference-in-differences estimates of the T-ATET in report - Heinrich et al. (2008) - tell the same story.

The findings from Andersson et al. (2013) turn out similar in the large but differ in important ways in the small. Unlike Heinrich et al. (2013), they pool men and women but report separate estimates for their two states. Like them, they also separate out the adult and dislocated worker funding streams within states. The relevant estimates appear in their Tables 4A to 4D. In their state A adults experience a three-quarter lock-in effect and then see impacts that gradually rise, stabilizing at around $\$ 300$ per quarter by the time the data end at 12 calendar quarters after enrollment. In contrast, displaced workers in State A (a medium-sized state on the Atlantic 
seaboard) experience earnings losses of around $\$ 900$ per quarter initially, trailing off to "only" about $\$ 125$ per quarter. In their State B (a large, Midwestern state), the adults experience a quite similar pattern of impacts, but stabilizing at around $\$ 400$ per quarter, while the displaced workers do much better: following a very long lock-in period their impacts rise to about $\$ 300$ per quarter at the very end of the data. In addition to not finding clear differences in impacts between men and women, Andersson et al. (2013) also report looking for differential impacts by race / ethnicity and by years of schooling and not finding much differences on those dimensions either. They find that quite similar estimates emerge from their cross-sectional and difference-indifferences estimators; like them, we highlight the cross-sectional estimates. ${ }^{128}$

We can compare, in a very broad sense, the estimates of the T-ATET from these two studies to the estimates of the effect of training obtained by Heckman, Hohmann, Smith, and Khoo (2000) by applying various non-experimental estimators to the experimental data from the JTPA experiment on individuals recommended prior to random assignment to receive classroom training in occupational skills (and possibly other services not including subsidized on-the-job training), the so-called "classroom training treatment stream." The JTPA experiment randomized adult participants and not dislocated workers (JTPA having the same distinction between these as WIA). Their Table IV presents instrumental variables estimates while their Table V presents cross-sectional and before-after estimates. In a very broad sense, and one should not push farther than that given the differences in programs, geographic locations, and identification strategies, they tell the same story here of substantively important but not completely implausible impacts of training on earnings following a lock-in effect.

The W-ATET estimates in Heinrich et al. (2013) for the adult stream show positive

\footnotetext{
${ }^{128}$ Most of the impact estimates of more than $\$ 300$ in absolute value in Andersson et al. (2013) easily attain conventional levels of statistical significance but with imperfect (and likely somewhat too small) standard errors. See their note 11 for additional details.
} 
impacts for women that start around $\$ 500$ per quarter and rise to about $\$ 600$ per quarter, and impacts for men that start around $\$ 800$ per quarter and then sink fairly rapidly to around $\$ 500$ per quarter. In stark contrast, the results for the dislocated worker stream reveal large and persistent lock-in effects that last about two years, followed by approximate zero impacts for men and approximately $\$ 100$ per quarter impacts for women. All of the estimates not approximately zero attain conventional statistical significance. Based on specification tests looking at differences in pre-period earnings, the authors present cross-sectional matching estimates for the adults and difference-in-differences matching estimates for the dislocated workers, though the cross-sectional results in Heinrich et al. (2008) exhibit the same basic patterns.

Hollenbeck (2009) presents estimates of the W-ATET from Indiana using ES registrants as the comparison group. Besides being from a different state, these estimates differ in their construction from those in Heinrich et al. (2013) because Hollenbeck (2009) measures outcomes from program exit (whether WIA or ES) rather than from program start. This not only omits an important part of the lock-in period for the WIA participants - one would not expect lock-in from the employment-focused ES - but also changes relative timing, as ES tends to have shorter enrollment spells than WIA. Hollenbeck's (2009) analysis shows similar post-lock-in W-ATET impacts for adults as found in Heinrich et al. (2013), with relatively precise point estimates of $\$ 549$ in the third quarter after exit and \$463 in the seventh quarter after exit. In contrast, dramatic differences emerge in regard to the W-ATET for participants served under the dislocated worker funding stream. Here Hollenbeck (2009) finds relatively precise (the reader, unfortunately, receives stars rather than standard errors) estimates of $\$ 410$ in the third quarter after exit and $\$ 310$ in the seventh quarter after exit (the last quarter available for the full sample). Hollenbeck 
reports that in his analysis, as in Andersson et al. (2013), the conditional difference-indifferences estimates closely resembled those from cross-sectional matching; it is the latter that he anoints as his preferred estimates and which we highlight here.

Where do the earnings impacts estimated in these studies come from? Do they result from increases in wages, from "intensive margin" increases in hours worked or from "extensive margin" increases in employment? What about increases in the duration of employment spells via higher match quality and/or matches to "better" firms? The administrative outcome data used in the WIA studies allow only modest insights into the mechanisms underlying realized earnings impacts. Basically, they only allow the construction of impacts on employment, defined as nonzero earnings, and then only at the level of the calendar quarter. In each of the studies considered here, the employment estimates parallel the earnings estimates in the sense that positive earnings impacts coincide with positive employment impacts. The magnitudes relative to the earnings impacts do vary somewhat, with particularly large employment impacts relative to earnings impacts for the displaced worker W-ATET in Heinrich et al. (2013) and for both funding streams’ W-ATET in Hollenbeck (2009).

Linking the usual administrative data to the Census Bureau's Longitudinal EmployerHousehold Dynamics (LEHD) data allows Andersson et al. (2013) to estimate impacts of WIA training on the characteristics of the firms at which participants end up. They consider standard characteristics from the literature including the LEHD firm "fixed effect" (bigger is better), firm turnover (less is better) and firm size (bigger is again better). They find (see their Table 6) impacts of modest size that parallel the earnings impacts discussed above. Thus, for state by funding stream combinations with positive earnings impacts, trainees have a net improvement in employer quality in the $12^{\text {th }}$ quarter after WIA registration. 
The non-experimental literature on WIA offers the reader methodological insights, useful findings for policy, and (at least) two puzzles. For adults, both W-ATET and T-ATET turn out positive and of reasonable magnitude in every study that presents them. Those findings justify continuing to provide similar services to a similar clientele under WIOA. In contrast, the literature offers heterogeneous findings for displaced workers. This leads to the first of the two puzzles: in the Heinrich et al. (2013) and Andersson et al. (2013) papers, why do the adult and dislocated worker programs have such astoundingly different impact estimates? The puzzle only becomes more complicated upon noting that almost all dislocated worker participants could have received services under the adult stream, while many adult participants could have received services under the dislocated worker stream. Second, whence the positive impacts for dislocated workers in Indiana in Hollenbeck (2009)? A Hoosier might argue that Indiana is just special, or perhaps especially well-run, but the fact that Hollenbeck (2009) obtains similar results in two other state analyses not discussed in detail here - see his Table 5 - suggests some feature of his methodology as the culprit. Aligning participants and comparison group members relative to the timing of exit rather than the timing of enrollment represents an obvious candidate, but Table 6 of Hollenbeck (2011) yields no smoking gun. Satisfactory resolution of both puzzles awaits future research.

In addition to the four non-experimental evaluations, the US Department of Labor presently has an experimental evaluation of WIA, called the "WIA Adult and Dislocated Worker Programs Gold Standard Experiment," in the field. This evaluation compares three treatment arms for participants in the adult and dislocated worker funding streams: eligible just for core services, eligible for core and intensive services, and eligible for all services including training. The comparison between the second and third arms will provide a benchmark of sorts for the 
non-experimental evaluations that estimate the T-ATET, once adjusted for whatever level of treatment group dropout (from WIA) arises in the experiment. The WIA experiment will also provide the first experimental impact estimates for dislocated workers, who were omitted from the JTPA evaluation. As a result, it should shed some light on the puzzling difference in impacts between participants in the two funding streams in the non-experimental studies.

In sharp contrast to the site recruitment difficulties in the JTPA experiment that led to serious concerns regarding external validity, the WIA experiment has done quite well on this dimension, apparently because it imposes a lower burden on sites by randomly assigning a smaller fraction of the intake to the control group. Its 28 sites include 26 from an initial random sample of 30 plus two additional randomly chosen replacement sites. Taken together, the sites will provide a sample size of around 35,000 , substantially more than the 20,601 in the JTPA experimental sample. Results from the experiment, for which follow-up data collection is in progress as we write, should become public in 2016 . When they do, they will contribute to both our substantive and methodological knowledge in important ways. ${ }^{129}$

\section{Job Corps}

We have very good evidence on the labor market effects of the Job Corps program thanks to an extensive experimental evaluation conducted in the mid-1990s. In particular, the experiment randomly assigned eligible applicants at (almost) all Job Corps centers around the U.S. to either a treatment group eligible to receive Job Corps or to a control group excluded from Job Corps for three years. Random assignment took place from November 1994 through December 1995. The design of the (formally titled) National Job Corps Study (NJCS) overcomes two of the main

\footnotetext{
${ }^{129}$ See http://www.mathematica-mpr.com/our-capabilities/case-studies/evaluating-the-effectiveness-of-employmentand-training-services for more.
} 
issues that raised concerns about external validity in the JTPA experiment. First, by conducting random assignment at (almost) every Job Corps center, it removed concerns about non-random site selection; the fact that the Job Corps, unlike JTPA or WIA, is run directly at the federal level enabled this strategy. Second, on average the experiment assigned only about seven percent of applicants to the control group. As a result, sites did not have to recruit many additional potential participants in order to maintain the size of their operation while still filling in the control group. This reduces site burden and also reduces concerns about external validity; put differently, the NJCS can make a credible claim that the experimental impact estimates apply to the program as it normally operates. The research sample in the NJCS includes about 6,000 in the control group and about 9,400 in the treatment group; for cost reasons the evaluation collected data on only a random subset of those randomly assigned to the treatment group.

The NJCS presents an interesting treatment contrast and, in so doing, highlights issues that arise in dealing with control group substitution. Around 73 percent of the treatment group enrolled in the Job Corps, with an average enrollment duration of about eight months. Only 1.4 percent of the control group defeated the experimental protocol by enrolling in the program during the embargo period. At the same time, and not at all surprisingly given the age of the applicants and their expressed interest in programs to improve their human capital, 71.7 percent of the control group enrolled in some sort of education or training program during the 48 months after random assignment. Some treatment group members also enrolled in programs other than the Job Corps, so that in total 92.5 percent received some sort of education and training. Thus, focusing strictly on incidence, the treatment increases receipt of some education and training by about 21 percentage points. At the same time, incidence misses much of the story here due to the substantial difference in intensity. The options facing control group members do not include 
long-duration residential programs like Job Corps. As a result, the difference in mean hours of education and training between the treatment and control groups (including all the zeros) equals 710 , or about 18 weeks of full time activity.

We focus here on the "intent to treat" (ITT) impacts estimated using matched earnings records from the Social Security Administration. Schochet, Burghardt, and McConnell (2008) document non-trivial differences between these estimates and those obtained using survey data and using administrative data from state UI systems. The ITT require careful interpretation in light of the nature of the treatment contrast presented by the experiment as described above. As expected given the timing of random assignment, estimated annual impacts for calendar years 1995 and 1996 equal $-\$ 270$ and $-\$ 179$, respectively, reflecting a "lock-in” effect due to reduced job search, and thus reduced employment, while treatment group members engage with the Job Corps. The estimated annual impacts turn positive in 1997 and 1998, equaling \$173 and \$218, respectively. ${ }^{130}$ All four estimates achieve conventional levels of statistical significance. Consistent with the earnings impacts, the evaluation finds positive impacts on measures of job quality as of the $16^{\text {th }}$ quarter after random assignment. Finally, the Job Corps also affected criminal behavior, measured as arrest and conviction rates. ${ }^{131}$ The headline: the Job Corps, nearly alone among employment and training programs for youth, has positive and substantial impacts on labor market outcomes. Comparison with the JOBSTART program found ineffective by Cave, Bos, Doolittle, and Toussaint (1993), which provided (more or less) a non-residential version of the Job Corps, suggests the importance of the residential aspect of the program.

\footnotetext{
${ }^{130}$ See Schochet, Burghardt and Glazerman (2001) for discussion of the finding of larger impacts for older participants and Flores-Lagunes, Gonzales, and Neumann (2008) for discussion of the lack of strong impacts among Hispanic participants.

${ }^{131}$ The big picture findings from the NJCS echo those of the earlier non-experimental evaluation documented in Long, Mallar, and Thornton (1981) and Mallar, Kerachsky, Thorton, and Long (1982).
} 
McConnell and Glazerman (2001) present a careful and comprehensive cost-benefit analysis. Job Corps costs a lot: about $\$ 16,500$ per participant in 1995 dollars. As a result, because the earnings impacts fade out over time as control group earnings catch up to treatment group earnings, it fails to pass a social cost-benefit test despite having positive impacts on both labor market and criminal justice outcomes. It does (easily) pass a cost-benefit test from the perspective of participants. Thus, the Job Corps presents a glass half full, but in a desert of dismal evaluation results for youth, that means something, and at the least suggests directions for future innovations in program design.

\section{Trade Adjustment Assistance (TAA)}

TAA recently received a thorough non-experimental evaluation using a "selection on observed variables" identification strategy building on a combination of survey and administrative data. The survey data allow a (somewhat) richer, and thus more compelling, set of conditioning variables than those in the WIA evaluations. On the other hand, the complicated structure of the TAA program makes the non-experimental evaluation task substantially more challenging than for WIA. In the end, Schochet et al. (2012) have produced valuable evidence by optimizing within the design constraints, but substantial uncertainty remains.

The evaluation focuses primarily on the impact of receiving "significant TAA services" for a sample of workers certified under TAA between November 1, 2005 and October 31, 2006 from 26 states and with UI claims starting in a wider window around that year as allowed in the law in effect at that time. ${ }^{132}$ UI claimants from the same time periods and the same local labor markets not certified under TAA constitute the comparison group. Significant TAA services

\footnotetext{
${ }^{132}$ The evaluation calls this the "certified-worker participant sample." Analyses using alternative definitions of the TAA treatment (and thus alternative samples of treated individuals) reach similar substantive conclusions.
} 
means more than just "light-touch TAA services or One-Stop core services provided through WIA or ES"; the evaluation measures service receipt using both administrative data and survey reports.

Not surprisingly given that TAA provides UI benefits and trade readjustment allowances (TRA) over a longer time period than for the comparison group and encourages longer-term training, TAA participants experience relatively long-lasting lock-in effects. In particular, in the first four quarters, Table 1 of Schochet et al. (2012) shows that the matched comparison group averaged 19.4 weeks of employment and $\$ 12,674$ in earnings more than the participants. The negative impacts fade out over time but never entirely disappear during the four-year follow-up period. For example, in quarters 13-16, the matched comparison group averages 2.0 more weeks of work and \$3,273 more in earnings than the participants. Subgroup analyses reveal less negative effects for younger TAA participants and no substantive difference between men and women. While the evaluation includes a (truly) extensive collection of sensitivity analyses on many dimensions, the question of whether the job loss that leads the participants into TAA might have more persistent consequences than the job losses among the comparison group lingers, though it would require an implausibly large difference to save the TAA program in a costbenefit sense.

\section{Other programs}

A variety of other programs, some large and most small, exist and have received some evaluative attention. ${ }^{133}$ We have chosen to focus on larger programs with relatively high quality evaluations and on programs operated via the Department of Labor. Our focus leaves out the many welfare-

\footnotetext{
${ }^{133}$ See http://wdr.doleta.gov/research/keyword.cfm for a partial list as well as the discussion around Table 8.7.
} 
to-work programs discussed in Ziliak (2015) and in Greenberg and Robins (2011) as well as the Food Stamp / SNAP employment and training programs evaluated in Puma and Burstein (1994). It also omits "sectoral training" programs under which taxpayers provide training for particular firms or small groups of firms, as in Maguire et al. (2010) as well as studies of vocational training provided by the community college system not financed by WIA or TAA, as in Jacobson, LaLonde, and Sullivan (2005). Finally, we also omit many evaluations with methodological, data, or sample size issues such as the Eyster et al. (2010) evaluation of the High Growth Job Training Initiative (HGJTI). ${ }^{134}$

\section{Program operation issues}

As we have noted along the way, in our view the literature spends relatively too much effort on estimating the ATET for programs that will, for various political reasons, never go away no matter what their ATET looks like, and relatively too little time providing compelling evidence on ways to operate the programs so that they will have larger ATETs than they presently do. In this section, we discuss some of what we do and do not know about program operation issues under three broad headings: performance management, program participation (i.e. how potential participants find their way to programs), and how participants get matched to particular services within programs and to jobs after they finish programs.

\section{Performance management}

The Department of Labor's flagship employment and training programs have played an important role in the intellectual and institutional development of federal performance

\footnotetext{
${ }^{134}$ Of course, the authors of these evaluations typically have a very clear sense of these issues, which often arise from institutional, political and data limitations beyond their control.
} 
management, starting with initial efforts under the CETA program. JTPA and WIA featured quantitative performance management systems operating at both the state and local levels that included financial incentives for good performance as well as potential penalties for poor performance; WIOA retains the WIA system with some modest modifications. ${ }^{135}$ Courty and Marschke (2011a) provide a detailed description of the JTPA system, and Heinrich (2004) does the same for WIA.

One can think about the performance management systems for U.S. governmentsponsored training programs as trying to accomplish two things: (1) provide quick and inexpensive proxies for impact estimates that would otherwise take a long time and cost a lot of money; (2) motivate program staff to work harder (i.e. apply more effort) and to work smarter (i.e. to figure out how to make a given amount of effort yield a higher payoff via changes in how the program operates). Success on the second task requires success on the first, for if the performance measures do not proxy effectively for impacts (i.e. changes in labor market outcomes relative to a counterfactual) then pressing programs to do well on them may reduce, rather than increase, their economic efficiency.

Concerns about performance measures in the economics literature center on three issues. The first is the correlation between the performance measures and program impacts. Here, the available evidence suggests concern, if not alarm, as the literature provides essentially no evidence of such a correlation; see in particular Barnow (2000) and Heckman, Heinrich, and Smith (2002) for studies that make use of the data from the JTPA experiment and Schochet and Burghardt (2008) for evidence from the Job Corps experiment.

\footnotetext{
${ }^{135}$ The most notable change concerns the reinstatement of regression adjustment of the performance measures based on participant characteristics. JTPA used such adjustments but WIA did not. Intuitively, regression adjustment aims to present local training centers with a level playing field, though one might argue that conditioning on the characteristics of the eligible population, rather than of the chosen participants, would do this better. See the discussion in Eberts, Bartik, and Huang (2011).
} 
The second concern springs from the literature on principal agent models when agents have multiple tasks; see, e.g., Dixit (2002) for an overview in a public sector context. This literature teaches that what gets rewarded gets done. If the government, acting on behalf of the taxpayer, wants training program staff to do five tasks, but the performance management system rewards only two of them, then we would expect to see training centers do a lot of those two and not much of the other three. Thus, for example, performance measures based on labor market outcomes in the relatively short run (e.g., anytime in the first year after participation) should lead programs away from services that have long-run impacts at the cost of short run reductions in outcomes, such as training in a new occupation, and toward services that improve short-run outcomes, such as job search assistance, regardless of their effect on long-run impacts.

The third concern centers on strategic responses to performance management. These include cream-skimming, the literature's term for selecting participants based on their expected outcome with training (i.e., $\left.Y_{1}\right)$ rather than based on expected impacts from training (i.e., $Y_{1}-Y_{0}$ ), where the latter maximizes the (economic) efficiency of the program. This concern follows immediately from the fact that, as described earlier, existing performance measures consist entirely of variants of $Y_{1}$.

Other potential strategic responses include manipulating the timing and incidence of formal enrollment as well as the timing of formal termination from the program in response to performance measures that include only those formally enrolled and which measure outcomes over defined program years. Under the nonlinear reward functions common in job training programs, it can make sense to reallocate weak trainees over time to particular periods by manipulating the timing of enrollment and termination. Suppose, for example, that a training center gets rewarded for an entered employment rate that exceeds 0.80 by any amount in a given 
program year, but that, absent a strategic response, it has a rate of 0.78 in every program year. If it can manipulate the program year in which marginal trainees count toward the performance measure so as to alternate its entered employment rate between 0.76 and 0.80 , it becomes better off under the performance management system, but without actually improving labor market outcomes in any way (and perhaps with an expenditure of real resources on the strategic response). The literature provides a wealth of compelling empirical evidence on both crude and also remarkably subtle responses to the incentives implicit in the performance management systems of U.S. job training programs: see Courty and Marschke (2011b) for an overview as well as Barnow and King (2005). See Barnow and Smith (2004) and Heckman et al. (2011) for more extensive summaries of the literature on performance management in U.S. employment and training programs, Radin (2006) for a critique from outside economics that emphasizes different concerns than we do here, and Wilson (1989) for a thoughtful presentation of the underlying problems of public management that motivate performance management.

\section{Program participation}

Studies of program participation consider how individuals come to participate in social programs. Such studies have interest for several reasons. First, program participation represents a choice, and economists (and other social scientists) like to understand the choices individuals make. Second, understanding how individuals choose to participate in programs aids in program design and targeting. Third, an understanding of the participation process provides the foundation for credible non-experimental evaluation. Fourth, it also informs discussions of external validity to the set of eligible non-participants. Fifth, program operators (and voters) may care about the equity with which programs services get distributed to particular identifiable 
groups within the eligible population. Currie (2006) reviews the literature on program participation.

In an institutional sense, participants find government-sponsored training programs in a variety of ways. They may get a referral from a friend or neighbor or from a social worker or caseworker in another program. They may, as the government hoped when it mandated colocation, head to the One-Stop center for some other purpose and, once there, find the lure of the current employment and training program impossible to resist. They may get referred by service providers, as when individuals seeking vocational training at their local community college get sent to the WIOA office to try to obtain funding for that endeavor. In contrast, some participants participate due to a requirement rather than a choice. For example, 9.5 percent of those randomized in the JTPA experiment report that a welfare program required them to participate and 0.5 percent report a court doing so. The Worker Profiling and Reemployment Services (WPRS) program and the Reemployment and Eligibility Assessment (REA) program require some UI claimants to participate in reemployment services (sometimes but not often including training) or risk disqualification for benefits. Finally, among those who make it into a program, actual enrollment depends in part on caseworker behavior. They may, perhaps out of goodwill and perhaps out of a desire to improve their measured performance, discourage some potential participants from enrolling by requiring additional visits to the one-stop center or by referring them to alternative services, while encouraging others. Heckman, Smith, and Taber (1996) find that caseworkers at the JTPA center in Corpus Christi, Texas appear to emphasize equity concerns rather than performance concerns in the process by which applicants became enrollees, a process that also includes applicant self-selection.

Standard economic models of participation tend not to emphasize these institutional 
features. Instead, as with the simple model we discussed earlier, they focus on more abstract notions of opportunity costs and expected benefits. Individuals participate when they face low costs to doing so, due to either ongoing skills deficits or transitory labor market shocks such as job loss, and when they expect large impacts from doing so. ${ }^{136}$ They may also view participation as a form of assisted job search, either literally, as when receiving job search assistance or subsidized on-the-job training at a firm, or figuratively, as when new skills learned in classroom training improve the frequency or quality of job offers. The literature also includes some informal discussion of the possible importance of credit constraints due to the absence of stipends or other payments for training participants in most current programs - the Job Corps is an exception in providing room and board - and the resulting value of alternative sources of financial support such as transfers or family support during training. The potentially crucial role of information, both in making the possibility of participation salient enough to induce explicit choice and in the sense of forming ideas about potential benefits, has played little role in the theoretical literature on training participation and only a very modest role in the empirical literature, as we describe next.

The empirical literature consists primarily of multivariate studies of the observed determinants of participation, with the determinants including demographics, human capital variables, past labor market outcomes and so on. The estimated reduced form effects of these variables then get interpreted in light of the sorts of theories just described. For example, a negative coefficient on age would suggest that younger workers perceive a higher benefit to participation due to more time over which to realize any earnings gain the training provides. In

\footnotetext{
${ }^{136}$ Ashenfelter (1983) emphasizes that for particularly attractive means-tested programs, potential participants may choose to reduce their opportunity cost of participation (e.g. by quitting a job) in order to qualify while Moffitt (1983) adds stigma to the participation cost-benefit calculation. We suspect that neither factor plays much role in the training context.
} 
some cases, the participation model functions mainly as an input into estimation of treatment effects via some estimator based on the propensity score, rather than as the primary object of interest in the study.

Several such studies look at the JTPA program. Anderson et al. (1993) examine participation in JTPA in Tennessee by comparing program records on enrollees with a sample of eligibles constructed from the Current Population Survey - a very imperfect enterprise for reasons outlined in Devine and Heckman (1996)'s study of the JTPA-eligible population. Their multivariate analysis reveals blacks, high school dropouts, and individuals with disabilities as underrepresented among participants, which they interpret as evidence of cream-skimming resulting from the JTPA performance standards.

Heckman and Smith (1999) study the JTPA participation process using rich data on experimental control group members and eligible non-participants at four of the sites in the JTPA experiment. Their headline findings concern the importance of labor force status transitions in the months leading up to the participation decision in determining participation, especially transitions to unemployment. These transitions need not entail a simultaneous change in earnings, as when an individual goes from "out of the labor force" to "unemployed" by initiating job search. This finding in turn suggests that analyses that rely solely on earnings and employment may miss an important part of the participation picture (and so may end up with biased impact estimates as well). Their analysis also highlights the importance of family factors, including marital status and family income, in determining participation, along with the usual suspects identified in other studies, such as age (declining) and education (hill-shaped).

Finally, Heckman and Smith (2004) combine the data from the National JTPA Study with data from the Survey of Income and Program Participation (SIPP) to decompose the process that 
leads from JTPA eligibility to JTPA enrollment into a series of stages: eligibility, awareness, application, acceptance (defined to mean reaching random assignment), and enrollment. Though descriptive in nature, the analysis reveals a number of important findings. First, decomposing the steps from eligibility to enrollment reveals that for some groups the key stage is program awareness, rather than enrollment conditional on application or acceptance. This adds nuance to the findings in the Anderson et al. (1993) paper and signals that substantively important differences in participation conditional on eligibility among groups arise from factors other than the incentives implicit in the performance management system. Second, looking at the stage from acceptance to enrollment - the stage over which program staff has the most influence does suggest some role for the performance management system as individuals with characteristics that predict relatively weak labor market outcomes have lower probabilities of enrollment. Finally, simply making a particular group eligible for a program does not mean that they will take it up.

We know of only one such study for WIA, namely the analysis in Andersson et al. (2013). Andersson et al. (2013) present both univariate and multivariate analyses (see their Table 3) of the characteristics of WIA enrollees that predict receipt of training. In particular, they find that younger enrollees have a greater chance of receiving training, which makes sense in terms of the basic advice of the lifecycle human capital model. They also find a hill-shaped conditional pattern by years of schooling, with those in the middle of the distribution, i.e. those with a high school diploma or some college, having the highest probability of training. This makes sense as well. Many training courses require high school completion and, even if they do not, they may require mastery of relatively technical written material. At the upper end of the distribution, college graduates likely have little need for further training in general (or may have 
other issues that training will not fix). Finally, while Andersson et al. (2013) find differences in univariate training chances between whites and non-whites, these largely disappear in the multivariate analyses.

In our view, participation in both employment and training programs in general and in the training components of those programs in particular remains fertile ground for additional research. In particular, the role of information in leading to program awareness and then to participation, the formation of ex ante beliefs about likely program impacts, the determinants of the timing of training within spells of unemployment or non-employment, and the role of other family members merit further researcher attention.

\section{Matching participants to services}

Large general employment and training programs such as JTPA, WIA, and WIOA face the complicated problem of matching particular participants to particular services. Even within broad service types, such as classroom training or subsidized on-the-job training, this represents a nontrivial problem. A given program office may have several different classroom training providers offering programs of varying lengths and varying skill prerequisites that aim to prepare trainees for a variety of different occupations as well as an array of heterogeneous employers willing to consider program participants for subsidized on-the-job training slots. This section briefly reviews the (remarkably) small extant literature in economics that considers different ways to match participants with services.

Caseworkers play a pivotal role in matching participants to services in the major U.S. employment and training programs (as they do elsewhere in the developed world). Typical motivations for this practice revolve around information asymmetries between the caseworker 
and the participant due to the caseworker's superior knowledge of local service providers, of local labor market conditions (e.g. occupations in demand), and (more speculatively) of the best matches, in terms of earnings and employment impacts, between participant characteristics and preferences and particular services and occupations. ${ }^{137}$

We have only very limited evidence in the United States (and not much more elsewhere) regarding how and how well caseworkers assign participants to services. The JTPA experiment and Andersson et al.'s (2013) WIA observational study both provide some information regarding what caseworkers believe about optimal service assignment rules. For example, Kemple, Doolittle, and Wallace (2003) find a number of ex ante reasonable patterns in univariate analyses for adults using the JTPA experimental data: (1) participants without a high school diploma or GED have a higher probability of assignment to adult basic education and a lower probability of assignment to classroom training in occupational skills; (2) participants receiving cash assistance, who thus have a source of income during training other than work, are more likely to receive classroom-based services; and (3) participants with limited work experience have a lower probability of assignment to job search assistance and subsidized on-the-job training (the latter of which requires a willing employer). Smith (1992) and Plesca and Smith (2007) provide further analyses using the JTPA data, while the Andersson et al. (2013) findings described in detail in our discussion of the determinants of participation in training provide evidence for the WIA program. Taken together, the analyses from the JTPA and WIA programs suggest that caseworkers have some reasonable ideas about service assignment as a function of participant characteristics, with the caveat that in both programs caseworkers take client interests and

\footnotetext{
${ }^{137}$ Caseworkers also perform a number of other functions, including referring participants to other services such as substance abuse programs, transfer programs and so on, helping participants clarify their interests and abilities, providing informal instruction in job search, monitoring eligibility and search intensity, and so on. Bloom et al. (2003) investigates some of these other aspects of the caseworker role.
} 
preferences into account, so that the observed patterns reflect the views of both groups.

A different line of research estimates heterogeneous treatment effects as a function of observed participant characteristics using experimental or observational variation and then uses those estimates to examine how well, or how poorly, existing caseworker service assignment patterns do relative to the minimum and maximum impacts possible given the estimates. Plesca and Smith (2005) undertake this exercise using the JTPA experimental data and consider assignment to the three experimental "treatment streams" based on services recommended prior to random assignment. They find benefits from assigning treatment stream using a statistical treatment rule based on estimated impacts relative to caseworker assignment. Lechner and Smith (2007) perform a similar exercise using observational data (with larger samples) from Switzerland and find that caseworkers do about as well as random assignment to treatment, and thus leave substantial potential gains on the table. Their paper emphasizes the importance of respecting capacity constraints under alternative allocation schemes. McCall, Smith, and Wunsch (2015) summarize the broader European literature, which reaches an overall conclusion similar to that of Lechner and Smith (2007).

A pair of experiments provides further evidence on caseworker performance at the service assignment task. Bell and Orr (2002) analyze the AFDC Homemaker-Home Health Aide Demonstrations. In that study, caseworkers predicted both the untreated outcome and the impact for each experimental sample member prior to random assignment. Interacting the treatment indicator with the impact prediction in the impact estimation reveals that caseworkers in this context have no idea who will benefit from training as a homemaker / home health aide. They do a much better job at predicting untreated outcome levels. This experiment shows what caseworkers know about the impact of one particular treatment, which is related to, but not the 
same as, picking the service with the highest expected impact. We think more experiments should undertake exercises like this one.

The second experiment, reported in Perez-Johnson, Moore, and Santillano (2011) compares alternative administrative models for delivering ITAs using a sample of WIA enrollees determined eligible for ITAs in eight sites in six states. ${ }^{138}$ The experiment included three treatment arms: structured choice, guided choice, and maximum choice, which differed primarily on three dimensions. First, under structured choice, but not the other two arms, the caseworker had veto power over training choices. Second, under structured choice, but not the other arms, the caseworker had discretion over the dollar value of the ITA. Third, the amount of counseling regarding the training choice varied from mandatory and substantial under structured choice, to mandatory and less intensive under guided choice, to optional under maximum choice. In all treatment arms, the eligible training provider list and any local rules about in-demand occupations constrained the training choices.

Operationally, the caseworkers were reluctant to be as directive regarding client training choices as envisioned in the original design for the structured choice treatment arm. Instead, according to Perez-Johnson, Moore, and Santilano (2011, pg. xxvii) caseworkers "tended to award Structured Choice customers' ITAs that enabled them to attend their preferred training programs." For this reason, program costs for the structured choice arm proved higher than for the other two arms. Potential trainees in the maximum choice arm largely opted out of counseling, providing a revealed preference evaluation of that service at the margin. A larger fraction of those in the maximum choice arm used ITAs, but overall training rates (including both ITA-funded and other training) and the occupational mix of training differed little across the three treatment arms. Enrollees in the structured choice and maximum choice arms had

\footnotetext{
${ }^{138}$ See also the earlier reports by McConnell et al. (2006) and McConnell, Decker and Perez-Johnson (2006).
} 
substantively and statistically larger probabilities of completing a training course and of earning a credential.

Earnings and employment outcomes differ somewhat between the survey data and the administrative data from state UI records. The report gives (somewhat unusually, relative to the literature) greater weight to the survey data, while we lean toward giving them equal weight. In the survey data, the constrained choice arm shows the highest earnings over all post-program periods, with a difference of about $\$ 500$ per quarter in the final two years of follow-up (roughly 2008-2009) relative to the guided choice arm and about $\$ 250$ per month relative to the maximum choice arm, though the latter difference fails to attain traditional levels of statistical significance. In contrast, in the administrative data reveal only small differences in labor market outcomes: for example, in the final two years of the follow-up period (calendar years 2008-2009), average quarterly earnings equal $\$ 4818, \$ 4713$, and $\$ 4734$ for the structured choice, guided choice and maximum choice arms, respectively, with none of the differences statistically significant. Overall, Perez-Johnson, Moore, and Santilano (2011) conclude that the stronger impact performance of the structured choice arm has more to do with the larger dollar value of the ITAs in that arm than with caseworker value-added. At the same time, the marginally better performance of the maximum choice arm relative to the guided choice arm, a contrast that highlights the value-added of the caseworkers as these arms both included the same relatively low cap on ITA value, suggests that caseworkers add little if any value in their informational role. $^{139}$

The leading alternative to having caseworkers assign participants to services consists of allowing participants to assign themselves to services, typically via some form of voucher, such

\footnotetext{
${ }^{139}$ An additional, less direct, way to evaluate the match between trainees and training measures the extent to which trainees end up in jobs directly related to their training as in Park (2012). The key issue in this approach relates to the benchmark - how much mismatch is too much, given that the optimum is not 100 percent?
} 
as the ITAs under WIA. The literature refers to this as demand-driven assignment. Arguments in favor of demand-driven assignment include (1) participants likely have private information about their tastes and abilities that allow them to make better matches than caseworkers; (2) participants may work harder and be more likely to complete programs and courses they choose for themselves; and (3) participant choice may put more competitive pressure on providers to do a good job. As noted in our discussion of the ITA experiment just above, ITAs under WIA typically embody a combination of caseworker input and participant choice, within the constraints of the eligible provider list.

The literature offers only limited evidence regarding vouchers in the training context. The ITA experiment described just above represents the best we have. Reframed from the voucher perspective, it shows that more flexible vouchers (i.e. vouchers less constrained by caseworkers and program rules) increase training incidence somewhat, do not change the mix of training very much, and marginally improve outcomes relative to the status quo of guided choice. Barnow (2009) provides a survey of the older U.S. literature that emphasizes thinking about a continuum of options with varying degrees of customer control and program guidance and limitation. McCall, Smith, and Wunsch (2015) include the somewhat larger European literature in their survey. Based on our reading, the literature suggests surprisingly modest effects of additional customer choice on impacts but some impact on customer satisfaction. Additional research on how participants use information in making choices, and on the effects of additional types of information on choices and outcomes, represents a logical next step.

In addition to participants and caseworkers, institutional factors also play an important role in determining service assignments. First, the law typically encourages programs to offer training in occupations actually in demand in the local labor market; under WIA, local programs 
vary in how, and how enthusiastically, they implement this aspect of the law. Second, the availability of local service providers constrains the set of available options; as a result, for example, WIA programs in urban areas typically offer a broader array of training options than those in rural areas. The reluctance of some providers to jump through the hoops required to get on the eligible provider list described earlier in our discussion of WIA implementation further limits the available options in some areas. Finally, broader institutional enthusiasm for particular services or service sequences, as with the "core then intensive then training" sequence in the WIA program, have an influence on service patterns. ${ }^{140}$

The literature suggests that caseworkers do not add much value in directing participants into particular services or trainees into particular training courses. This does not mean that they could not do better and it could just mean that they seek to maximize something else, such as equity or measured performance, instead of value-added. It also does not mean that they do not add value in their other roles - see, e.g., Rosholm (2014) and the broader discussion in McCall, Smith and Wunsch (2015). We still have much to learn regarding this dimension of the training provision process.

\section{Summary and conclusions}

The United States continues to spend relatively little on employment and training programs in general or on government-sponsored training more narrowly than most other developed countries. It remains unclear which countries (if any) have found the optimum. The years since LaLonde (2003) have seen some valuable research on employment and training programs in the U.S., but the quantity of high quality work remains low. We conjecture that this lack results from

\footnotetext{
${ }^{140}$ A small literature considers, with a combination of theory and calibration, the optimal mix of broad service categories and their interaction with the design of social insurance and transfer programs. See e.g. Wunsch (2013) and the references therein.
} 
both the relatively small budgetary footprint of this program category as well as from data and data access limitations. Taken together, the recent evidence presents a mixed but somewhat disheartening picture. WIA training and WIA overall have fairly robust positive earnings effects for both men and women served under the adult funding stream, effects that tend to pass costbenefit tests under reasonable assumptions. In contrast, WIA training and WIA overall appear to have a negative effect on individuals served under the dislocated worker funding stream. We find the available non-experimental evidence a bit more compelling for WIA training versus WIA without training than for WIA versus no-WIA and the findings for adults appear more robust to mildly different design decisions and/or to the set of states studied than the findings for dislocated workers. More attention to explaining the differences across states and streams would have great value; perhaps the ongoing WIA experimental evaluation will shed some light.

The TAA analysis reveals that we should perhaps seek a more efficient way to compensate workers who suffer individually while the public benefits from reduced trade barriers. The Job Corps experiment highlights the potential value of immersive, residential treatments in changing the outcomes of youth, while at the same time the fact that any positive impacts, even ones that end up not passing a cost-benefit test, elicit cheers from the audience reinforces the difficulty of the underlying task.

Given the demonstrated inability of the U.S. political system to kill even programs with dismal evaluation track records stretching over decades, future evaluation research should focus relatively more on impacts on marginal participants, which would inform decisions to increase or decrease program budgets at the margin, and on ways to improve program design, implementation and performance management, as with the WIA ITA experiment.

The last two decades have seen a major "data gap" emerge between the United States and 
various central and northern European countries. The administrative data available for research on government-subsidized training programs in the United States pales in comparison to that available in e.g. Germany, Sweden, or Denmark in its quality (i.e. richness of individual characteristics, temporal fineness of outcome variables, lack of measurement error in the timing and incidence of service receipt and enrollment, etc.), the ease with which serious researchers can gain access to it, and the ease with which they can use it if they do gain access. These limitations associated with administrative data in the United States mean that much policyrelevant research that would improve our understanding of training programs does not get done. This research would often cost the government little or nothing as graduate students and professors would do it in order to generate publishable papers for which they receive indirect compensation.

At the same time, it remains essentially impossible to undertake evaluations of job training programs using standard social science data sets in the United States due to sample size issues in the major panel data sets (e.g. the Panel Study of Income Dynamics) and due to measurement issues (especially poor measurement of program participation) in both the crosssectional data sets and the panel data sets. Matching of administrative data on participants to one or more of the major surveys - we suggest the SIPP, which combines relatively large sample sizes with a short panel and detailed information on earnings and program participation - could address the measurement issues at relatively low cost, and allow the generation of important new knowledge about how the citizenry interacts with these programs.

Other areas where data remain weak in the U.S. context could be addressed with less controversy. While the Department of Labor provides some information about variation in state UI programs over time, similar (and, ideally, more comprehensive) information on many other 
programs such as WIA (and now WIOA), the Worker Profiling and Reemployment Services System (WPRS), and the Reemployment and Eligibility Assessment (REA) program does not exist to our knowledge. ${ }^{141}$ Providing it would facilitate research on these specific programs and on the system of active and passive labor market programs as a whole. Also valuable, as noted earlier, would be improved information on program costs, on average and at the margin, for different types of services, for different types of clients, and in different locations. The intersection between community colleges and employment and training programs would also benefit from improved data; at present community college data do not indicate which students have their courses paid for by programs such as WIA and neither the aggregated WIA data available to the public nor the WIA administrative records typically provided to researchers indicate the identity of individual service providers. The intersection between workforce development programs and the community college system has great substantive importance; having the data required for serious research would allow evidence-based policy to improve it.

On the methods side, the United States continues to lead the world in the evaluation of government-sponsored training programs via large scale social experiments. Both the Job Corps experiment and the WIA experiment solve important problems regarding site selection and external validity that arose in the earlier JTPA experiment. The non-experimental evaluations of WIA and TAA reflect, to the extent allowed by the data, recent advances in the literature on nonparametric and semi-parametric estimation of treatment effects. European studies of the value of particular conditioning variables have served to make these U.S. studies more credible by showing that some of the variables absent in the United States do not add that much in terms of bias reduction. On the negative side, the tidal wave of compelling studies of educational

\footnotetext{
${ }^{141}$ See http://www.unemploymentinsurance.doleta.gov/unemploy/statelaws.asp for the DOL information on state UI
} laws. 
interventions using regression discontinuity designs over the past decade has no analogue in the job training literature due to the on-going failure to "design in" usable discontinuities in this policy domain. Similarly, the federal government often misses opportunities for staged roll-outs of programs, which would allow the application of standard panel data estimation methods.

Finally, we note the potential for institutional reform in the broad sense, designed to embody an alternative vision of what Smith (2011) calls "evaluation policy." The success of the Department of Education's Institute for Education Sciences (IES) at generating truly remarkable improvements in the quality of official evaluations of educational interventions (and, indeed, in the entire academic literature that evaluates educational interventions) suggests consideration of a similar institution in the world of active labor market programs. ${ }^{142}$ Similarly, the success of the requirement that tied rigorous evaluation to the granting of waivers under the old AFDC program in the 1980s and 1990s suggests a similar scheme for allow states to innovate in their workforce systems in exchange for providing the public good of high-quality evidence.

\footnotetext{
${ }^{142}$ See Institute of Education Sciences (2008) for more on the IES success story.
} 


\section{References}

Abadie, Alberto, Joshua Angrist, and Guido Imbens. 2002. "Instrumental Variables Estimates of the Effects of Subsidized Training on the Quantiles of Trainee Earnings." Econometrica 70(1): 91-117.

Anderson, Kathryn, Richard Burkhauser, and Jennie Raymond. 1993. "The Effect of Creaming on Placement Rates under the Job Training Partnership Act." Industrial and Labor Relations Review 46: 613-24.

Andersson, Fredrik, Harry Holzer, Julia Lane, David Rosenblum, and Jeffrey Smith. 2013. "Does Federally-Funded Job Training Work? Nonexperimental Estimates of WIA Training Impacts Using Longitudinal Data on Workers and Firms.” NBER Working Paper No. 19446.

Angrist, Joshua, Guido Imbens, and Donald Rubin. 1996. "Identification of Causal Effects Using Instrumental Variables." Journal of the American Statistical Association 91(434): 444-455.

Angrist, Joshua and Alan Krueger. 1999. "Empirical Strategies in Labor Economics.” In Orley Ashenfelter and David Card (eds.) Handbook of Labor Economics, Volume 3A. Amsterdam: North-Holland. 1277-1366.

Angrist, Joshua and Jorn-Steffen Pischke. 2010. "The Credibility Revolution in Empirical Economics: How Better Research Design Is Taking the Con out of Econometrics." Journal of Economic Perspectives 24(2): 3-30.

Ashenfeltcr, Orley. 1978. "Estimating the Effect of Training Programs on Earnings." Review of Economics and Statistics 6(1): 47-57

Ashenfelter, Orley. 1983. "Determining Participation in Income-Tested Social Programs," Journal of the American Statistical Association 78: 517-525.

Balducchi, David, Terry Johnson ,and Mark Gritz. 1997. "The Role of the Employment Service.” In Christopher O'Leary and Stephen Wandner (eds.) Unemployment Insurance in the United States: Analysis of Policy Issues. Kalamazoo, MI: W.E. Upjohn Institute for Employment Research. 457-504.

Barnow, Burt. 1987. "The Impact of CETA Programs on Earnings: A Review of the Literature." Journal of Human Resources 22(2): 157-193.

Barnow, Burt. 1993. "Thirty Years of Changing Federal, State, and Local Relationships in Employment and Training Programs." Publius: The Journal of Federalism 23(3): 75-94.

Barnow, Burt. 2000. "Exploring the Relationship between Performance Management and Program Impact: A Case Study of the Job Training Partnership Act." Journal of Policy Analysis and Management 19(1): 118-141. 
Barnow, Burt. 2009. "Vouchers in U.S. Vocational Training Programs: An Overview of What We Have Learned.” Journal for Labor Market Research 42: 71-84.

Barnow, Burt. 2011. "Lessons from the WIA Performance Measures." In Douglas Besharov and Phoebe Cottingham (eds.) The Workforce Investment Act: Implementation Experiences and Evaluation Findings. Kalamazoo, MI: W.E. Upjohn Institute for Employment Research. 209231.

Barnow, Burt, and David Greenberg. 2015. "Do Estimated Impacts on Earnings Depend on the Source of the Data Used to Measure Them? Evidence from Previous Social Experiments." Evaluation Review 39(2): 179-228.

Barnow, Burt and Hobbie, Richard (eds.). 2013. The American Recovery and Reinvestment Act: The Role of Workforce Programs. Kalamazoo, MI: W.E. Upjohn Institute for Employment Research.

Barnow, Burt and Christopher King. 2005. The Workforce Investment Act in Eight States. Report Prepared for U.S. Department of Labor, Employment and Training Administration.

Barnow, Burt and Demetra Nightingale. 2007. "An Overview of U.S. Workforce Development Policy in 2005." In Harry Holzer and Demetra Nightengale (eds.) Reshaping the American Workforce in a Changing Economy. Washington, DC: Urban Institute Press.

Barnow, Burt, and Jeffrey Smith. 2004. "Performance Management of U.S. Job Training Programs" in Christopher O'Leary, Robert Straits and Stephen Wandner (eds.), Job Training Policy in the United States, Kalamazoo, MI: W.E. Upjohn Institute for Employment Research, 21-56.

Barnow, Burt and John Trutko. 2015. "The Value of Efficiency Measures: Lessons from Workforce Development Programs.” Public Performance and Management Review 38: 487-513.

Baum, Sandy, Diane Cardenas Elliott, and Jennifer Ma. 2014. Trends in Student Aid 2014. New York, NY: College Board.

Bell, Stephen and Larry Orr. 2002. "Screening (and Creaming?) Applicants to Job Training Programs: the AFDC Homemaker-Home Health Aide Demonstrations." Labour Economics 9: 279-301.

Bell, Stephen, Larry Orr, John Blomquist, and Glen Cain. 1995. Program Applicants as a Comparison Group in Evaluating Training Programs. Kalamazoo, MI: W.E. Upjohn Institute for Employment Research.

Betsey, Charles, Robinson Hollister, and Mary Papageorgiou (Eds.). 1985. Youth Employment and Training Programs: The YEDPA Years. Washington, DC: National Academies Press

Bitler, Marianne, Jonah Gelbach, and Hilary Hoynes. 2005. "Distributional Impacts of the SelfSufficiency Project.” NBER Working Paper No.11626. 
Bitler, Marianne, Jonah Gelbach, and Hilary Hoynes. 2006. "What Mean Impacts Miss:

Distributional Effects of Welfare Reform Experiments." American Economic Review 96: 988-1012.

Black, Dan, Jose Galdo and Jeffrey Smith. 2007. "Evaluating the Worker Profiling and Reemployment Services System Using a Regression Discontinuity Design." American Economic Review Papers and Proceedings 97(2): 104-107.

Black, Dan, Jeffrey Smith, Mark Berger, and Brett Noel. 2003. "Is the Threat of Reemployment Services More Effective than the Services Themselves? Evidence from Random Assignment in the UI System." American Economic Review 93(4): 1313-1327.

Blank, Diane, Laura Heald, and Cynthia Fagnoni. 2011. “An Overview of WIA.” In Douglas Besharov and Phoebe Cottingham (eds.) The Workforce Investment Act: Implementation Experiences and Evaluation Findings. Kalamazoo, MI: W.E. Upjohn Institute for Employment Research. 49-78.

Bloom, Howard. 1984. "Accounting for No-Shows in Experimental Evaluation Designs." Evaluation Review 8(2): 225-46.

Bloom, Howard, Carolyn Hill, and James Riccio. 2003. "Linking Program Implementation and Effectiveness: Lessons from a Pooled Sample of Welfare-to-Work Experiments." Journal of Poicy Analysis and Management 22(4): 551-575.

Boo, Katherine. 2004. "Letter from South Texas: The Churn.” New Yorker. March 29.

Borden, William. 2011. "The Challenges of Measuring Performance.” In Douglas Besharov and Phoebe Cottingham (eds.) The Workforce Investment Act: Implementation Experiences and Evaluation Findings. Kalamazoo, MI: W.E. Upjohn Institute for Employment Research. 177208.

Borus, Michael and Daniel Hamermesh. 1978. "Estimating Fiscal Substitution by Public Service Employment Programs.” Journal of Human Resources 13(4): 561-565.

Bound, John, Charles Brown and Nancy Mathiowetz. 2001. "Measurement Error in Survey Data." In James Heckman and Edward Leamer (eds.) Handbook of Econometrics, Volume 5. Amsterdam: North-Holland. 3705-3843.

Bradley, David. 2013. The Workforce Investment Act and the One-Stop Delivery System. CRS Report for Congress. Washington, DC: Congressional Research Service.

Burtless, Gary and Larry Orr. 1995. "The Case for Randomized Field Trials in Economic and Policy Research.” Journal of Economic Perspectives 9(2): 63-84.

Bushway, Shawn, Brian Johnson and Lee Ann Slocum. 2007. "Is the Magic Still There? The Use 
of the Heckman Two-Step Correction for Selection Bias in Criminology." Journal of Quantitative Criminology 23: 151-178..

Busso, Matias, John DiNardo and Justin McCrary. 2014. "New Evidence on the Finite Sample Properties of Propensity Score Reweighting and Matching Estimators." Review of Economics and Statistics 96(5): 885-897.

Butler, Wendell and Richard Hobbie. 1976. Employment and Training Programs. Congress of the United States, Congressional Budget Office.

Card, David, Jochen Kluve, and Andrea Weber. 2010. "Active Labour Market Policy Evaluations: A Meta-Analysis.” Economic Journal 120: F452-F477.

Card, David, Jochen Kluve, and Andrea Weber. 2015. "What Works? A Meta Analysis of Recent Active Labor Market Program Evaluations.” NBER Working Paper No. 21431.

Carniero, Pedro, Karsten Hansen and James Heckman. 2003. "Estimating Distributions of Treatment Effects with an Application to the Returns to Schooling and Measurement of the Effects of Uncertainty on College Choice." International Economic Review 44(2): 361-422.

Carneiro, Pedro, James Heckman, and Edward Vytlacil. 2011. "Estimating Marginal Returns to Education.” American Economic Review 101(6): 2754-2781.

Cave, George, Hans Bos, Fred Doolittle and Cyril Toussaint. 1993. JOBSTART: Final Report on a Program for School Dropouts. New York, NY: MDRC.

Center on Budget and Policy Priorities. 2012. Policy Basics: An Introduction to TANF. Washington, DC: Center on Budget and Policy Priorities.

Clague, Ewan and Leo Kramer. 1976. Manpower Policies and Programs: A Review. Kalamazoo, MI: W.E. Upjohn Institute for Employment Research.

Cook, Robert, Charles Adams, and Lane Rawlins.1985. Public Service Employment: The Experience of a Decade. Kalamazoo, MI: W.E. Upjohn Institute for Employment Research.

Cook, Thomas. 2008. "'Waiting for Life to Arrive': A History of the Regression-Discontinuity Design in Psychology, Statistics and Economics." Journal of Econometrics 142(2): 636-654.

Couch, Kenneth. 1992. "New Evidence on the Long-Term Effects of Employment Training Programs." Journal of Labor Economics 10(4): 380-388.

Courty, Pascal and Gerald Marschke. 2011a. "The JTPA Incentive System." In James Heckman, Carolyn Heinrich, Pascal Courty, Gerald Marschke and Jeffrey Smith (eds.) The Performance of Performance Standards. Kalamazoo, MI: W.E. Upjohn Institute for Employment Research. 6593. 
Courty, Pascal and Gerald Marschke. 2011b. "Measuring Government Performance: An Overview of Dysfunctional Responses." In James Heckman, Carolyn Heinrich, Pascal Courty, Gerald Marschke and Jeffrey Smith (eds.) The Performance of Performance Standards. Kalamazoo, MI: W.E. Upjohn Institute for Employment Research. 203-229.

Crépon, Bruno, Esther Duflo, Marc Gurgand, Roland Rathelot, and Philippe Zamora. 2013. "Do Labor Market Policies have Displacement Effects? Evidence from a Clustered Randomized Experiment." Quarterly Journal of Economics 128(2): 531-580.

Currie, Janet. 2006. “The Take-up of Social Benefits.” In Alan Auerbach, David Card, and John Quigley (eds.) Poverty, the Distribution of Income, and Public Policy. New York: Russell Sage. 80-148.

Dahlby, Bev. 2008. The Marginal Social Cost of Public Funds. Cambridge, MA: MIT Press.

D’Amico, Ronald, Kate Dunham, Jennifer Henderson-Frakes, Deborah Kogan, Vinz Koller, Melissa Mack, Micheline Magnotta, Jeffrey Salzman, Andrew Wiegand, Gardner Carrick, and Dan Weissbein. 2004. The Workforce Investment Act after Five Years: Results from the National Evaluation of the Implementation of WIA. Oakland, California: Social Policy Research Associates

D’Amico, Ronald and Jeffrey Salzman. 2004. "Implementation Issues in Delivering Training Services to Adults under WIA." In Christopher O'Leary, Robert Straits and Stephen Wandner (eds.) Job Training Policy in the United States. Kalamazoo, MI: W.E. Upjohn Institute for Employment Research. 101-134.

Davidson, Carl and Stephen Woodbury. 1993. "The Displacement Effect of Reemployment Bonus Programs.” Journal of Labor Economics 11(4): 575-605.

Decker, Paul, and Gillian Berk. 2011. "Ten Years of the Workforce Investment Act (WIA): Interpreting the Research on WIA and Related Programs." Journal of Policy Analysis and Management 30(4): 906-926.

Dehejia, Rajeev and Sadek Wahba. 1999. "Causal Effects in Nonexperimental Studies: Reevaluating the Evaluation of Training Programs." Journal of the American Statistical Association. 94(448): 1053-1062.

Dehejia, Rajeev and Sadek Wahba. 2002. "Propensity Score Matching Methods for NonExperimental Causal Studies." Review of Economics and Statistics 84(1): 151-161.

DeRocco, Emily. 2006. Training and Guidance Letter 17-05 (TEGL 17-05): Common Measures Policy for the Employment and Training Administration's (ETA) Performance Accountability System and Related Performance Issues. Washington, DC: U.S. Department of Labor Employment and Training Administration.

Devine, Theresa, and James Heckman. 1996. "The Structure and Consequences of Eligibility 
Rules for a Social Program.” In Solomon Polachek (ed.) Research in Labor Economics, Volume 15. Greenwich, CT: JAI Press. 111-170.

Dickinson, Katherine, Terry Johnson, and Richard West. 1987. "An Analysis of the Sensitivity of Quasi-Experimental Net Impact Estimates of CETA Programs.” Evaluation Review 11(4): $452-472$.

Dixit, Avinash. 2002. "Incentives and Organizations in the Public Sector: An Interpretative Review." Journal of Human Resources 37(4): 696-727.

Djebbari, Habiba and Jeffrey Smith. 2008. "Heterogeneous Program Impacts: Experimental Evidence from the PROGRESA Program.” Journal of Econometrics 145(1-2): 64-80.

Doolittle, Fred and Linda Traeger. 1990. Implementing the National JTPA Study. New York, NY: MDRC.

Eberts, Randall, Timothy Bartik, and Wei-Jang Huang. 2011. "Recent Advances in Performance Measurement of Federal Workforce Development Programs." In Douglas Besharov and Phoebe Cottingham (eds.) The Workforce Investment Act: Implementation Experiences and Evaluation Findings. Kalamazoo, MI: W.E. Upjohn Institute for Employment Research. 233-275.

Eberts, Randall and Harry Holzer. 2004. "Overview of Labor Exchange Policies and Services." In David Balducchi, Randall Eberts, and Christopher O'Leary (eds.) Labor Exchange Policy in the United States. Kalamazoo, MI: W.E. Upjohn Institute for Employment Research. 1-31.

Eberts, Randall and Stephen Wandner. 2013. "Data Analysis of the Implementation of the Recovery Act Workforce Development and Unemployment Insurance Provisions.” In Burt Barnow and Richard Hobbie (eds.) The American Recovery and Reinvestment Act: The Role of Workforce Programs. Kalamazoo, MI: W.E. Upjohn Institute for Employment Research. 267307.

Eberwein, Curtis, John Ham and Robert LaLonde. 1997. "The Impact of Classroom Training on the Employment Histories of Disadvantaged Women: Evidence from Experimental Data." Review of Economic Studies 64(4): 655-682.

Eyster, Lauren, Demetra Smith Nightengale, Burt Barnow, Carolyn O'Brien, John Trutko and Daniel Keuhn. 2010. Implementation and Early Training Outcomes of the High Growth Job Training Initiative. Washington, DC: The Urban Institute.

Federal Register. 2014. March 27. 79(59): 17184-17188.

Ferber, Robert and Werner Hirsch. 1981. Social Experimentation and Economic Policy. New York: Cambridge University Press.

Fisher, Ronald. 1935. The Design of Experiments. Edinburgh: Oliver and Boyd. 
Flores-Lagunes, Alfonso, Arturo Gonzalez, and Todd Neumann. 2008. "Learning But Not Earning? The Impact of Job Corps Training on Hispanic Youth.” Economic Inquiry 48(3): 651667.

Ford, Reuben, David Gyarmati, Kelly Foley, Doug Tattrie, and Liza Jimenez. 2003. Can Work Incentives Pay for Themselves? Final Report on the Self-Sufficiency Project for Welfare Applicants. Ottawa: Social Research and Demonstration Corporation.

Forslund, Anders and Alan Krueger. 1997. "An Evaluation of Swedish Active Labor Market Policy: New and Received Wisdom." In Richard Freeman, Robert Topel and Birgitta Swedenburg (eds.) The Welfare State in Transition: Reforming the Swedish Model. Chicago, IL: University of Chicago Press for NBER. 267-298.

Fraker, Thomas and Rebecca Maynard. 1987. "The Adequacy of Comparison Group Designs for Evaluations of Employment Related Programs." Journal of Human Resources 22(2): 194-227.

Franklin, Grace and Randall Ripley. 1984. CETA Politics and Policy, 1973-1982. Knoxville: TN: University of Tennessee Press.

Frölich, Markus. 2004. "Finite-sample Properties of Propensity-score Matching and Weighting Estimators.” Review of Economics and Statistics 86: 77-90.

Frölich, Markus and Michael Lechner. 2010. "Exploiting Regional Treatment Intensity for the Evaluation of Labor Market Policies." Journal of the American Statistical Association 105(491): 1014-1029.

Frost, Robert. 1920. “The Road Not Taken.” In: Robert Frost (ed.), Mountain Interval. New York: Henry Holt.

Garfinkel, Irwin. 1973. “Is In-Kind Redistribution Efficient?” Quarterly Journal of Economics 87(2): 320-330.

Gechter, Michael. 2014. "Generalizing the Results from Social Experiments." Unpublished manuscript, Boston University.

Greenberg, David, Charles Michalopoulos, and Philip Robins. 2003. "A Meta-Analysis of Government-Sponsored Training Programs." Industrial and Labor Relations Review 57(1): 3153.

Greenberg, David, Charles Michalopoulos, and Philip Robins. 2004. "What Happens to the Effects of Government-Funded Training Programs Over Time?" Journal of Human Resources 39(1): 277-293.

Greenberg, David and Philip Robins. 2008. "Incorporating Nonmarket Time into Benefit-Cost Analyses of Social Programs: An Application to the Self-Sufficiency Project." Journal of Public Economics 92: 766-794. 
Greenberg, David and Philip Robins. 2011. "Have Welfare-to-Work Programs Improved Over Time in Putting Welfare Recipients to Work?" Industrial and Labor Relations Review 64(5): 920-930.

Greenberg, David and Mark Shroder. 2004. The Digest of Social Experiments, Third Edition. Washington, DC: Urban Institute Press.

Greenberg, David, Mark Shroder and Matthew Onstott. 1999. "The Social Experiment Market." Journal of Economic Perspectives 13(3): 157-172.

Gueron, Judith and Howard Ralston. 2013. Fighting for Reliable Evidence. New York, NY: Russell Sage Foundation.

Ham, John and Robert LaLonde. 1996. "The Effect of Sample Selection and Initial Conditions in Duration Models: Evidence from Experimental Data.” Econometrica 64(1): 175-205.

Heckman, James. 1992. "Randomization and Social Policy Evaluation." In Charles Manski and Irwin Garfinkel (eds.) Evaluating Welfare and Training Programs. Cambridge, MA: Harvard University Press. 201-230.

Heckman, James, Carolyn Heinrich, Pascal Courty, Gerald Marschke and Jeffrey Smith. 2011. The Performance of Performance Standards. Kalamazoo, MI: W.E. Upjohn Institute for Employment Research.

Heckman, James, Carolyn Heinrich, and Jeffrey Smith. 2002. "The Performance of Performance Standards." Journal of Human Resources 37(4): 778-811.

Heckman, James, Neil Hohmann, and Jeffrey Smith, with the assistance of Michael Khoo. 2000. "Substitution and Dropout Bias in Social Experiments: A Study of an Influential Social Experiment." Quarterly Journal of Economics 115(2): 651-694.

Heckman, James, Hidehiko Ichimura, and Petra Todd. 1997. "Matching as an Econometric Evaluation Estimator: Evidence from Evaluating a Job Training Programme." Review of Economic Studies 64(4): 605-654.

Heckman, James, Hidehiko Ichimura, Jeffrey Smith, and Petra Todd. 1998. "Characterizing Selection Bias Using Experimental Data.” Econometrica 66(5): 1017-1098.

Heckman, James and Alan Krueger. 2003. Inequality in America. Cambridge, MA: MIT Press.

Heckman, James, Robert LaLonde, and Jeffrey Smith. 1999. "The Economics and Econometrics of Active Labor Market Programs." In Orley Ashenfelter and David Card (eds.) Handbook of Labor Economics, Volume 3A. Amsterdam: North-Holland, 1865-2097.

Heckman, James, Lance Lochner and Christopher Taber. 1998. “General-Equilibrium Treatment 
Effects: A Study of Tuition Policy.” American Economic Review 88(2): 381-386.

Heckman, James and Salvador Navarro. 2004. "Using Matching, Instrumental Variables, and Control Functions to Estimate Economic Choice Models." Review of Economics and Statistics 86(1): 30-57.

Heckman, James and Richard Robb. 1985. "Alternative Methods for Evaluating the Impacts of Interventions: An Overview.” Journal of Econometrics 30(1-2): 239-267.

Heckman, James and Jeffrey Smith. 1995. “Assessing the Case for Social Experiments.” Journal of Economic Perspectives 9(2): 85-110.

Heckman, James and Jeffrey Smith. 1999. "The Pre-Program Earnings Dip and the Determinants of Participation in a Social Program: Implications for Simple Program Evaluation Strategies." Economic Journal 109(457): 313-348.

Heckman, James and Jeffrey Smith. 2000. "The Sensitivity of Experimental Impact Estimates: Evidence from the National JTPA Study." In David Blanchflower and Richard Freeman (eds.), Youth Employment and Joblessness in Advanced Countries. Chicago: University of Chicago Press for NBER, 331-356.

Heckman, James and Jeffrey Smith. 2004. "The Determinants of Participation in a Social Program: Evidence from the Job Training Partnership Act.” Journal of Labor Economics 22(2): 243-298.

Heckman, James, Jeffrey Smith. and Nancy Clements. 1997. "Making the Most Out of Programme Evaluations and Social Experiments: Accounting for Heterogeneity in Programme Impacts." Review of Economic Studies 64(4): 487-535.

Heckman, James, Jeffrey Smith, and Christopher Taber. 1996. "What Do Bureaucrats Do? The Effects of Performance Standards and Bureaucratic Preferences on Acceptance into the JTPA Program." In Gary Libecap (ed.) Advances in the Study of Entrepreneurship, Innovation and Economic Growth: Reinventing Government and the Problem of Bureaucracy, Volume 7. Greenwich, CT: JAI Press, 191-217.

Heckman, James, Jeffrey Smith, and Christopher Taber. 1998. "Accounting for Dropouts in Evaluations of Social Programs." Review of Economics and Statistics 80(1): 1-14

Heinberg, John, John Trutko, Burt Barnow, Mary Farrell, and Asaph Glosser. 2005. Unit Costs of Intensive and Training Services for WIA Adults and Dislocated Workers: An Exploratory Study of Methodologies and Estimates in Selected States and Localities: Final Report. Report Prepared for U.S. Department of Labor, Employment and Training Administration.

Heinrich, Carolyn. 2004. "Improving Public-Sector Performance Management: One Step Forward, Two Steps Back?” Public Finance and Management 4(3): 317-351. 
Heinrich, Carolyn, Peter Mueser, and Kenneth Troske. 2008. Workforce Investment Act NonExperimental Net Impact Evaluation: Final Report. Washington, DC: IMPAQ International.

Heinrich, Carolyn, Peter Mueser, Kenneth Troske, Kyung-Seong Jeon, and Daver Kahvecioglu. 2013. "Do Public Employment and Training Programs Work?" IZA Journal of Labor Economics 2:6.

Heinrich, Carolyn and Peter Mueser. 2014. "Training Program Impacts and the Onset of the Great Recession." Unpublished manuscript, University of Missouri.

Hendra, Richard, James Riccio, Richard Dorsett, David Greenberg, Genevieve Knight, Joan Phillips, Philip Robins, Sandra Vegeris, and Johana Walter. 2011. Breaking the Low-pay, No-pay Cycle: Final Evidence from the UK Employment Retention and Advancement (ERA) Demonstration. UK Department for Work and Pensions Research Report No. 765.

Herman, Alexis. 1998. Implementing the Workforce Investment Act of 1998. US Department of Labor, Employment and Training Administration. Retrieved November 9, 2014, from www.doleta.gov/usworkforce/documents/misc/wpaper3.cfm.

Hirano, Keisuke, Guido Imbens, and Geert Ridder. 2003. "Efficient Estimation of Average Treatment Effects Using the Estimated Propensity Score.” Econometrica 71(4): 1161-1189.

Hollenbeck, Kevin. 2009. "Return on Investment Analysis of a Selected Set of Workforce System Programs in Indiana." Report submitted to the Indiana Chamber of Commerce Foundation, Indianapolis, Indiana. http://research.upjohn.org/reports/15.

Hollenbeck, Kevin. 2011. "Short-Term Net Impact Estimates and Rates of Return.” In Douglas Besharov and Phoebe Cottingham (eds.) The Workforce Investment Act: Implementation Experiences and Evaluation Findings. Kalamazoo, MI: W.E. Upjohn Institute for Employment Research. 347-370.

Hollenbeck, Kevin, and Wei-Jang Huang. 2014. "Net Impact and Benefit-Cost Estimates of the Workforce Development System in Washington State." Upjohn Institute Technical Report No. 13-029.

Hotz, V. Joseph. 1992. "Designing an Evaluation of the Job Training Partnership Act." In Charles Manski and Irwin Garfinkel (eds.) Evaluating Welfare and Training Programs. Cambridge, MA: Harvard University Press. 76-114.

Hotz, V. Joseph, Guido Imbens, and Jacob Klerman. 2006. "Evaluating the Differential Effects of Alternative Welfare-to-Work Training Components: A Reanalysis of the California GAIN Program." Journal of Labor Economics 24(3): 521-566.

Hotz, V. Joseph, Guido Imbens and Julie Mortimer. 2005. "Predicting the Efficacy of Future Training Programs Using Past Experiences at Other Locations." Journal of Econometrics 125: 241-270. 
Hotz, V. Joseph and Karl Scholz. 2002. "Measuring Employment and Income Outcomes for Low-Income Populations with Administrative and Survey Data." In Studies of Welfare Populations: Data Collection and Research Issues. National Research Council: National Academy Press. 275-315.

Huber, Erika, David Kassabian, and Elissa Cohen. 2014. Welfare Rules Databook: State TANF Policies as of July 2013, OPRE Report 2014-52. Washington, DC: Office of Planning, Research and Evaluation, Administration for Children and Families, US Department of Health and Human Services.

Huber, Martin, Michael Lechner and Conny Wunsch. 2013. "The Performance of Estimators Based on the Propensity Score." Journal of Econometrics 175: 1-21.

Iacus, Stefano, Gary King, and Giuseppe Porro. 2012. "Causal Inference without Balance Checking: Coarsened Exact Matching." Political Analysis 20(1): 1-24.

Institute of Education Sciences (IES), U.S. Department of Education. 2008. Rigor and Relevance Redux: Director's Biennial Report to Congress. IES 2009-6010. Washington, DC: IES.

Jacobson, Louis, Robert LaLonde and Daniel Sullivan. 1993. "Earnings Losses of Displaced Workers." American Economic Review 83(4): 685-709.

Johnson, George. 1979. "The Labor Market Displacement Effect in the Analysis of the Net Impact of Manpower Training Programs." In F.E. Bloch (ed.) Evaluating Manpower Training Programs: Research in Labor Economics (Supplement 1): 227-254.

Johnson, George and James Tomola. 1977. "The Fiscal Substitution Effect of Alternative Approaches to Public Service Employment Policy.” Journal of Human Resources 12(1): 3-26.

Johnston, Janet. 1987. The Job Training Partnership Act: A Report by the National Commission for Employment Policy. Washington, DC: Government Printing Office.

Kemple, James, Fred Doolittle, and John Wallace. 1993. The National JTPA Study: Site Characteristics and Participation Patterns. New York, NY: MDRC.

Kesselman, Jonathon. 1978. "Work Relief Programs in the Great Depression." In John Palmer (ed.) Creating Jobs: Public Employment Programs and Wage Subsidies. Washington, DC: The Brookings Institution.

King, Christopher. 1999. "Federalism and Workforce Policy Reform." Publius: The Journal of Federalism 29(2): 53-71.

King, Christopher T., and Burt S. Barnow. 2011. "The Use of Market Mechanisms." In Douglas Besharov and Phoebe Cottingham (eds.) The Workforce Investment Act: Implementation Experiences and Evaluation Findings. Kalamazoo, MI: W.E. Upjohn Institute for Employment 
Research. 81-111.

Koenker, Roger and Gilbert Basset. 1978. "Regression Quantiles.” Econometrica 46: 33-50.

Kornfeld, Robert and Howard Bloom. 1999. "Measuring Program Impacts on Earnings and Employment: Do Unemployment Insurance Wage Reports of Employers Agree with Surveys of Individuals?" Journal of Labor Economics 17(1): 168-197.

Krolikowski, Pawel. 2014. "Reassessing the Experience of Displaced Workers." Unpublished manuscript, University of Michigan.

LaLonde, Robert. 1986. "Evaluating the Econometric Evaluations of Training Programs with Experimental Data.” American Economic Review 76(4): 604-620.

LaLonde, Robert. 2003. "Employment and Training Programs." In Robert Moffitt (ed.) MeansTested Transfer Programs in the United States. Chicago: University of Chicago Press. 517-585.

Lechner, Michael and Smith, Jeffrey. 2007. "What is the Value Added by Caseworkers?" Labour Economics 14(2): 135-151.

Lechner, Michael and Stephan Wiehler. 2011. "Kids or Courses? Gender Differences in the Effects of Active Labor Market Policies.” Journal of Population Economics 24(3): 783-812.

Lechner, Michael and Conny Wunsch. 2009. "Are Training Programs More Effective When Unemployment is High?” Journal of Labor Economics 27(4): 653-692.

Lechner, Michael and Conny Wunsch. 2013. "Sensitivity of Matching-Based Program Evaluations to the Availability of Control Variables.” Labour Economics 21: 111-121.

Levitan, Sar and Frank Gallo.1988. A Second Chance: Training for Jobs. Kalamazoo, MI: W.E. Upjohn Institute for Employment Research.

Lise, Jeremy, Shannon Seitz, and Jeffrey Smith. 2004. "Equilibrium Policy Experiments and the Evaluation of Social Programs.” NBER Working Paper No. 10283.

Long, David, Charles Maller and Craig Thornton. 1981. "Evaluating the Benefits and Costs of the Job Corps.” Journal of Policy Analysis and Management 1(1): 55-76.

Lower-Basch, Elizabeth. 2014. SNAP E\&T. Washington, DC: Center for Law and Social Programs.

Maguire, Sheila, Joshua Freely, Carol Clymer, Maureen Conway and Deena Schwartz. 2010. Tuning In to Local Labor Markets: Findings From the Sectoral Employment Impact Study. Philadelphia, PA: P/PV.

Mallar, Charles, Stuart Kerachsky, Craig Thornton, and David Long. 1982. Evaluation of the 
Economic Impact of the Job Corps Program: Third Follow-up Report. Princeton, NJ: Mathematica Policy Research.

Mangum, Garth. 1968. MDTA: The Foundation of Federal Manpower Policy. Baltimore, MD: Johns Hopkins University Press.

McCall, Brian, Conny Wunsch, and Jeffrey Smith. 2015. "Government-Sponsored Vocational Training.” Unpublished manuscript, University of Michigan.

McConnell, Sheena, Paul Decker, and Irma Perez-Johnson. 2006. "The Role of Counseling in Voucher Programs: Findings from the Individual Training Account Experiment.” Unpublished manuscript, Mathematica Policy Research.

McConnell, Sheena and Steven Glazerman. 2001. National Job Corps Study: The Benefits and Costs of Job Corps. Princeton, NJ: Mathematica Policy Research.

McConnell, Sheena, Elizabeth Stuart, Kenneth Fortson, Paul Decker, Irma Perez-Johnson, Barbara Harris, and Jeffrey Salzman. 2006. Managing Customers' Training Choices: Findings from the Individual Training Account Experiment: Final Report. Princeton, NJ: Mathematica Policy Research.

Mikelson, Kelly and Demetra Nightingale. 2004. Estimating Public and Private Expenditures on Occupational Training in the United States. Washington, DC: The Urban Institute.

Mirengoff, William and Lester Rindler. 1978. CETA: Manpower Programs under Local Control. Washington, DC: National Academy of Sciences.

Moffitt, Robert. 1983. "An Economic Model of Welfare Stigma.” American Economic Review 73(5): 1023-1035.

Mueller-Smith, Michael. 2015. "The Criminal and Labor Market Impacts of Incarceration." Unpublished manuscript, University of Michigan.

Muller, Seán. 2015. "Interaction and External Validity: Obstacles to the Policy Relevance of Randomized Evaluations.” World Bank Economic Review. 29 (Suppl 1): S226-S237.

Musgrave, Richard. 1959. The Theory of Public Finance: A Study in Public Economy. New York, NY: McGraw-Hill.

Musgrave, Richard and Peggy Musgrave. 1976. Public Finance in Theory and Practice. New York: McGraw-Hill.

Nathan, Richard, Robert Cook, Lane Rawlins, and Associates. 1981. Public Service Employment: A Field Evaluation. Washington, DC: The Brookings Institution.

National Skills Coalition. 2014. Side-by-Side Comparison of Occupational Training and Adult 
Education \& Family Literacy Provisions in the Workforce Investment Act and the Workforce Innovation and Opportunity Act. Washington, DC: National Skills Coalition.

Neyman, Jerzy. 1923. "Statistical Problems in Agricultural Experiments." Journal of the Royal Statistical Society 2:107-180.

Oates, Jane. 2012. Training and Employment Notice 39-11 (TEIN 39-11): Release and Availability of Career Pathways Technical Assistance Resources. Washington, DC: U.S. Department of Labor Employment and Training Administration.

O'Leary, Christopher, Robert Straits, and Stephen Wandner. 2004. "U.S. Job Training: Types, Participants, and History." In Christopher O'Leary, Robert Straits, and Stephen Wandner (eds.) Job Training Policy in the United States. Kalamazoo, MI: W.E. Upjohn Institute for Employment Research. 1-20.

Orr, Larry. 1998. Social Experiments: Evaluating Public Programs with Experimental Methods. New York: Sage Publications.

Park, Jooyoun. 2012. "Does Occupational Training by the Trade Adjustment Assistance Program Really Help Reemployment? Success Measured as Matching." Review of International Economics 20(5): 999-1016.

Patel, Nisha and Steve Savner. 2001. Implementation of Individual Training Account Policies under the Workforce Investment Act: Early Information from Local Areas. Washington, DC: Center for Law and Social Policy.

Pederson, Jonas, Michael Rosholm and Michael Svarer. 2012. "Experimental Evidence on the Effects of Early Meetings and Activation.” IZA Discussion Paper No. 6970.

Perez-Johnson, Irma, Quinn Moore, and Robert Santilano. 2011. Improving the Effectiveness of Individual Training Accounts: Long-term Findings from an Experimental Evaluation of Three Service Delivery Models: Final Report. Princeton, New Jersey: Mathematica Policy Research.

Perry, Charles, Bernard Anderson, Richard Rowan, and Herbert Northrup, 1975. The Impact of Government Manpower Programs in General, and on Minorities and Women. Philadelphia, PA: Industrial Research Unit, the Wharton School, University of Pennsylvania.

Plesca, Miana. 2010. "A General Equilibrium Analysis of the Employment Service." Journal of Human Capital 4(3): 274-329.

Plesca, Miana and Jeffrey Smith. 2005. "Rules Versus Discretion in Social Programs: Empirical Evidence on Profiling in Employment and Training Programs." Unpublished manuscript, University of Maryland.

Plesca, Miana and Jeffrey Smith. 2007. "Evaluating Multi-treatment Programs: Theory and Evidence from the U.S. Job Training Partnership Act Experiment." Empirical Economics 32(2-3): 491-528. 
Puhani, Patrick. 2000. "The Heckman Correction for Sample Selection and its Critique.” Journal of Economic Surveys 14(1): 53-68.

Puma, Michael and Nancy Burstein. 1994. "The National Evaluation of the Food Stamp Employment and Training Program." Journal of Policy Analysis and Management. 13(2): 311330.

Quandt, Richard. 1972. "Methods of Estimating Switching Regressions.” Journal of the American Statistical Association 67: 306-310.

Radin, Beryl. 2006. Challenging the Performance Movement: Accountability, Complexity and Democratic Values. Washington, DC: Georgetown University Press.

Rosholm, Michael. 2014. "Do Caseworkers Help the Unemployed? Evidence for Making a Cheap and Effective Twist to Labor Market Policies for Unemployed Workers." IZA World of Labor 72.

Roy, A.D. 1951. "Some Thoughts on the Distribution of Earnings." Oxford Economic Papers 3:135-146.

Rubin, Donald. 1974. "Estimating Causal Effects of Treatments in Randomized and NonRandomized Studies.” Journal of Educational Psychology 66:688-701.

Schochet, Peter, Ronald D'Amico, Jillian Berk, Sarah Dolfin and Nathan Wozny. 2012. Estimated Impacts for Participants in the Trade Adjustment Assistance (TAA) Program Under the 2002 Amendments. Princeton, NJ: Mathematica Policy Research.

Schochet, Peter and John Burghardt. 2008. "Do Job Corps Performance Measures Track Program Impacts?” Journal of Policy Analysis and Management 27(3): 556-576.

Schochet, Peter, John Burghardt, and Steven Glazerman. 2001. National Job Corps Study: The Impacts of Job Corps on Participants' Employment and Related Outcomes. Princeton, NJ: Mathematica Policy Research.

Schochet, Peter, John Burghardt, and Sheena McConnell. 2008. "Does Job Corps Work?" Impact Findings from the National Job Corps Study." American Economic Review 98(5): 1864-1886.

Sianesi, Barbara, 2014. "Dealing with Randomisation Bias in a Social Experiment: the Case of ERA.” IFS Working Papers W14/10, Institute for Fiscal Studies.

Smith, Jeffrey. 1992. The JTPA Selection Process: A Descriptive Analysis. Report Submitted to the U.S. Department of Labor as part of the National JTPA Study.

Smith, Jeffrey. 1997. "Measuring Earnings Levels Among the Poor: Evidence from Two Samples of JTPA Eligibles." Unpublished manuscript, University of Western Ontario. 
Smith, Jeffrey. 2011. “Improving Impact Evaluation in Europe.” In Douglas Besharov and Phoebe Cottingham, eds., The Workforce Investment Act: Implementation Experiences and Evaluation Findings. Kalamazoo, MI: W.E. Upjohn Institute for Employment Research. 473494.

Smith, Jeffrey and Petra Todd. 2005a. "Does Matching Overcome LaLonde's Critique of Nonexperimental Methods?” Journal of Econometrics 125(1-2): 305-353.

Smith, Jeffrey and Petra Todd. 2005b. "Rejoinder.” Journal of Econometrics 125(1-2): 365-375.

Smith, Jeffrey and Alexander Whalley. 2015. "How Well Do We Measure Public Job Training?" Unpublished manuscript, University of Michigan.

Social Policy Research Associates. 2013. PY 2012 WIASRD Data Book. Oakland, CA: Social Policy Research Associates.

Spaulding, Shayne. 2001. Performance-Based Contracting under the Job Training Partnership Act. Baltimore, MD: Johns Hopkins University Master's Thesis.

Stapleton, David, Gina Livermore, Craig Thornton, Bonnie O’Day, Robert Weathers, Krista Harrison, So O’Neil, Emily Sama Martin, David Wittenburg, and Debra Wrig. 2008. Ticket to Work at the Crossroads: A Solid Foundation with an Uncertain Future. Princeton, NJ: Mathematica Policy Research.

Taggart, Robert. 1981. A Fisherman's Guide: An Assessment of Training and Remediation Strategies. Kalamazoo, MI: W.E. Upjohn Institute for Employment Research.

Todd, Petra and Kenneth Wolpin. 2006. "Assessing the Impact of a School Subsidy Program in Mexico Using a Social Experiment to Validate a Dynamic Behavioral Model of Child Schooling and Fertility." American Economic Review 96(5): 1384-1417.

Trutko, John and Burt Barnow. 1997. Implementation of the 1992 Job Training Partnership Act (JTPA) Amendments: Report to Congress. Washington, D.C.: U.S. Department of Labor, Employment and Training Administration.

Trutko, John and Burt Barnow. 1999. Vouchers under JTPA: Lessons for Implementation of the Workforce Investment Act. Arlington, VA: James Bell Associates.

Trutko, John and Burt Barnow. 2007. Variation in Training Rates across States and Local Workforce Investment Boards: Final Report. Arlington, VA: Capital Research Corporation.

Trutko, John and Burt Barnow. 2010. Implementing Efficiency Measures for Employment and Training Programs: Final Report. Arlington, VA: Capital Research Corporation.

U.S. Bureau of the Budget. 1966. Appendix of the Budget of the United States Government for 
Fiscal Year 1967. Washington, DC: U.S. Government Printing Office.

U.S. Bureau of the Budget. 1967. Appendix of the Budget of the United States Government for Fiscal Year 1968. Washington, DC: U.S. Government Printing Office.

U.S. Bureau of the Budget. 1968. Appendix of the Budget of the United States Government for Fiscal Year 1969. Washington, DC: U.S. Government Printing Office.

U.S. Bureau of the Budget. 1969. Appendix of the Budget of the United States Government for Fiscal Year 1970. Washington, DC: U.S. Government Printing Office.

U.S. Bureau of the Budget. 1970. Appendix of the Budget of the United States Government for Fiscal Year 1971. Washington, DC: U.S. Government Printing Office.

U.S. Department of Agriculture. 2014. Food and Nutrition Service: 2015 Explanatory Notes. Retrieved March 29, 2015 from http://www.obpa.usda.gov/32fns2015notes.pdf.

U.S. Department of Education. 2015. Federal Student Aid: Federal Pell Grants. Retrieved February 1, 2015 from https://studentaid.ed.gov/types/grants-scholarships/pell.

U.S. Department of Education. 2014. Programs: Federal Pell Grant Program. Retrieved February 1, 2015 from http://www2.ed.gov/programs/fpg/index.html.

U.S. Department of Education. 2014. Programs: Adult Education: Basic Grants to States. Retrieved January 28, 2015 from http://www2.ed.gov/programs/adultedbasic/funding.html.

U.S. Department of Health and Human Services. 2014. TANF Financial Data - FY 2013. Retrieved January 28, 2015 from http://www.acf.hhs.gov/programs/ofa/resource/tanf-financialdata-fy-2013.

U.S. Department of Labor. 1973. Manpower Report of the President: A Report on Manpower Requirements, Resources, Utilization, and Training. Washington, DC: U.S. Government Printing Office.

U.S. Department of Labor. 2013. About Job Corps. Retrieved November 23, 2014, from http://www.jobcorps.gov/AboutJobCorps.aspx.

U.S. Department of Labor. 2014. FY 2015 Department of Labor Budget in Brief. Washington, DC: U.S. Department of Labor.

U.S. Department of Labor. 2000. One-Stop Partners. Retrieved November 15, 2014, from http://www.doleta.gov/programs/factsht/pdf/onestoppartners.pdf.

U.S. Department of Labor. 2014. Workforce Investment Act: Adults and Dislocated Workers Program. Retrieved November 15, 2014, from http://www.doleta.gov/programs/general_info.cfm. 
U.S. Department of Labor. 2010. Wagner-Peyser/Labor Exchange. Retrieved November 1, 2014, from http://www.doleta.gov/programs/wagner_peyser.cfm.

U.S. Department of Labor. 2010. Workforce Investment Act One-Stop Partners. Retrieved November 15, 2014, from http://www.doleta.gov/usworkforce/onestop/partners.cfm.

U.S. Department of Labor. 2014. Workforce Innovation and Opportunity Act (WIOA) Factsheet. Retrieved November 16, 2014, from http://www.doleta.gov/wioa/pdf/WIOA-Factsheet.pdf.

U.S. Department of Labor. 2014. Budget Authority Tables: Training and Employment Programs. Retrieved February 15, 2015, from http://www.doleta.gov/budget/bahist.cfm.

U.S. Department of Labor. 2015. Budget Authority Tables: Training and Employment Programs. Retrieved May 15, 2015, from http://www.doleta.gov/budget/bahist.cfm.

U.S. Department of Labor. 2014. Training and Employment Guidance Letter No. 36-10 (TEGL 36-10). Retrieved November 22, 2014, from http://wdr.doleta.gov/directives/corr_doc.cfm?DOCN=3052.

U.S. Department of Labor. 2014. WIA Youth Formula Funded Program. Retrieved November 23, 2014 from http://www.doleta.gov/youth_services/wiaformula.cfm.

U.S. Department of Labor. 2014. Senior Community Service Employment Program. Retrieved November 24, 2014 from http://www.doleta.gov/seniors/.

U.S. Department of Labor. 2014. The Trade Adjustment Assistance Program Brochure. Retrieved November 24, 2014 from http://www.doleta.gov/tradeact/docs/program_brochure2014.pdf.

U.S. Department of Labor. 2014. ETA Programs for Migrant and Seasonal Farmworkers. Retrieved November 23, 2014 from http://www.doleta.gov/Farmworker/.

U.S. Department of Labor. 2014. Reintegration of Ex-Offenders (RExO). Retrieved November 23, 2014 from http://www.doleta.gov/RExO/.

U.S. Department of Labor. 2014. YouthBuild. Retrieved November 24, 2014 from http://www.doleta.gov/Youth_services/Youth_Build.cfm.

U.S. Department of Labor. No date. Budget Authority from 1948-1989. Unpublished internal document.

U.S. Department of Labor. 2014. Quarterly Workforce System Results. Retrieved November 22, 2014 from http://www.doleta.gov/performance/results/eta_default.cfm\#wiastann.

U.S. Department of Labor. 2014. VETS Employment Services Fact Sheet 1. Retrieved November 
23, 2014 from http://www.dol.gov/vets/programs/empserv/employment_services_fs.htm.

U.S. Department of Labor. 2014. VETS HVRP Fact Sheet. Retrieved November 23, 2014 from http://www.dol.gov/vets/programs/fact/Homeless_veterans_fs04.htm.

U.S. Department of Labor. 2015. Summary of Appropriation Budget Authority, Fiscal Year 2014. Retrieved April 18, 2015, from

http://www.doleta.gov/budget/docs/14_final_appropriation_action.pdf

U.S. General Accounting Office. 1996. Job Training Partnership Act: Long Term Earnings and Employment Outcomes. Report HEHS-96-40. Washington, DC: US General Accounting Office.

U.S. General Accounting Office. 2002. Workforce Investment Act: Youth Provisions Promote New Service Strategies, But Additional Guidance Would Enhance Program Development. Report GAO-02-413. Washington, DC: US General Accounting Office

U.S. Office of Management and Budget. 1992. Guidelines and Discount Rates for Benefit-Cost Analysis of Federal Programs. Circular No. A-94 Revised. https://www.whitehouse.gov/omb/circulars_a094/

Van Horn, Carl and Aaron Fichter. 2011. "Eligible Training Provider Lists and Consumer Report Cards." In Douglas Besharov and Phoebe Cottingham (eds.) The Workforce Investment Act: Implementation Experiences and Evaluation Findings. Kalamazoo, MI: W.E. Upjohn Institute for Employment Research. 153-172.

Van Horn, Carl, Kathy Krepcio, and Stephen Wandner. 2015. Identifying Gaps and Setting Strategic Priorities for Employment and Training Research (2014-2019). Report prepared for U.S. Department of Labor, Employment and Training Administration.

Wallace, Geoffrey and Robert Haveman. 2007. "The Implications of Differences between Employer and Worker Employment/earnings Reports for Policy Evaluation." Journal of Policy Analysis and Management 26(4): 737-754.

White, Michael, and Jane Lakey. 1992. The Restart Effect: Does Active Labour Market Policy Reduce Unemployment? London, UK: Policy Studies Institute.

Wilson, James. 1989. Bureaucracy: What Government Agencies Do and Why They Do It. New York: Basic Books.

Wunsch, Conny. 2013. "Optimal Use of Labor Market Policies: The Role of Job Search Assistance." Review of Economics and Statistics 95(3): 1030-1045.

YouthBuild. https://youthbuild.org/. Accessed November 23, 2014.

Ziliak, James. 2015. “Temporary Assistance for Needy Families.” NBER Working Paper No. 21038. 
Table 8.1

Major Employment and Training Programs 1963-1973

\begin{tabular}{|c|c|c|c|c|c|}
\hline $\begin{array}{l}\text { Name and Authorizing } \\
\text { Legislation }\end{array}$ & $\begin{array}{l}\text { Dates of Operation } \\
\text { (FY 1963-1974) }\end{array}$ & General Purpose & Administrative Agencies & Target Groups & Average Annual Enrollment \\
\hline $\begin{array}{l}\text { Manpower Development and } \\
\text { Training Act }\end{array}$ & 1963-1974 & $\begin{array}{l}\text { Vocational training in a classroom } \\
\text { setting and subsidized training by } \\
\text { employers on the job }\end{array}$ & $\begin{array}{l}\text { National: Department of Labor } \\
\text { (DOL) and Department of } \\
\text { Health, Education, and Welfare } \\
\text { (HEW) } \\
\text { Local: Employment Service } \\
\text { (ES), school districts, skills } \\
\text { centers }\end{array}$ & $\begin{array}{l}\text { Economically } \\
\text { disadvantaged and } \\
\text { dislocated workers }\end{array}$ & $\begin{array}{l}\text { Economically disadvantaged } \\
126,200 \\
\text { Dislocated workers } 83,700\end{array}$ \\
\hline $\begin{array}{l}\text { Vocational education (Smith } \\
\text { Hughes Act of 1917) }\end{array}$ & 1964-1974 & $\begin{array}{l}\text { Occupational training in public } \\
\text { schools }\end{array}$ & $\begin{array}{l}\text { National: HEW } \\
\text { Local: School districts }\end{array}$ & $\begin{array}{l}\text { General not seeking } \\
\text { academic degree } \\
\text { population }\end{array}$ & $6,674,0000$ \\
\hline $\begin{array}{l}\text { Neighborhood Youth Corps in- } \\
\text { school, summer, out-of-school } \\
\text { (Economic Opportunity Act of } \\
\text { 1964) }\end{array}$ & $1965-1974$ & $\begin{array}{l}\text { Subsidized work experience in } \\
\text { public and nonprofit agencies }\end{array}$ & $\begin{array}{l}\text { National: DOL } \\
\text { Local: Community action } \\
\text { agencies (CAAs), local } \\
\text { governments, schools, ES }\end{array}$ & Disadvantaged youth & $\begin{array}{l}\text { In school } 129,400 \\
\text { Out of school } 84,300 \\
\text { Summer } 362,500\end{array}$ \\
\hline Job Corps (EOA) & $1965-1974$ & $\begin{array}{l}\text { Vocational skills training and } \\
\text { basic skills in a residential setting }\end{array}$ & $\begin{array}{l}\text { National: Office of Economic } \\
\text { Opportunity (OEO); DOL after } \\
1969\end{array}$ & Disadvantaged youth & 42,100 \\
\hline Operation Mainstream (EOA) & $1967-1974$ & $\begin{array}{l}\text { Subsidized employment in } \\
\text { paraprofessional positions in } \\
\text { public and nonprofit agencies }\end{array}$ & $\begin{array}{l}\text { National: OEO, DOL after } 1967 \\
\text { Local: CAAs and public } \\
\text { agencies }\end{array}$ & Disadvantaged adults & 20,000 \\
\hline $\begin{array}{l}\text { Job Opportunities in the } \\
\text { Business Sector (Presidential } \\
\text { initiative) }\end{array}$ & 1968-1974 & $\begin{array}{l}\text { Subsidized on-the-job training in } \\
\text { the private sector }\end{array}$ & $\begin{array}{l}\text { National: DOL and National } \\
\text { Alliance of Business (NAB) } \\
\text { Local: NAB offices }\end{array}$ & Disadvantaged adults & 49,300 \\
\hline $\begin{array}{l}\text { Work Incentive Program (Social } \\
\text { Security Act) }\end{array}$ & $1967-1974$ & $\begin{array}{l}\text { Vocational training, work } \\
\text { experience, support services, } \\
\text { placement }\end{array}$ & $\begin{array}{l}\text { National: DOL } \\
\text { Local: welfare offices, ES, and } \\
\text { WIN offices }\end{array}$ & $\begin{array}{l}\text { Aid to Families with } \\
\text { Dependent Children } \\
\text { (AFDC) recipients }\end{array}$ & 124,700 \\
\hline $\begin{array}{l}\text { Concentrated Employment } \\
\text { Program (EOA) }\end{array}$ & $1968-1974$ & $\begin{array}{l}\text { Coordinates employment and } \\
\text { training services of other } \\
\text { programs }\end{array}$ & $\begin{array}{l}\text { National: DOL } \\
\text { Local: CAAs, local government }\end{array}$ & $\begin{array}{l}\text { Disadvantaged youth and } \\
\text { adults }\end{array}$ & 92,900 \\
\hline $\begin{array}{l}\text { Public Employment Program } \\
\text { (Emergency Employment Act) }\end{array}$ & $1972-1974$ & Subsidized public employment & $\begin{array}{l}\text { National: DOL } \\
\text { Local: Chief elected officials }\end{array}$ & Unemployed adults & 234,300 \\
\hline
\end{tabular}

Source: Barnow (1993) 
Table 8.2

Historical Budget Authority

U.S. Department of Labor Employment and Training Programs

(in thousands of nominal dollars)

\begin{tabular}{|c|c|c|c|c|c|c|}
\hline & $\begin{array}{c}\text { Total } \\
\text { Employment } \\
\text { and Training }\end{array}$ & $\begin{array}{c}\text { Dislocated } \\
\text { Workers }\end{array}$ & Adults & $\begin{array}{c}\text { Youth } \\
\text { Except Job } \\
\text { Corps } \\
\end{array}$ & Job Corps & $\begin{array}{l}\text { E\&T Programs } \\
\text { as pct of GDP }\end{array}$ \\
\hline \multicolumn{7}{|c|}{ MDTA era $(1962-1972)^{a}$} \\
\hline 1965 & 529,406 & $\mathrm{x}$ & 266,505 & 127,742 & 52,523 & $0.07 \%$ \\
\hline 1966 & 671,095 & $\mathrm{x}$ & 339,649 & 263,337 & 303,527 & $0.09 \%$ \\
\hline 1967 & 861,044 & $\mathrm{x}$ & 296,247 & 348,833 & 209,000 & $0.10 \%$ \\
\hline 1968 & 398,497 & $\mathrm{x}$ & 296,418 & 281,864 & 282,300 & $0.04 \%$ \\
\hline 1969 & 409,992 & $\mathrm{x}$ & 272,616 & 320,696 & 278,400 & $0.04 \%$ \\
\hline 1970 & $1,451,215$ & $\mathrm{x}$ & 336,380 & 356,589 & 169,782 & $0.14 \%$ \\
\hline 1971 & $1,622,997$ & $\mathrm{X}$ & 335,752 & 426,458 & 160,187 & $0.15 \%$ \\
\hline 1972 & $2,682,066$ & $\mathrm{x}$ & 424,368 & 517,244 & 202,185 & $0.22 \%$ \\
\hline \multicolumn{7}{|c|}{ CETA era $(1973-1982)^{b}$} \\
\hline 1973 & $1,549,416$ & $\mathrm{n} / \mathrm{a}$ & $\mathrm{n} / \mathrm{a}$ & $\mathrm{n} / \mathrm{a}$ & $\mathrm{n} / \mathrm{a}$ & $0.11 \%$ \\
\hline 1974 & $2,275,584$ & $\mathrm{n} / \mathrm{a}$ & $\mathrm{n} / \mathrm{a}$ & $\mathrm{n} / \mathrm{a}$ & $\mathrm{n} / \mathrm{a}$ & $0.15 \%$ \\
\hline 1975 & $3,739,450$ & $\mathrm{n} / \mathrm{a}$ & $\mathrm{n} / \mathrm{a}$ & $\mathrm{n} / \mathrm{a}$ & $\mathrm{n} / \mathrm{a}$ & $0.23 \%$ \\
\hline 1976 & $5,827,720$ & $\mathrm{n} / \mathrm{a}$ & $\mathrm{n} / \mathrm{a}$ & $\mathrm{n} / \mathrm{a}$ & $\mathrm{n} / \mathrm{a}$ & $0.33 \%$ \\
\hline $\begin{array}{c}\text { Transition } \\
\text { Quarter }\end{array}$ & 597,500 & $\mathrm{n} / \mathrm{a}$ & $\mathrm{n} / \mathrm{a}$ & $\mathrm{n} / \mathrm{a}$ & $\mathrm{n} / \mathrm{a}$ & $0.13 \%$ \\
\hline 1977 & $17,200,830$ & $\mathrm{n} / \mathrm{a}$ & $\mathrm{n} / \mathrm{a}$ & $\mathrm{n} / \mathrm{a}$ & $\mathrm{n} / \mathrm{a}$ & $0.85 \%$ \\
\hline 1978 & $3,652,630$ & $\mathrm{n} / \mathrm{a}$ & $\mathrm{n} / \mathrm{a}$ & $\mathrm{n} / \mathrm{a}$ & 280,000 & $0.16 \%$ \\
\hline 1979 & $10,510,312$ & $\mathrm{n} / \mathrm{a}$ & $\mathrm{n} / \mathrm{a}$ & $\mathrm{n} / \mathrm{a}$ & 380,000 & $0.41 \%$ \\
\hline 1980 & $8,387,193$ & $\mathrm{n} / \mathrm{a}$ & $\mathrm{n} / \mathrm{a}$ & $\mathrm{n} / \mathrm{a}$ & 470,000 & $0.30 \%$ \\
\hline 1981 & $8,100,887$ & $\mathrm{n} / \mathrm{a}$ & $\mathrm{n} / \mathrm{a}$ & $\mathrm{n} / \mathrm{a}$ & 465,000 & $0.26 \%$ \\
\hline 1982 & $3,300,301$ & $\mathrm{n} / \mathrm{a}$ & $\mathrm{n} / \mathrm{a}$ & $\mathrm{n} / \mathrm{a}$ & $\mathrm{n} / \mathrm{a}$ & $0.10 \%$ \\
\hline \multicolumn{7}{|c|}{ JTPA era $(1983-2000)^{c}$} \\
\hline 1983 & $4,329,876$ & $\mathrm{n} / \mathrm{a}$ & \multicolumn{2}{|c|}{$\mathrm{n} / \mathrm{a}$} & $\mathrm{n} / \mathrm{a}$ & $0.12 \%$ \\
\hline 1984 & $6,863,525$ & 317,250 & \multicolumn{2}{|c|}{$4,849,862$} & $1,014,100$ & $0.17 \%$ \\
\hline 1985 & $4,100,662$ & 222,500 & \multicolumn{2}{|c|}{$2,710,700$} & 617,000 & $0.09 \%$ \\
\hline 1986 & $3,649,194$ & 95,702 & \multicolumn{2}{|c|}{$2,419,061$} & 612,480 & $0.08 \%$ \\
\hline 1987 & $4,041,913$ & 200,000 & \multicolumn{2}{|c|}{$2,590,000$} & 656,350 & $0.08 \%$ \\
\hline 1988 & $4,138,911$ & 287,220 & \multicolumn{2}{|c|}{$2,527,536$} & 716,135 & $0.08 \%$ \\
\hline 1989 & $4,140,485$ & 283,773 & \multicolumn{2}{|c|}{$2,497,205$} & 755,317 & $0.07 \%$ \\
\hline 1990 & $4,283,975$ & 463,603 & \multicolumn{2}{|c|}{$2,444,585$} & 789,122 & $0.07 \%$ \\
\hline 1991 & $4,968,253$ & 526,979 & \multicolumn{2}{|c|}{$2,961,364$} & 867,486 & $0.08 \%$ \\
\hline 1992 & $4,555,331$ & 576,986 & \multicolumn{2}{|c|}{$2,435,196$} & 919,533 & $0.07 \%$ \\
\hline 1993 & $4,843,266$ & 651,246 & $1,015,021$ & $1,535,056$ & 966,075 & $0.07 \%$ \\
\hline 1994 & $5,410,010$ & $1,151,000$ & 988,021 & $1,496,964$ & $1,040,469$ & $0.07 \%$ \\
\hline 1995 & $4,352,602$ & $1,228,550$ & 996,813 & 311,460 & $1,089,222$ & $0.06 \%$ \\
\hline 1996 & $4,513,678$ & $1,091,900$ & 850,000 & 751,672 & $1,093,942$ & $0.06 \%$ \\
\hline 1997 & $5,178,903$ & $1,286,200$ & 895,000 & 997,672 & $1,153,509$ & $0.06 \%$ \\
\hline 1998 & $6,837,464$ & $1,345,510$ & 955,000 & $1,000,965$ & $1,246,217$ & $0.08 \%$ \\
\hline
\end{tabular}




\begin{tabular}{|l|c|c|c|c|c|c|}
\hline \multicolumn{7}{|c|}{ WIA era $(2000-2014)^{d}$} \\
\hline 1999 & $7,018,662$ & $1,403,510$ & 954,000 & $1,250,965$ & $1,307,947$ & $0.07 \%$ \\
\hline 2000 & $5,969,155$ & $1,589,025$ & 950,000 & $1,250,965$ & $1,357,776$ & $0.06 \%$ \\
\hline 2001 & $6,041,678$ & $1,433,951$ & 950,000 & $1,377,965$ & $1,399,148$ & $0.06 \%$ \\
\hline 2002 & $6,417,023$ & $1,602,110$ & 945,372 & $1,353,065$ & $1,454,241$ & $0.06 \%$ \\
\hline 2003 & $5,713,068$ & $1,454,891$ & 894,577 & $1,038,669$ & $1,509,094$ & $0.05 \%$ \\
\hline 2004 & $5,566,051$ & $1,445,939$ & 893,195 & 995,059 & $1,535,623$ & $0.05 \%$ \\
\hline 2005 & $5,680,372$ & $1,303,918$ & 882,486 & 980,801 & $1,544,951$ & $0.04 \%$ \\
\hline 2006 & $5,736,193$ & $1,528,549$ & 840,588 & 928,716 & $1,573,270$ & $0.04 \%$ \\
\hline 2007 & $5,595,655$ & $1,390,434$ & 826,105 & 964,930 & $1,566,205$ & $0.04 \%$ \\
\hline 2008 & $5,147,987$ & $1,464,707$ & 861,540 & 983,021 & 919,506 & $0.04 \%$ \\
\hline 2009 & $9,581,432$ & $2,902,391$ & $1,356,540$ & $2,231,569$ & $1,242,938$ & $0.04 \%$ \\
\hline 2010 & $7,337,268$ & $1,410,880$ & 860,116 & $1,026,569$ & $1,680,626$ & $0.05 \%$ \\
\hline 2011 & $7,170,341$ & $1,283,303$ & 769,576 & 905,754 & $1,734,150$ & $0.05 \%$ \\
\hline 2012 & $7,699,612$ & $1,210,536$ & 770,811 & 904,042 & $1,702,946$ & $0.05 \%$ \\
\hline
\end{tabular}

Notes

$\mathrm{x}$ indicates not applicable; $\mathrm{n} / \mathrm{a}$ indicates not available. Budget Authority figures unless otherwise noted. Table excludes funding for Wagner-Peyser Act.

Footnotes

a. MDTA era:

The "Total Employment and Training" budget may seem unusually large in 1972 due to Emergency Employment Assistance, a temporary program.

During the MDTA era, "Youth Except Job Corps" is Neighborhood Youth Corps.

Budget data in the following categories for the following years are obligations: "Adults" (1965-1972); "Youth except Job Corps" (1965-1972); "Job Corps" (1970-1972).

Budget data for "Job Corps" for 1965-1969 are appropriations.

b. CETA era:

The "Total Employment and Training" budget is large in some years due to the following programs: Community Service Employment for Older Americans (1974-1981); Temporary Employment Assistance (1975-1981); YEDPA (1977 total employment and training budget includes appropriations for YEDPA, which were disbursed over four years, 1978-1981).

"Total Employment and Training" budget data for 1977 is a combination of Budget Authority and outlays.

Budget data for "Job Corps" for years 1978-1981 are outlays.

c. JTPA era:

From 1983-1992: JTPA IIA included both Adult and Youth activities, so the funds cannot be divided into separate categories; combined Adults and Youth budget includes JTPA Summer Youth Employment and Training.

d. WIA era:

Budget figures for 2009 may seem unusually large due to the following: all categories in 2009 include appropriations for ARRA, which were disbursed over several years.

Sources

DOL Budget Authority from 1948-1989; DOL (2014) Budget Authority Tables; DOL (2015) Budget Authority Tables; 1967, 1968, 1969, 1970, and 1971 Appendices of US Government Budgets; 1973 Manpower Report of the President; Betsey et al. (1985). 
Table 8.3

\section{Characteristics of WIA Adult and Dislocated Worker Exiters by Training Status April 2012-March 2013}

\begin{tabular}{|c|c|c|c|c|}
\hline & \multicolumn{2}{|c|}{ Adults } & \multicolumn{2}{|c|}{ Dislocated Workers } \\
\hline & All & Training & All & Training \\
\hline \multicolumn{5}{|l|}{ Age } \\
\hline $18-21$ & 9.3 & 11.0 & 3.2 & 2.2 \\
\hline $22-54$ & 76.9 & 81.7 & 77.2 & 83.6 \\
\hline 55 and over & 13.8 & 7.3 & 19.6 & 14.2 \\
\hline \multicolumn{5}{|l|}{ Gender } \\
\hline Female & 47.6 & 54.5 & 48.5 & 47.6 \\
\hline Male & 52.4 & 45.5 & 51.5 & 52.4 \\
\hline $\begin{array}{l}\text { Individual with } \\
\text { Disability }\end{array}$ & 3.9 & 3.3 & 3.1 & 2.4 \\
\hline \multicolumn{5}{|l|}{ Race/Ethnicity } \\
\hline Hispanic & 10.5 & 15.2 & 12.8 & 12.8 \\
\hline Black, not Hispanic & 23.6 & 23.5 & 18.0 & 18.8 \\
\hline White not Hispanic & 59.2 & 54.0 & 62.8 & 63.1 \\
\hline Other & 6.7 & 7.3 & 6.4 & 5.3 \\
\hline Veteran & 7.8 & 7.3 & 7.6 & 8.8 \\
\hline $\begin{array}{l}\text { Average Pre-program } \\
\text { Quarterly Earnings }\end{array}$ & $\$ 6,006$ & $\$ 5,432$ & $\$ 8,566$ & $\$ 8,295$ \\
\hline Low Income & 50.2 & 60.9 & NA & NA \\
\hline Limited English & 3.0 & 3.3 & NA & NA \\
\hline Single Parent & 15.1 & 20.3 & NA & NA \\
\hline Public Assistance & 27.4 & 32.0 & NA & $\mathrm{NA}$ \\
\hline \multicolumn{5}{|l|}{$\begin{array}{l}\text { Highest Grade / } \\
\text { Education }\end{array}$} \\
\hline Less than 12 & 10.8 & 8.1 & NA & NA \\
\hline High School Grad & 37.8 & 40.7 & NA & NA \\
\hline High School Equiv. & 8.0 & 9.3 & NA & NA \\
\hline Some Postsecondry & 30.2 & 31.3 & NA & NA \\
\hline College Graduate BA & 13.2 & 10.5 & NA & NA \\
\hline
\end{tabular}

Source: Social Policy Research Associates (2013) 
Table 8.4

Characteristics of WIA Youth Exiters

by Education Status April 2012-March 2013

\begin{tabular}{|c|c|c|c|c|c|}
\hline & \multirow[t]{2}{*}{ All } & \multicolumn{2}{|c|}{ Attending School } & \multicolumn{2}{|c|}{ Not Attending School } \\
\hline & & $\begin{array}{l}\text { High } \\
\text { School or } \\
\text { Below }\end{array}$ & Postsecondary & $\begin{array}{c}\text { High } \\
\text { School } \\
\text { Dropout }\end{array}$ & $\begin{array}{l}\text { High School } \\
\text { Graduate }\end{array}$ \\
\hline Number of Exiters & 112,386 & 52,954 & 4,630 & 28,087 & 26,706 \\
\hline \multicolumn{6}{|l|}{ Age } \\
\hline $14-15$ & 6.6 & 13.7 & 0.1 & 0.4 & 0.0 \\
\hline $16-17$ & 36.6 & 60.5 & 4.4 & 26.4 & 5.8 \\
\hline 18 & 21.9 & 19.9 & 19.7 & 24.8 & 23.4 \\
\hline $19-21$ & 34.8 & 5.9 & 75.8 & 48.4 & 70.8 \\
\hline \multicolumn{6}{|l|}{ Gender } \\
\hline Female & 54.6 & 54.1 & 63.6 & 51.2 & 57.4 \\
\hline Male & 45.4 & 45.9 & 36.4 & 48.8 & 42.6 \\
\hline $\begin{array}{l}\text { Individual with } \\
\text { Disability }\end{array}$ & 13.2 & 19.0 & 5.9 & 7.7 & 8.8 \\
\hline \multicolumn{6}{|l|}{ Race/Ethnicity } \\
\hline Hispanic & 32.5 & 35.1 & 43.5 & 27.2 & 31.1 \\
\hline $\begin{array}{l}\text { Black, not } \\
\text { Hispanic }\end{array}$ & 32.5 & 32.3 & 23.4 & 33.1 & 33.8 \\
\hline White not Hispanic & 29.8 & 27.1 & 29.2 & 34.9 & 30.1 \\
\hline Other & 5.2 & 5.5 & 3.9 & 4.8 & 5.0 \\
\hline $\begin{array}{l}\text { Veteran (among 19- } \\
21)\end{array}$ & 0.3 & 0.1 & 0.3 & 0.1 & 0.5 \\
\hline $\begin{array}{l}\text { Homeless or } \\
\text { Runaway Youth }\end{array}$ & 4.5 & 2.6 & 3.4 & 6.7 & 5.6 \\
\hline Offender & 9.5 & 6.2 & 5.2 & 15.3 & 9.5 \\
\hline $\begin{array}{l}\text { Pregnant or Parenting } \\
\text { Youth }\end{array}$ & 24.0 & 19.5 & 40.5 & 26.0 & 28.2 \\
\hline $\begin{array}{l}\text { Basic Literacy Skills } \\
\text { Deficient }\end{array}$ & 64.3 & 61.0 & 56.4 & 74.5 & 61.3 \\
\hline Ever in Foster Care & 3.7 & 4.7 & 3.1 & 3.0 & 2.6 \\
\hline
\end{tabular}

Source: Social Policy Research Associates (2013) 
Table 8.5

Services Received by WIA Adult and Dislocated Worker Exiters, PY 2008-PY 2012

\begin{tabular}{|c|c|c|c|c|c|}
\hline \multicolumn{6}{|c|}{ WIA - SERVICES RECEIVED BY ADULT EXITERS } \\
\hline Year & 2008 & 2009 & 2010 & 2011 & 2012 \\
\hline \multicolumn{6}{|c|}{ General Information } \\
\hline Total Number of Exiters & $1,040,676$ & $1,187,450$ & $1,252,411$ & $1,144,947$ & $1,111,555$ \\
\hline Did Not Receive Training & $89.1 \%$ & $86.8 \%$ & $86.7 \%$ & $89.3 \%$ & $89.6 \%$ \\
\hline Received Training & $10.9 \%$ & $13.2 \%$ & $13.3 \%$ & $10.7 \%$ & $10.4 \%$ \\
\hline \multicolumn{6}{|c|}{ Types of Training } \\
\hline On-the-job training & $9.0 \%$ & $7.4 \%$ & $8.9 \%$ & $10.8 \%$ & $12.6 \%$ \\
\hline Skill upgrading \& retraining & $12.4 \%$ & $14.5 \%$ & $13.1 \%$ & $13.1 \%$ & $13.0 \%$ \\
\hline Entrepreneurial training & $0.4 \%$ & $0.1 \%$ & $0.3 \%$ & $0.3 \%$ & $0.2 \%$ \\
\hline $\begin{array}{l}\mathrm{ABE} \text { or ESL in combination } \\
\text { with training }\end{array}$ & $2.5 \%$ & $2.9 \%$ & $4.3 \%$ & $3.4 \%$ & $3.1 \%$ \\
\hline Customized training & $6.5 \%$ & $7.5 \%$ & $6.8 \%$ & $5.7 \%$ & $5.7 \%$ \\
\hline $\begin{array}{l}\text { Other occupational skills } \\
\text { training }\end{array}$ & $72.5 \%$ & $70.7 \%$ & $71.0 \%$ & $70.4 \%$ & $69.2 \%$ \\
\hline
\end{tabular}

\begin{tabular}{|c|c|c|c|c|c|}
\hline \multicolumn{6}{|c|}{ WIA - SERVICES RECEIVED BY DISLOCATED WORKER EXITERS } \\
\hline Year & 2008 & 2009 & 2010 & 2011 & 2012 \\
\hline \multicolumn{6}{|c|}{ General Information } \\
\hline Total Number of Exiters & 364,044 & 581,985 & 760,853 & 750,409 & 705,706 \\
\hline Did Not Receive Training & $83.8 \%$ & $80.8 \%$ & $81.8 \%$ & $84.5 \%$ & $86.0 \%$ \\
\hline Received Training & $16.2 \%$ & $19.2 \%$ & $18.2 \%$ & $15.5 \%$ & $14.0 \%$ \\
\hline \multicolumn{6}{|c|}{ Types of Training } \\
\hline On-the-job training & $7.5 \%$ & $5.9 \%$ & $6.8 \%$ & $10.1 \%$ & $11.8 \%$ \\
\hline Skill upgrading \& retraining & $13.6 \%$ & $16.3 \%$ & $14.6 \%$ & $15.2 \%$ & $14.7 \%$ \\
\hline Entrepreneurial training & $1.5 \%$ & $0.3 \%$ & $0.3 \%$ & $0.4 \%$ & $0.3 \%$ \\
\hline $\begin{array}{l}\mathrm{ABE} \text { or ESL in combination } \\
\text { with training }\end{array}$ & $2.1 \%$ & $2.3 \%$ & $1.8 \%$ & $1.7 \%$ & $1.4 \%$ \\
\hline Customized training & $1.5 \%$ & $1.4 \%$ & $1.3 \%$ & $1.0 \%$ & $0.7 \%$ \\
\hline $\begin{array}{l}\text { Other occupational skills } \\
\text { training }\end{array}$ & $77.2 \%$ & $76.4 \%$ & $78.2 \%$ & $74.7 \%$ & $74.4 \%$ \\
\hline
\end{tabular}

Notes: Years 2008 through 2011 are program years, e.g., PY 2008 is July 1, 2008 through June 30, 2009; 2012 is April 1, 2012 through March 31, 2013. Types of training received may not sum to $100 \%$ due to enrollment in more than one type of training and rounding.

Source: Social Policy Research Associates (2013). 


\section{Table 8.6 \\ Outcomes for PY 2012 WIA Exiters for Selected Subgroups of Adults, Dislocated Workers, and Youth}

\begin{tabular}{|c|c|c|c|}
\hline & $\begin{array}{c}\text { Entered } \\
\text { Employment } \\
\text { Rate } \\
\end{array}$ & $\begin{array}{c}\text { Employment } \\
\text { Retention Rate }\end{array}$ & $\begin{array}{l}\text { Six-Month } \\
\text { Average } \\
\text { Earnings }\end{array}$ \\
\hline Adults & $59.9 \%$ & $81.9 \%$ & $\$ 13,335$ \\
\hline Veterans & $56.5 \%$ & $81.0 \%$ & $\$ 15,726$ \\
\hline Public assistance & $62.7 \%$ & $80.4 \%$ & $\$ 10,447$ \\
\hline $\begin{array}{l}\text { Individuals with } \\
\text { Disabilities }\end{array}$ & $41.2 \%$ & $75.4 \%$ & $\$ 11,086$ \\
\hline Older individuals & $47.9 \%$ & $81.4 \%$ & $\$ 14,437$ \\
\hline With Training & $74.5 \%$ & $87.3 \%$ & $\$ 15,986$ \\
\hline $\begin{array}{l}\text { With only core } \\
\text { and intensive }\end{array}$ & $58.6 \%$ & $81.1 \%$ & $\$ 12,935$ \\
\hline Dislocated Workers & $60.0 \%$ & $84.3 \%$ & $\$ 15,930$ \\
\hline Veterans & $56.6 \%$ & $82.4 \%$ & $\$ 17,073$ \\
\hline $\begin{array}{l}\text { Displaced } \\
\text { Homemakers }\end{array}$ & $54.8 \%$ & $80.0 \%$ & $\$ 11,049$ \\
\hline $\begin{array}{l}\text { Individuals with } \\
\text { Disabilities }\end{array}$ & $45.5 \%$ & $78.7 \%$ & $\$ 13,152$ \\
\hline Older individuals & $48.1 \%$ & $81.4 \%$ & $\$ 16,221$ \\
\hline With Training & $81.2 \%$ & $90.0 \%$ & $\$ 16,965$ \\
\hline $\begin{array}{l}\text { With only core } \\
\text { and intensive }\end{array}$ & $56.4 \%$ & $82.8 \%$ & $\$ 15,653$ \\
\hline Older Youth & $69.7 \%$ & $87.7 \%$ & NA \\
\hline Veterans & $54.8 \%$ & $60.0 \%$ & NA \\
\hline Public Assistance & $64.8 \%$ & $85.0 \%$ & NA \\
\hline $\begin{array}{l}\text { Individuals with } \\
\text { Disabilities }\end{array}$ & $70.0 \%$ & $87.9 \%$ & $\mathrm{NA}$ \\
\hline Out-of-school & $69.9 \%$ & $87.5 \%$ & NA \\
\hline All Youth & $\begin{array}{l}\text { Placement in } \\
\text { Employment or } \\
\text { Education }\end{array}$ & $\begin{array}{c}\text { Attainment of a } \\
\text { Degree or } \\
\text { Certificate }\end{array}$ & $\begin{array}{l}\text { Literacy and } \\
\text { Numeracy } \\
\text { Gains }\end{array}$ \\
\hline & $66.0 \%$ & $62.3 \%$ & $47.5 \%$ \\
\hline
\end{tabular}

Source: Data at http://www.doleta.gov/performance/results/eta_default.cfm\#wiastann retrieved November 22, 2014. Note that the outcome data is for Program Year 2012, July 1, 2012 through June 30, 2013, while the participant data in the two prior tables covers a slightly different period. The data for older youth is based on seven jurisdictions: Arizona, Hawaii, Michigan, Minnesota, Puerto Rico, Rhode Island, and Vermont. 
Table 8.7

List of Selected Means Tested Employment and Training Programs and Budgets

\begin{tabular}{|c|c|c|}
\hline Program Title & Agency / Office & $\begin{array}{c}\text { Funding - FY } \\
2014 \text { in Millions } \\
\text { of Dollars }^{\mathrm{a}} \\
\end{array}$ \\
\hline \multicolumn{3}{|c|}{ Department of Labor Programs } \\
\hline Job Corps & DOL / Employment Training Administration & $\$ 1,684$ \\
\hline WIA Dislocated Workers & DOL / Employment Training Administration & $\$ 1,219^{\mathrm{b}}$ \\
\hline WIA Youth & DOL / Employment Training Administration & $\$ 818$ \\
\hline WIA Adults & DOL / Employment Training Administration & $\$ 764$ \\
\hline Wagner-Peyser Funded Employment Service & DOL / Employment Training Administration & $\$ 664$ \\
\hline Senior Community Service Employment Program & DOL / Employment Training Administration & $\$ 433$ \\
\hline Trade Adjustment Assistance (TAA) & DOL / Employment Training Administration & $\$ 306^{\mathrm{c}}$ \\
\hline $\begin{array}{l}\text { Disabled Veterans Outreach Program (DVOP) and } \\
\text { Local Veterans' Employment Representative } \\
\text { Program (LVER) }\end{array}$ & $\begin{array}{l}\text { DOL / Veterans' Employment and Training } \\
\text { Service }\end{array}$ & $\$ 175$ \\
\hline H-1B Job Training Grants & DOL / Employment Training Administration & $\$ 166^{\mathrm{d}}$ \\
\hline National Farmworker Jobs Program (NFJP) & DOL / Employment Training Administration & $\$ 82$ \\
\hline Reintegration of Ex-Offenders (RExO) & DOL / Employment Training Administration & $\$ 80$ \\
\hline YouthBuild & DOL / Employment Training Administration & $\$ 78$ \\
\hline $\begin{array}{l}\text { Indian and Native American Employment and } \\
\text { Training }\end{array}$ & DOL / Employment Training Administration & $\$ 46$ \\
\hline $\begin{array}{l}\text { Homeless Veterans Reintegration Program } \\
\text { (HVRP) }\end{array}$ & $\begin{array}{l}\text { DOL / Veterans' Employment and Training } \\
\text { Service }\end{array}$ & $\$ 38$ \\
\hline \multicolumn{3}{|c|}{ Programs of Other Federal Agencies } \\
\hline Pell Grants & $\begin{array}{l}\text { Ed / Office of Vocational and Adult } \\
\text { Education }\end{array}$ & $\$ 8,181^{\mathrm{e}}$ \\
\hline $\begin{array}{l}\text { Temporary Assistance for Needy Families (TANF) } \\
\text { Grants }\end{array}$ & $\begin{array}{l}\text { HHS / Administration for Children \& } \\
\text { Families }\end{array}$ & $\$ 1,517^{\mathrm{f}}$ \\
\hline Adult Education - Grants to States & $\begin{array}{l}\text { Ed / Office of Vocational and Adult } \\
\text { Education }\end{array}$ & $\$ 564$ \\
\hline SNAP Employment \& Training & USDA / Food and Nutrition Service & $\$ 416^{\mathrm{g}}$ \\
\hline
\end{tabular}

\section{Footnotes}

a. Unless otherwise noted. Figures rounded to nearest million. Appropriations unless otherwise noted. All figures are in nominal dollars. DOL ETA figures reflect budgets after the evaluations set aside.

b. Includes National Emergency Grants

c. Budget for training only (does not include cash payments)

d. Actual collected through fees

e. Estimated expenditures for 2011-2012 school year for postsecondary vocational training

f. Expenditures, FY 2013

g. Appropriations, FY 2013

Sources

Food and Nutrition Service - 2015 Explanatory Notes; DOL Budget in Brief FY2015;

http://www2.ed.gov/programs/adultedbasic/funding.html; http://www.acf.hhs.gov/programs/ofa/resource/tanf-financialdata-fy-2013; http://www.doleta.gov/budget/docs/14_final_appropriation_action.pdf 


\section{Figure 8.1}

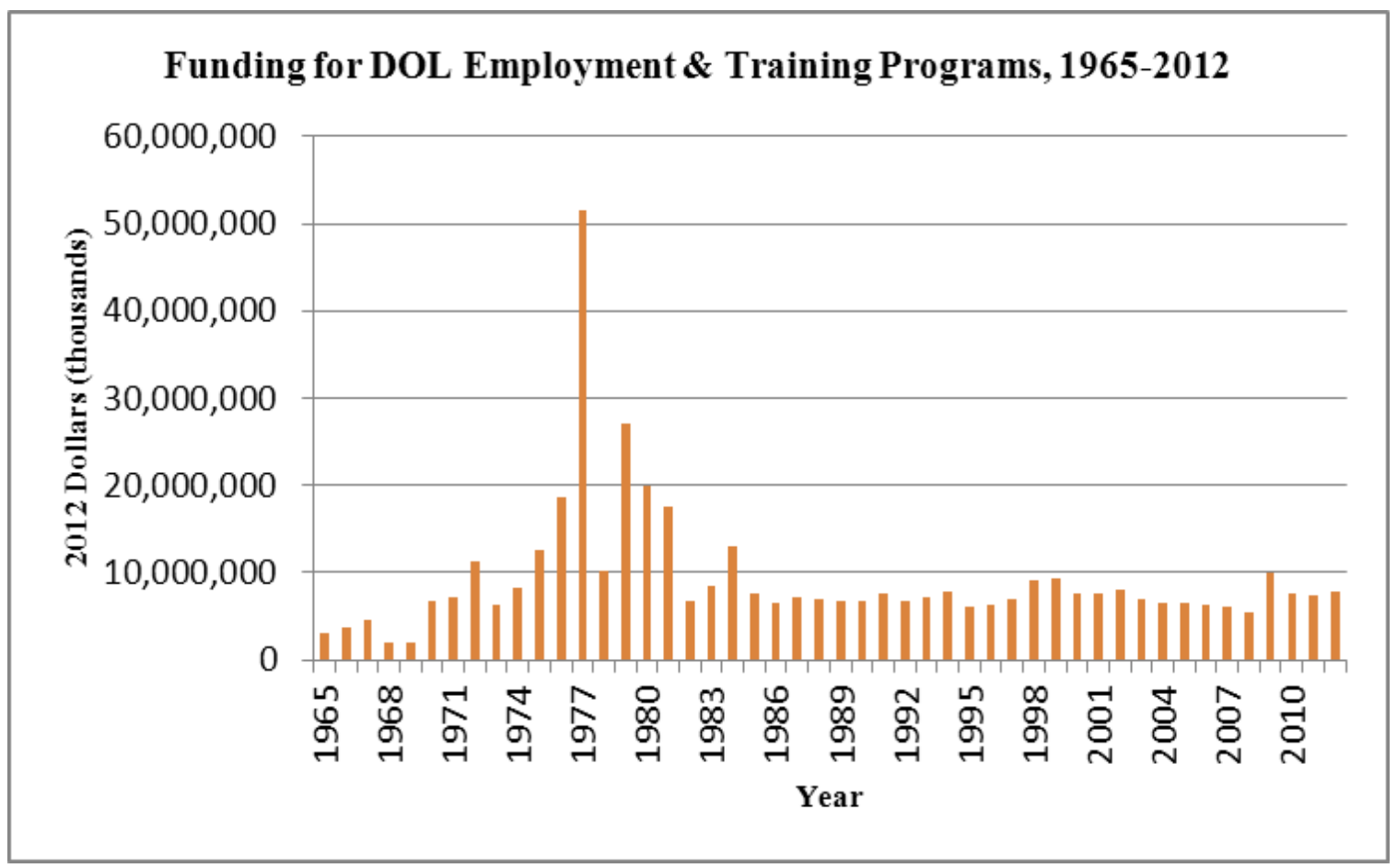


Figure 8.2

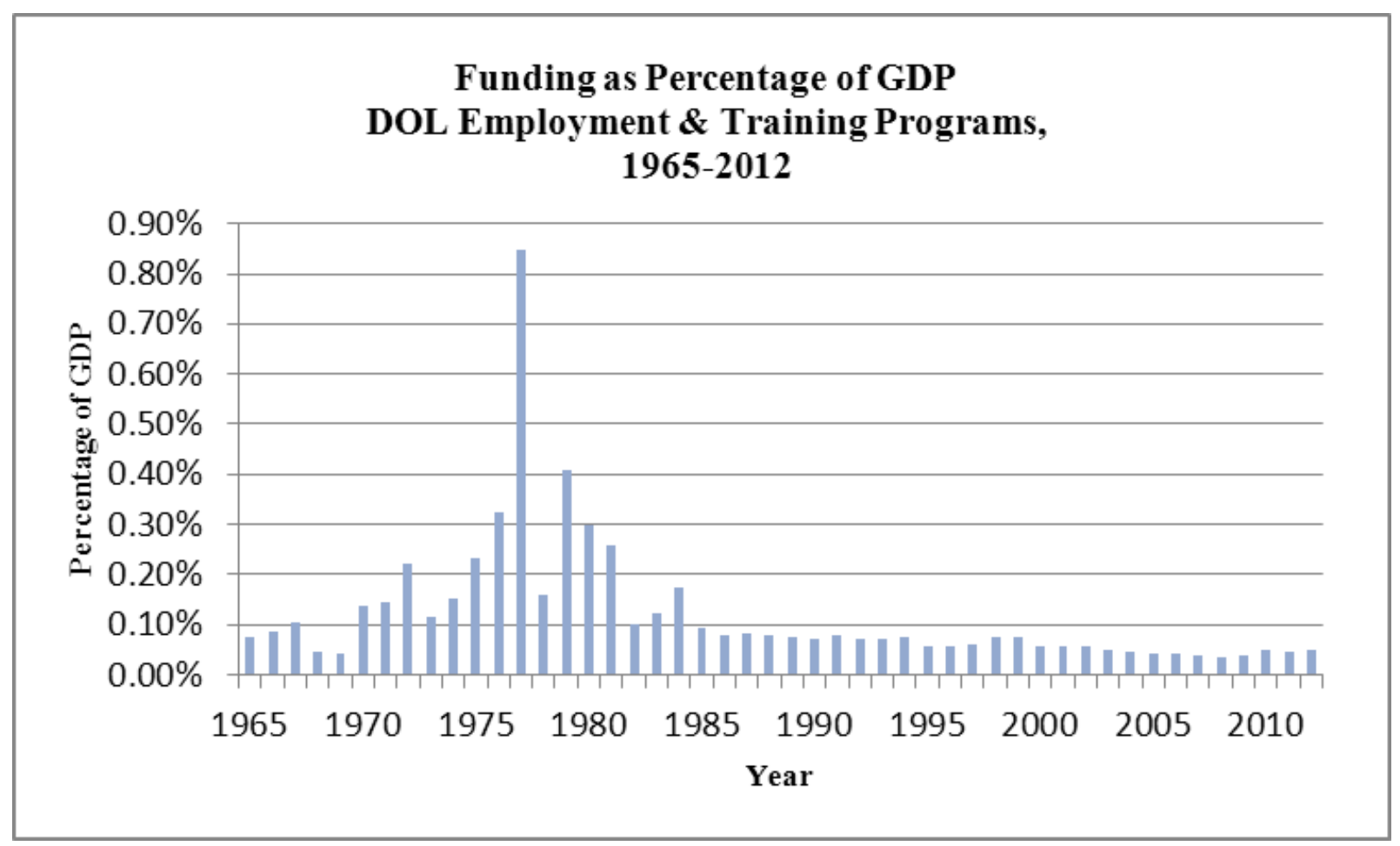

